\title{
Using Machine Learning to Estimate the Heterogeneous Effects of Livestock Transfers*
}

\author{
Conner Mullally, Mayra Rivas, and Travis McArthur
}

January 14, 2021

\begin{abstract}
We evaluate a program in Guatemala offering training and transfers of a local chicken variety using a randomized phase-in design with imperfect compliance. We do not find strong evidence for or against positive average intent-to-treat effects on household-level outcomes, including indicators of expenditure, calorie and protein intake, diet quality, egg consumption and production, as well as chicken ownership and management. Among girls between the ages of six and 60 months, we find that the program reduced stunting by $23.5( \pm 19.4)$ percentage points, while also improving other height and weight outcomes. Boys are more likely to suffer from intestinal illness, which could explain differences in program impacts by gender. Using machine learning methods, we show that the poorest households enjoyed the largest impacts on diet quality and animal protein consumption, while children in the poorest households experienced the largest impacts on the probability of consuming animal source foods. Larger effects on animal source food consumption among poorer households did not translate into greater impacts on height or weight.
\end{abstract}

Keywords: Livestock, eggs, poultry, chickens, stunting, child health, nutrition, animal source foods, impact evaluation, machine learning, Latin America, Guatemala, randomized trial

*Corresponding author: connerm@ufl.edu. Conner Mullally is Assistant Professor of Food and Resource Economics at the University of Florida. Mayra Rivas is a PhD candidate in School of Natural Resources and Environment at the University of Florida. Travis McArthur is Assistant Professor of Food and Resource Economics at the University of Florida. We would like to thank Yuri Soares, Lorena Mejicanos, Patricia Yanez Pagans, discussants at the 2018 Annual Meeting of the Agricultural and Applied Economics Association, and seminar participants at the University of Minnesota Department of Applied Economics for helpful comments on an earlier draft. We would also like to thank Khanti Consulting for data collection and the Mancomunidad Copan Ch'orti' for their support. This paper was made possible through a consultancy for the Multilateral Investment Fund of the Inter-American Development Bank. The opinions expressed in this publication are those of the authors and do not necessarily reflect the views of the Inter-American Development Bank Group, its respective Boards of Directors, or the countries they represent. 


\section{Introduction}

Transferring chickens to poor households has attracted attention in the media (CNN, 2016) and in development policy circles (Gates, 2016) as a promising antipoverty tool. The enthusiasm stems partly from the fact that a modest chicken flock can generate income while requiring minimal investments of time, money, or land, making small-scale poultry farming an appropriate enterprise for households with few resources (Sonaiya and Swan, 2004). Chicken transfers could also improve human capital outcomes if they increase consumption of animal source foods among young children. Multicountry analysis from Headey, Hirvonen, and Hoddinott (2018) reveals a strong correlation between animal source food consumption and child health, where the latter is measured by the incidence of stunting. Poor child health can decrease earnings in adulthood, primarily through impaired cognitive development (Attanasio et al., 2018; Attanasio, Meghir, and Nix, 2019; Figlio et al., 2014; Hoddinott et al., 2008). Egg consumption may be particularly effective in improving child health, as eggs have a better digestability-corrected amino acid profile than meat, fish, or soy while also being rich in micronutrients and fatty acids that are essential for brain development (Jin and Iannotti, 2014). But caution is warranted, as increased poultry and livestock ownership can undermine child health gains through increased exposure to pathogens contained in animal waste (Headey and Hirvonen, 2016; Headey et al., 2017). Furthermore, chicken transfer programs could be quickly undone by unexpected animal health shocks, as chickens are highly susceptible to disease.

We use machine learning and average intent-to-treat effect estimation to evaluate the impacts of a chicken transfer program in Guatemala. We examine two sets of outcomes: household-level indicators of expenditure, diet quality, nutrient intake, egg production, chicken ownership, and poultry management, and individual-level indicators of body weight, height, diet, exposure to animal waste, and intestinal illness among boys and girls who were between the ages of six and 60 months when follow-up data were collected. The program studied here transferred a "chicken set" to participating households in exchange for completing a poultry training program and meeting other requirements. The chicken set included ten females and two males of the local "naked-neck" variety, a fifty pound 
bag of commercial chicken feed, forage plants for use once the feed supply was exhausted, and animal health services.

We estimate program effects using baseline and follow-up data from 14 clusters (18 communities and 391 households) assigned to be early recipients of the program and 14 clusters (18 communities and 400 households) randomly assigned to be late recipients of the program. Follow-up data were collected in May 2017, 14 months after all but a negligible portion of chicken-recipient households in the treatment group had received their chickens and one month after the start of chicken set distribution to the control group, where "treatment" and "control" refer to clusters selected to be early and late recipients of the program, respectively. Participation was not randomized or compulsory within communities. At follow-up, $46.3 \%$ of households in the treatment group sample had received a chicken set at least 80 days earlier, which is the amount of time needed for program chickens to begin producing eggs, versus $13.5 \%$ of households in the control group sample.

We find no statistically significant average intent-to-treat effects at the household level, but the 95\% confidence intervals around our estimates are too wide to be characterized as precise null effects. The slow pace of program implementation in communities assigned to the treatment group suggests that impacts on some indicators may have dissipated before follow-up data were collected. We conclude that we do not have enough evidence to determine whether the program affected householdlevel indicators, on average. In contrast, the program had large positive impacts on anthropometric indicators for girls. Assignment to the treatment group raised the average weight-for-age and heightfor-age Z-scores by 0.349 standard deviations ( \pm 0.281 standard deviations according to the $95 \%$ confidence interval) and 0.539 standard deviations ( \pm 0.433), respectively. Stunting among girls fell by 23.5 percentage points $( \pm 19.4)$, an improvement of $57 \%$ relative to the control group. Severe stunting among girls fell by 14.3 percentage points $( \pm 13.1)$, a decrease of $18 \%$ relative to the control group. Impacts on girls are robust to multiple hypothesis testing adjustments, mode of inference, regression specification, and sample construction. Average impacts on anthropometric indicators for boys are positive but small and imprecisely estimated. We speculate that the higher incidence of intestinal illness among boys could explain differences in impacts on height and weight by gender. Relative to 
girls between the ages of six and 60 months, boys were $23 \%$ more likely to have had intestinal illness in the 30 days prior to follow-up interviews and had intestinal illness for almost one additional day over the same time horizon, on average. Importantly, the program does not appear to have increased intestinal illness or exposure to animal waste. Estimated average impacts on dietary indicators are small and not statistically significant for girls and boys.

To explore impacts that average intent-to-treat effects may miss, we estimate heterogeneous intent-to-treat effects using machine learning methods (Chernozhukov et al., 2018b). At the household level, we find that the poorest households had the largest impacts on the food consumption score (World Food Program, 2008) and consumption of animal protein. We also find that children from the poorest households enjoyed the largest impacts on the probability of consuming animal source foods in the past day. We explore why the poorest children did not also enjoy the biggest positive effects on height and weight and present descriptive evidence for differences in hygiene and the incidence of intestinal illness by wealth as offering plausible explanations.

Our study adds to a growing literature on assessing livestock transfers. One large strand of this literature studies the effects of "graduation" programs offering entrepreneurial training, life skills coaching, regular home visits, a stipend, health services, and assets (usually livestock) to impoverished women. Examples include Misha et al. (2019); Raza, de Poel, and Ourti (2018); Banerjee et al. (2015); Roy et al. (2015); Emran, Robano, and Smith (2014); Bandiera et al. (2013); and Krishna, Poghosyan, and Das (2012), among others. The vast majority of graduation evaluations focus on variants of a single intervention-BRAC's "Targeting the Ultra Poor" program in Bangladesh—and tend to find large positive effects on income, assets, and food security. Among existing randomized control trial evaluations of graduation programs, to our knowledge only Raza, de Poel, and Ourti (2018) evaluate impacts on child height and weight. They find that Targeting the Ultra Poor improves weight-forheight but not height-for-age. Given the bundle of interventions and variety of asset types included in Targeting the Ultra Poor, it is difficult to say what portion of its child health impacts can be attributed to livestock. 
A smaller strand of the livestock transfer literature evaluates programs offering training and livestock transfers with a "pass-on-the-gift" component, i.e., program participants must agree to pass offspring from transferred livestock to other households to receive program benefits. Nearly all studies of pass-on-the-gift evaluate programs implemented by Heifer International. To our knowledge, the lone exception is Glass et al.s (2017) evaluation of a program that distributed pigs in Democratic Republic of the Congo, where they find positive effects on financial inclusion as well as self-reported mental and physical health. A series of studies on Heifer International's goat program in Nepal find positive effects on financial inclusion and women's empowerment (Janzen et al., 2018) and suggestive evidence for improved dietary diversity among children (Darrouzet-Nardi et al., 2016) as well as child height and weight (Miller et al., 2016, 2014). A pair of evaluations of Heifer's program offering dairy cows, draft cattle, and goats in Zambia find that all three livestock types increase household expenditures while cows and goats increase dietary diversity (Jodlowski et al., 2016; Kafle, Winter-Nelson, and Goldsmith, 2016). Using propensity score matching, Rawlins et al. (2014) find positive effects of dairy cows on child height and weight in Rwanda but no impacts of meat goats on these same outcomes.

We make three main contributions to the literature. First, we are aware of no other published studies of livestock transfers that use machine learning to study treatment effect heterogeneity. The specific approach we use was developed by Chernozhukov et al. (2018b), and it allows us to examine many potential dimensions of treatment effect heterogeneity while limiting concerns over specification searching and preserving valid inference.

Second, the context of the program studied here differs substantially from that of existing livestock transfer evaluations, both in terms of the implementing agency and location. Virtually all previous evaluations of livestock transfers in the economics literature focus on programs administered by non-governmental organizations with extensive implementation experience. We evaluate a program managed by a government agency that had never previously attempted a large-scale livestock transfer program, and the implementer's lack of experience was severely tested by a disease outbreak at a program breeding facility. Furthermore, the existing evidence on livestock transfers comes almost exclusively from South Asia and Sub-Saharan Africa, with the exceptions of Honduras and Peru in 
Banerjee et al. (2015). Guatemala has a substantially higher GDP per capita and is more urbanized than Bangladesh, Nepal, Zambia, or Rwanda, for example (World Bank, 2019a,c). But Guatemala is characterized by extreme income inequality, with poverty heavily concentrated in rural areas (Guatemala National Institute of Statistics, 2015). Among the countries studied in the literature reviewed above, only Zambia and Honduras have larger Gini coefficients (World Bank, 2019b).

Third, we use random variation in program implementation to identify impacts on child height and weight in an environment where chronic malnutrition is rampant in rural areas. At 46.5\%, Guatemala has one of the highest rates of stunting in the world among children under five years of age (World Food Program, 2018). By comparison, stunting rates in Bangladesh, Nepal, and Rwanda (the three countries for which we have evidence on livestock transfers and child height) for children under five are $36 \%, 38 \%$, and $36 \%$, respectively (National Institute of Statistics of Rwanda, 2015; National Institute of Population Research and Training, 2016; Nepal Ministry of Health, 2016).

\section{Background}

The program studied here was known as Recovery of Natural Capital of the Dry Corridor Region, and was supported by the Multilateral Investment Fund of the Inter-American Development Bank and implemented by the Mancomunidad Copan Ch'orti'. The Mancomunidad is an association formed by four municipalities in the Guatemalan department of Chiquimula that facilitates cooperation in regional development projects. Chiquimula is located in the "Dry Corridor", a region that stretches from the southern tip of Mexico through Central America to Panama. Severe droughts affected the Dry Corridor during the agricultural years ending in 2013, 2014, and 2015, capped by an El Niñodriven drought in 2015-2016 characterized as the worst the region had seen in 30 years (El Nuevo Diario, 2016; FAO, 2017). The population in Chiquimula is largely indigenous, reliant on agriculture, and has a poverty rate of $71 \%$ (INE, 2015). Chiquimula has some of the highest rates of malnutrition among children and overall food insecurity in Guatemala (Government of Guatemala, 2013). In the 2014-2015 National Survey of Maternal and Child Health, 55.6\% of children in Chiquimula below five 
years of age were stunted and $19.2 \%$ were underweight according to standards set by the World Health Organization (2011), while $40.2 \%$ of children in Chiquimula between the ages of six and 60 months were anemic (Ministry of Public Health and Social Assistance, 2017).

The main objective of the program was to increase the resilience of households located in the Guatemalan Dry Corridor. A major feature of the program was the creation of farmer field schools in communities to train households in basic grain production, agroforestry, adaptation to climate change, and poultry management. Each topic was covered through weekly three-hour classes over the course of eight weeks. A second major program component was the distribution of naked-neck chickens. By breeding and distributing naked-neck chickens, the Mancomunidad sought to build resilience for program participants while conserving a productive asset well-suited to the hot and drought-prone conditions of the Dry Corridor.

Naked-neck chickens are especially productive in adverse conditions relative to other breeds. In a laboratory experiment, Chen et al. (2004) found that normally-feathered chickens produce about $7 \%$ more eggs over a year (173 versus 161) than naked-neck chickens when the ambient temperature is $22^{\circ} \mathrm{C}$. But at $32^{\circ} \mathrm{C}$ the additional ventilation provided by the naked-neck's absence of neck feathers results in $9.7 \%$ additional eggs produced (124 versus 113), higher average weight per egg (42.8 grams versus 40 grams), and better maintenance of body weight (90\% versus $85 \%$ ). As discussed by Wong et al. (2017), indigenous chicken varieties have co-evolved alongside their environments. We would therefore expect naked-neck chickens to have advantages over specialized egg layers with respect to disease resistance, the ability to scavenge for food, and avoidance of predators. Laboratory results like those of Chen et al. (2004) will not fully translate to conditions in Chiquimula. But the Mancomunidad estimated that the ten hens given to each program participant receiving chickens could produce around 500 eggs per year, suggesting a potentially large impact on access to animal source foods.

Program implementation worked as follows. Mancomunidad personnel arrived at each community to conduct a household census, followed by a meeting to publicize the program and describe 
the farmer field schools and other program details. Communities too small to support their own farmer field schools were combined into clusters with other neighboring communities. Larger communities sometimes had multiple farmer field schools. Households in the cohort studied in this article were allowed to pick which modules they attended and any resident of the community served by a farmer field school (according to the program's census) was eligible to enroll.

Each participating household received a chicken set if they satisfied the following criteria: nearperfect attendance at the local farmer field school's poultry sessions, constructing a hen house using local materials, dedicating a small area to forage plants for their chickens, and signing a pledge to transfer ten female and two male chickens back to the program once their birds began to reproduce and their offspring were old enough to be moved (i.e., pass-on-the-gift). The cost per household of the chicken set, including training and all materials, was approximately $\$ 500$ by 2018 and paid for by the program. ${ }^{1}$ To put this figure in context, estimated annual expenditure per capita was $\$ 1,113$ in 2017 for the households in our data set. While the program's various components are directed at the entire household, the individuals attending the poultry module and receiving chickens were all women. By January 2018, the poultry component of the program had produced 147,340 birds and distributed chickens to 4,239 households (Multilateral Investment Fund, 2018).

At each farmer field school, the chickens received by the first group of households to complete the poultry module were raised by program technicians at a dedicated facility. Subsequent graduates of the poultry module received chickens that had been raised by earlier program participants from the same cluster and later passed back to the program to satisfy the above-mentioned pledge. In the present study, about $1 \%$ of households assigned to the treatment group and $3 \%$ of control group households had received pass-on-the-gift birds when follow-up data were collected. Waiting for additional pass-on-the-gift transfers before collecting follow-up data would have further contaminated the control group. In addition, $5 \%$ of households in the treatment group and $3 \%$ of households in the control group participated in a program component other than chicken training and transfers at follow-up. The Mancomunidad made attendance of all modules compulsory for future program

\footnotetext{
${ }^{1}$ Cost figures are taken from program documentation provided by the Mancomunidad Copan Ch'orti'.
} 
cohorts, but this change did not affect the treatment group used in our study. We therefore interpret our results as reflecting the impact of poultry training and chicken transfers delivered directly to beneficiary households through the program.

\section{Evaluation design and data}

All 133 communities located in the most drought-prone areas served by the Mancomunidad were included in the program. Capacity constraints dictated that the program would be rolled out over approximately five years. To that end, communities were divided into five cohorts. The Mancomunidad's initial plan was to phase the program into one cohort per year, but implementation challenges described below resulted in slow rollout for some cohorts and quicker implementation in others.

\subsection{Evaluation design}

An initial cohort of 15 communities received the program in 2014. Communities assigned to the first cohort were selected by the Mancomunidad and were prioritized after experiencing severe effects of a drought. An additional 50 communities in relatively affluent coffee-producing areas were assigned by the Mancomunidad to the program's last cohort. The remaining 68 communities were grouped into clusters large enough to support a farmer field school and randomly assigned to cohort two, three, or four by the research team. Under the evaluation plan agreed to with the Mancomunidad, program technicians would finish distributing chickens raised by the program in one cohort before moving on to another. This aspect of the plan was not followed to the letter, as can be seen in figure 2, because the Mancomunidad did not want delays in earlier cohorts to affect transfers to later cohorts. In addition, the evaluation plan did not set rules on the distribution of chickens between participating households (i.e., through pass-on-the-gift) or on the order and pace of distribution within a given cohort.

The randomization was carried out at the cluster level as follows. At the request of the Mancomunidad, three clusters (totaling five communities) were randomly assigned to cohort three so that 
the Mancomunidad could adhere closely to the schedule agreed upon with donors. The remaining 48 clusters (with 63 communities) were matched into strata of three clusters each using Euclidean distance as a function of population size, number of communities, altitude (indicators for low, medium, and high), and indicators for being located in one of three watersheds. Community-level data were provided by the Mancomunidad. Each member of a stratum was randomly assigned to program cohort two, three, or four. Cohort four would serve as the control group for the evaluation, with followup data being collected before cohort four could plausibly be affected by the program. Communities were not told in advance when exactly they could expect the program to arrive, which should limit bias from anticipatory effects.

There was a budget constraint on the evaluation that limited the number of surveys to be collected, ruling out a midline survey and forcing the research team to decide how to distribute the survey budget between cohorts two, three, and four. The research team assumed that if data were collected before cohort four was affected by the program, then cohort three would only be weakly affected at that point, particularly as compared to cohort two. Therefore survey data were only collected from the 16 strata of clusters assigned to cohorts two and four, including 16 clusters/19 communities assigned to cohort two (i.e., the treatment group) and 16 clusters/22 communities assigned to cohort four (the control group). Approximate locations of communities included in the data set are shown in figure 1. Some communities were dropped from the sample used in estimation for reasons described in the next section.

\subsection{Data collection and sample construction}

The sample of interviewed households was constructed in three stages. First, since a census was not available or feasible given budget constraints when baseline data were collected, supervisors from the data collection team met with local leaders and created rosters of individuals living in each of the 41 communities assigned to program cohorts two and four. The field team made it as clear as possible to community leaders that no benefit would be gained from appearing on the list and that the purpose 


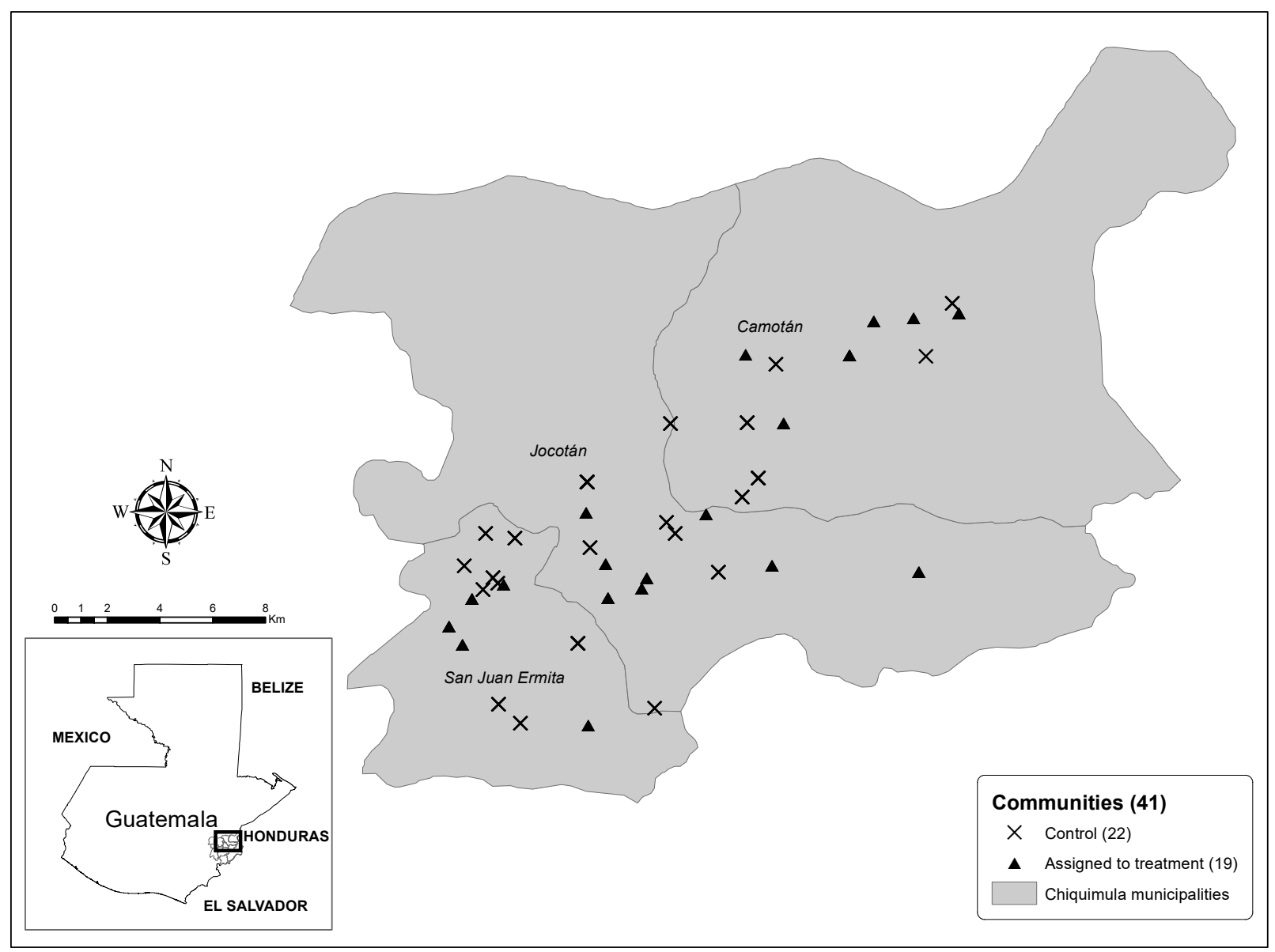

of the list was to gather information that would help the Mancomunidad serve the community. Next, a random sample of households was selected from each cluster. Finally, households remained in the sample if they reported participating in at least one productive agricultural activity (raising animals or planting crops). Households not satisfying these critera were replaced in the sample. The purpose of filtering households by participation in agriculture was to identify households with a high probability of future participation in a farmer field school.

Figure 2 shows the timing of baseline and endline data collection as well as the cumulative number of chicken set deliveries to households in our data set. Chicken set distribution to households in the treatment group began in August 2014, leveled off sharply in March 2016, and continued at a slow pace into 2018. Transfers to the treatment group after late 2016 are the result of households in the 
treatment group attending farmer field schools outside their communities. The jump in chicken set distribution in the control group visible in April and May 2017 indicates the start of program rollout in control communities, while prior chicken set deliveries to control areas are from lack of compliance with treatment assignment (e.g., households in the control group attending farmer field schools in neighboring communities). The approximate 8o-day lag between delivery and the start of egg production ensures that none of the chickens transferred to control group households between April 2017 and the start of follow-up data collection in May 2017 would have begun producing eggs. We discuss the timing of data collection and implications for our analysis in appendix A.2.

As mentioned in the introduction and noted in figure 2, the program chicken-breeding facility suffered an outbreak of Marek's disease, which is contagious and deadly to chickens. We discuss the causes and consequences of the outbreak as well as other program challenges in appendix A.1. A vaccine against Marek's disease was introduced into the program in August 2015. Although we do not have data on chicken deaths, the outbreak could have affected the $42 \%$ of program participants in the treatment group who received their chickens before the vaccine was introduced. $82 \%$ of households who received vaccinated chickens reported that their birds produced eggs versus $32 \%$ of households who received their chickens before the vaccine was introduced. When discussing our results later in the paper, we consider the role of the disease outbreak in limiting program impacts.

Figure 2: Timing of data collection and chicken transfers

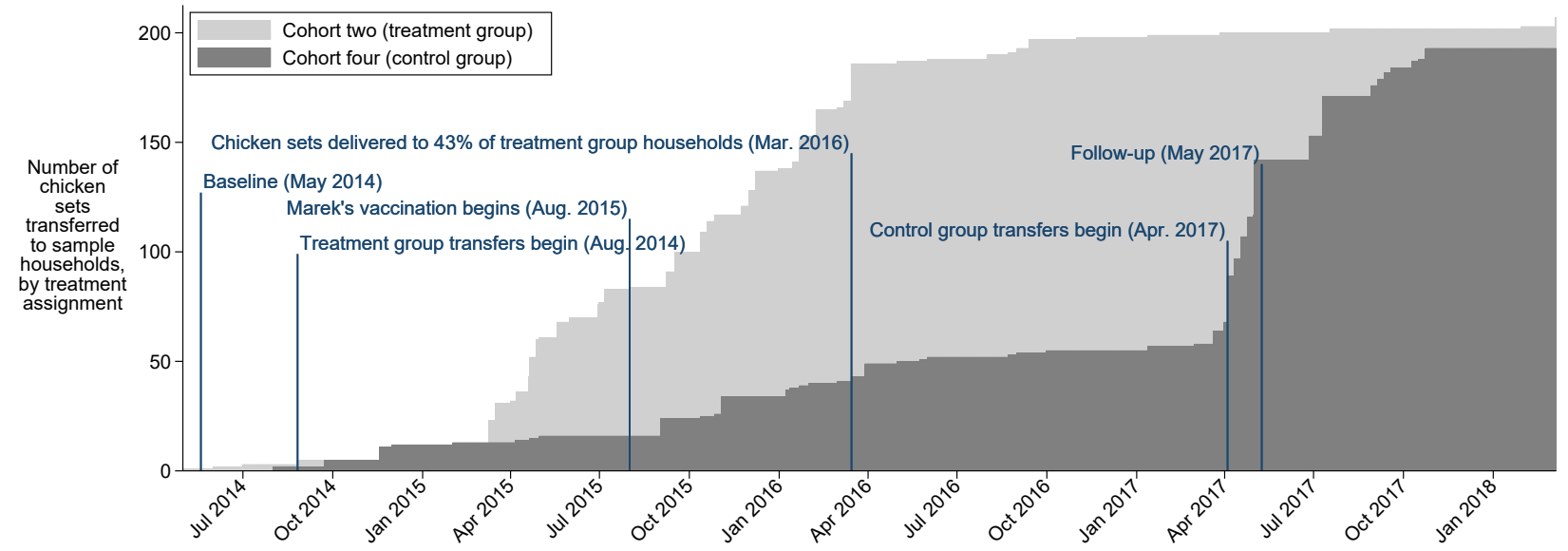

Notes: Chickens reach egg-laying age around 80 days after delivery. 
Enumerators completed follow-up interviews with $92.3 \%$ of the baseline sample. We restrict our analysis to households interviewed in both survey rounds and show that our results are robust to attrition in appendix A.11. Prior to analysis, we dropped two contaminated strata (with a total of four communities) where the Mancomunidad mistakenly intervened in the control clusters but not in the clusters assigned to treatment. Assignment to the treatment group was randomized within the remaining strata, so our identification strategy is unaffected by dropping the contaminated observations. $^{2}$ Our final sample includes 14 strata, 28 clusters, 36 communities, and 791 households, among which 14 clusters and 18 communities with 391 households were assigned to treatment and 14 clusters and 18 communities with 400 households were assigned to control. Power calculations are shown in section A.7 of the appendix.

\subsection{Baseline summary statistics and balance}

Table 1 shows averages and standard deviations by treatment status as well as estimated differences in means for key demographic indicators and household-level outcomes, all estimated using baseline data. Although baseline chicken ownership is fairly high, egg production is quite low and heavily skewed, as the median level of egg production among chicken owners is zero over the six months preceding baseline interviews. Egg consumption also looks somewhat high, but the average of roughly 1.35 eggs consumed daily per adult male equivalent is misleading, as the median is 0.65 and $31 \%$ of households reported consuming zero eggs. In general, differences in means are small relative to the spread of the data, with calorie consumption and number of naked-neck chickens showing statistically significant differences. The imbalance in naked-neck chickens is the result of outliers in the control group that are not completely addressed through winsorization. We control for lagged outcomes when estimating program impacts and show robustness to controlling for imbalanced baseline outcomes in appendices A.16 and A.17.

\footnotetext{
${ }^{2}$ In appendix A.8 we compare baseline characteristics for our main estimating sample and the contaminated strata that were dropped, and in general they look very similar. In addition, we present results using the full sample in appendix A.18, and show our conclusions are unaffected.
} 
Table 1: Baseline summary statistics and balance: household-level variables

\begin{tabular}{|c|c|c|c|}
\hline & Treatment & Control & Difference \\
\hline \multirow[t]{2}{*}{ Household size (adult male equivalents) } & 4.069 & 3.976 & 0.055 \\
\hline & $\{1.799\}$ & $\{1.802\}$ & [0.136] \\
\hline \multirow[t]{2}{*}{ Dependency ratio } & 38.996 & 39.518 & -0.334 \\
\hline & $\{22.500\}$ & $\{22.281\}$ & {$[3.798]$} \\
\hline \multirow[t]{2}{*}{ Woman-headed household (o/1) } & 0.161 & 0.188 & -0.029 \\
\hline & $\{0.368\}$ & $\{0.391\}$ & [0.040] \\
\hline \multirow[t]{2}{*}{ Wealth $(\log )$} & 9.619 & 9.412 & 0.220 \\
\hline & $\{1.396\}$ & $\{1.353\}$ & {$[0.294]$} \\
\hline \multirow[t]{2}{*}{ Annual food expenditure per adult male equivalent (log) } & 7.250 & 7.432 & -0.190 \\
\hline & $\{1.269\}$ & $\{1.131\}$ & [0.193] \\
\hline \multirow[t]{2}{*}{ Daily calories per adult male equivalent (log) } & 8.340 & 8.463 & $-0.137^{* *}$ \\
\hline & $\{0.730\}$ & $\{0.734\}$ & {$[0.058]$} \\
\hline \multirow[t]{2}{*}{ Daily grams of animal protein per adult male equivalent $(\log )$} & 1.809 & 1.954 & -0.172 \\
\hline & $\{1.388\}$ & $\{1.333\}$ & {$[0.270]$} \\
\hline \multirow[t]{2}{*}{ Daily servings of eggs } & 0.393 & 0.430 & -0.056 \\
\hline & $\{0.570\}$ & $\{0.619\}$ & [0.099] \\
\hline \multirow[t]{2}{*}{ Eggs consumed per day per adult male equivalent } & 1.307 & 1.408 & -0.137 \\
\hline & $\{2.063\}$ & $\{2.354\}$ & {$[0.291]$} \\
\hline \multirow[t]{2}{*}{ Food consumption score } & 20.597 & 21.541 & -1.190 \\
\hline & $\{8.411\}$ & $\{8.398\}$ & {$[1.585]$} \\
\hline \multirow[t]{2}{*}{ Chickens owned } & 11.263 & 10.355 & 1.363 \\
\hline & $\{11.867\}$ & $\{10.670\}$ & {$[1.212]$} \\
\hline \multirow[t]{2}{*}{ Naked-neck chickens owned } & 1.402 & 1.210 & $0.346^{* *}$ \\
\hline & $\{3.305\}$ & $\{2.863\}$ & {$[0.143]$} \\
\hline \multirow[t]{2}{*}{ Uses poultry registry $(\mathrm{o} / 1)$} & 0.107 & 0.095 & 0.012 \\
\hline & $\{0.310\}$ & $\{0.294\}$ & {$[0.024]$} \\
\hline \multirow[t]{2}{*}{ Eggs produced in last six months (log) } & 1.421 & 1.527 & -0.084 \\
\hline & $\{2.299\}$ & $\{2.504\}$ & {$[0.219]$} \\
\hline \multirow[t]{2}{*}{ Sold at least one egg in last six months $(\mathrm{o} / \mathrm{1})$} & 0.038 & 0.037 & 0.009 \\
\hline & $\{0.192\}$ & $\{0.190\}$ & {$[0.019]$} \\
\hline Observations & 391 & 400 & 791 \\
\hline
\end{tabular}

Notes: ${ }^{*} p<0.10,{ }^{* *} p<0.05,{ }^{* * *} p<0.01$. Standard deviations in curly braces, standard errors in brackets. All regressions for differences in means include the treatment indicator, an intercept, and indicators for thirteen strata. Standard errors and degrees of freedom were estimated as in Young (2016). Continuous outcomes were top coded their $1^{\text {st }}$ and $99^{\text {th }}$ percentiles. Wealth includes the value of land, livestock, agricultural implements, housing, consumer durables, and savings. All variables in logs were created using the inverse hyperbolic sine transformation. Food quantity data were collected using a consumption module similar to that of the Guatemalan National Survey of Living Standards, modified for the study context. Calorie and protein data were obtained using a food composition table for Central America (INCAP, 2012). The food consumption score is a quality-weighted measure of dietary diversity (World Food Program, 2008). 
Table 2 shows baseline summary statistics and balance for age and anthropometric indicators among girls and boys, respectively, between the ages of six to 60 months at baseline. By focusing on the ages of six to 60 months, we ensure a high degree of overlap between the timing of chicken transfers and the first 1,000 days of life (from conception until the second birthday), a critical period for child nutrition and corresponding effects on health outcomes, particularly height (Shrimpton et al., 2001; Victora et al., 2010). As discussed in appendix A.3, we estimate the overlap between each child's first 1,000 days and the productive life of chickens received by their households. Estimated median overlap between the productive life of program chickens and the first 1,00o days of life among the 115 children in treatment group households receiving chicken sets before follow-up is 449 days. ${ }^{3}$ Note that there are 212 treatment group children at follow-up. In the control group, there are only 29 children who were in their first 1,00o days of life when chickens were delivered and received their chickens before follow-up. ${ }^{4}$

Our anthropometric indicators include weight-for-age and height-for-age Z-scores as well as indicators for not being underweight, severely underweight, stunted, or severely stunted, all calculated according to guidelines from the World Health Organization (2011). Impacts on Z-scores would indicate that the program shifted the distribution of height or weight relative to a healthy population, while changes in indicators for stunting and underweight would imply that children with the poorest health status were affected by the program.

\footnotetext{
${ }^{3}$ When estimating the overlap between the first 1,00o days of life and the productive life of program chickens, we assume that the first 1,000 days of life start 280 days before the date of birth and end 720 days after birth. We also assume that egg production starts no earlier than 80 days after chicken set delivery and that program chickens have a productive life of two years, as per the estimates given to the research team by the Mancomunidad. Finally, we assume that children whose households stated that their program chickens did not lay eggs had no exposure to productive program chickens.

${ }^{4}$ The ratio of boys to girls between the ages of six and 6o months in our sample is 1.29 at baseline and 1.24 at follow-up. In Guatemala, the sex ratio at birth is 1.05 (Central Intelligence Agency, 2016). When considering all ages, the sex ratio is almost exactly 1:1. Protocols for obtaining anthropometric data were identical for boys and girls. Field supervisors reported no greater difficulty in obtaining data for girls relative to boys. Whether the larger number of boys in the sample arose purely by chance or reflects a demographic quirk of the program area is unclear.
} 
Table 2: Baseline summary statistics and balance: children ages six to 60 months

\begin{tabular}{|c|c|c|c|}
\hline & Treatment & Control & Difference \\
\hline \multicolumn{4}{|l|}{$\underline{\text { Girls }}$} \\
\hline \multirow[t]{2}{*}{ Age in months } & 32.604 & 31.655 & 1.298 \\
\hline & $\{17.057\}$ & $\{16.194\}$ & {$[2.458]$} \\
\hline \multirow[t]{2}{*}{ Height-for-age (Z-score) } & -1.474 & -1.724 & 0.233 \\
\hline & $\{1.977\}$ & $\{1.739\}$ & {$[0.248]$} \\
\hline \multirow{2}{*}{ Not stunted $(\mathrm{o} / 1)$} & 0.516 & 0.462 & 0.054 \\
\hline & $\{0.502\}$ & $\{0.501\}$ & {$[0.091]$} \\
\hline \multirow[t]{2}{*}{ Not severely stunted $(\mathrm{o} / \mathrm{1})$} & 0.802 & 0.790 & 0.007 \\
\hline & $\{0.401\}$ & $\{0.409\}$ & [0.06o $]$ \\
\hline \multirow[t]{2}{*}{ Weight-for-age (Z-score) } & -0.940 & -0.944 & -0.035 \\
\hline & $\{1.305\}$ & $\{1.391\}$ & {$[0.149]$} \\
\hline \multirow[t]{2}{*}{ Not underweight (o/1) } & 0.813 & 0.773 & 0.021 \\
\hline & $\{0.392\}$ & $\{0.421\}$ & {$[0.054]$} \\
\hline \multirow{2}{*}{ Not severely underweight $(\mathrm{o} / \mathrm{1})$} & 0.956 & 0.941 & 0.024 \\
\hline & $\{0.206\}$ & $\{0.236\}$ & {$[0.036]$} \\
\hline Observations & 91 & 119 & 210 \\
\hline \multicolumn{4}{|l|}{ Boys } \\
\hline \multirow[t]{2}{*}{ Age in months } & 32.210 & 30.694 & 1.082 \\
\hline & $\{15.016\}$ & $\{16.049\}$ & {$[1.806]$} \\
\hline \multirow[t]{2}{*}{ Height-for-age (Z-score) } & -1.766 & -1.762 & -0.055 \\
\hline & $\{1.794\}$ & $\{1.891\}$ & [0.439] \\
\hline \multirow[t]{2}{*}{ Not stunted $(\mathrm{o} / \mathrm{1})$} & 0.572 & 0.478 & 0.103 \\
\hline & $\{0.497\}$ & $\{0.501\}$ & {$[0.094]$} \\
\hline \multirow[t]{2}{*}{ Not severely stunted (o/1) } & 0.826 & 0.776 & 0.045 \\
\hline & $\{0.380\}$ & $\{0.418\}$ & [0.079] \\
\hline \multirow[t]{2}{*}{ Weight-for-age (Z-score) } & -0.911 & -0.995 & 0.059 \\
\hline & $\{1.513\}$ & $\{1.395\}$ & {$[0.306]$} \\
\hline \multirow[t]{2}{*}{ Not underweight (o/1) } & 0.790 & 0.791 & -0.016 \\
\hline & $\{0.409\}$ & $\{0.408\}$ & {$[0.045]$} \\
\hline \multirow[t]{2}{*}{ Not severely underweight $(\mathrm{o} / \mathrm{1})$} & 0.949 & 0.948 & 0.006 \\
\hline & $\{0.220\}$ & $\{0.223\}$ & {$[0.036]$} \\
\hline Observations & 138 & 134 & 272 \\
\hline
\end{tabular}

Notes: ${ }^{*} p<0.10,{ }^{* *} p<0.05,{ }^{* *} p<0.01$. Standard deviations in curly braces, standard errors in brackets. All regressions for differences in means include the treatment indicator, an intercept, and indicators for thirteen strata. Z-scores as well as indicators for stunting and underweight calculated according to World Health Organization standards (World Health Organization, 2011). Weight-for-age and height-for-age were top and bottom coded at 6 and -6, respectively, following guidelines set by the World Health Organization (2011). Standard errors and degrees of freedom estimated as in Young (2016). 


\section{Empirical approach}

We estimate average effects of assignment to the treatment group rather than the control group, i.e., intent-to-treat effects. We opt not to estimate effects of the treatment itself. Imperfect compliance with assigned treatments implies that randomization only identifies the effects of program participation in the absence of spillovers as well as other assumptions laid out in Imbens and Angrist (1994). For households in our data set, average distance to the nearest neighbor is 74 meters. Ruling out any exchange of eggs (for example) within communities seems like an excessively strong assumption.

\subsection{Estimation and inference for average intent-to-treat effects}

Household-level intent-to-treat effects are estimated using the following regression:

$$
y_{h c s t}=\gamma_{s}+\rho y_{h c s t-1}+\delta \operatorname{Treat}_{c}+\varepsilon_{h c s t}
$$

where $h, c, s$, and $t$ index household, cluster, stratum, and time period, respectively. The $\gamma_{s}$ parameter is a stratum fixed effect, $y_{h c s t-1}$ is the lagged outcome, Treat $_{c}$ is a dummy variable equal to one for households in clusters assigned to the treatment group, and $\delta$ is the average intent-to-treat effect. ${ }^{5}$

We use a slightly different specification when estimating impacts on height and weight indicators among children because lagged outcomes are only observed for individuals who were alive at baseline. We compensate by using lagged outcomes among siblings, when available:

$$
y_{i h c s t}=\gamma_{s}+\gamma_{y_{i}}+\gamma_{\bar{y}}+\rho_{1} y_{i h c s t-1}+\rho_{2} \bar{y}_{h c s t-1}+\beta A g e_{i h c s t}+\delta \operatorname{Treat}_{c}+\varepsilon_{i h c s t}
$$

where $i$ indexes child, $y_{\text {ihcst-1 }}$ is the lagged outcome (set to zero for individuals not yet born at baseline), $\bar{y}_{h c s t-1}$ is the average lagged outcome among siblings of the same gender as child $i$ (e.g., the lagged average height-for-weight $Z$-score among girl siblings if child $i$ is a girl, set to zero if no such

\footnotetext{
${ }^{5}$ We used lagged food expenditure for $y_{i c s t-1}$ when estimating impacts on total expenditure because the latter was only measured at follow-up.
} 
siblings exist), $\gamma_{y_{i}}$ is the coefficient on a dummy variable equal to one if $y_{i h c s t-1}$ is observed, $\gamma_{\bar{y}}$ is the coefficient on a dummy variable equal to one if $\bar{y}_{h c s t-1}$ is observed in the data, and $A g e_{i h c s t}$ is age in months as measured at follow-up.

Since individual-level diet indicators were not collected at baseline, we remove $\gamma_{y_{i}}, \gamma_{\bar{y}}, y_{i h c s t-1}$, and $\bar{y}_{h c s t-1}$ from the model when estimating impacts on dietary diversity and consumption of animal source foods among children and replace them with the lagged outcome measured at the household level using seven-day recall. For inference, we estimate cluster-robust standard errors and effective degrees of freedom as in Young (2016), which should result in valid inference despite having just 28 clusters in the data. We adjust for multiple comparisons by reporting $q$-values and $95 \%$ confidence intervals adjusted for the false discovery rate (Benjamini and Hochberg, 1995; Benjamini and Yekutieli, 2005). We describe our rules for multiple hypothesis testing in detail in appendix A.6.

\subsection{Estimation and inference for heterogeneous intent-to-treat effects}

We use a procedure described in Chernozhukov et al. (2018b) to explore program impact heterogeneity beyond gender-specific effects on children. The method of Chernozhukov et al. (2018b) allows us to model heterogeneous treatment effects as a function of a large number of observed characteristics while avoiding "overfitting", i.e., without obtaining an excellent in-sample fit at the expense of highlyvariable out-of-sample performance. Overfitting could lead to mistakenly detecting treatment effect heterogeneity that is a quirk of a given sample rather than reflective of the population of interest. In addition, when applying the method of Chernozhukov et al. (2018b) we can predict heterogeneous treatment effects using machine learning methods without placing any distributional assumptions on the estimates generated by a given algorithm. In general, the theory needed to justify hypothesis testing using machine learning estimates is not well developed, although there are exceptions (Athey, Tibshirani, and Wager, 2019; Belloni, Chernozhukov, and Hansen, 2014). In contrast, hypothesis testing is carried out just as in any application of linear regression when applying the method of Chernozhukov et al. (2018b). We present key details of our approach to estimating impact heterogeneity 
below and reserve a detailed discussion for appendix A.4.

To apply the method of Chernozhukov et al. (2018b), we begin by estimating the following equation:

$$
y_{i c s}=\alpha^{\prime} \boldsymbol{X}_{i c s}+\beta_{1}\left(\text { Treat }_{c}-p\left(Z_{i c s}\right)\right)+\beta_{2}\left(\text { Treat }_{c}-p\left(Z_{i c s}\right)\right)\left(S\left(Z_{i c s}\right)-\bar{S}\right)+\varepsilon_{i c s}
$$

The vector $\boldsymbol{Z}_{i c s}$ includes covariates that could explain impact heterogeneity and are observed at baseline or otherwise unaffected by assignment to treatment. In appendix A.5 we describe and justify each variable included in $Z_{i c s}$. The propensity score is given by $p\left(Z_{i c s}\right)$ and is set to 0.5 for all observations by virtue of randomization, ${ }^{6} S\left(Z_{i c s}\right)$ is a "proxy predictor" for the conditional intent-to-treat effect obtained through machine learning methods, and $\bar{S}$ is the mean of the proxy predictor. The average intent-to-treat effect is given by $\beta_{1}$, while $\beta_{1}+\beta_{2}\left(S\left(Z_{i c s}\right)-\bar{S}\right)$ is a linear approximation to the intent-to-treat effect conditional on $Z_{i c s}$. The properties of ordinary least squares ensure that $\beta_{1}+\beta_{2}\left(S\left(Z_{i c s}\right)-\bar{S}\right)$ is the "best linear predictor" of the conditional intent-to-treat effect given $S\left(Z_{i c s}\right)$, i.e., the linear predictor that yields the smallest mean squared error (Chernozhukov et al., 2018b). The vector $\boldsymbol{X}_{i c s}$ contains a column of ones and additional terms meant to improve precision, including stratum indicators, $S\left(Z_{i c s}\right)$, and a proxy predictor for the conditional mean of $y_{i c s}$ when assigned to the control group.

We also estimate equation 4 :

$$
\begin{aligned}
y_{i c s} & =\alpha^{\prime} \boldsymbol{X}_{i c s}+\gamma_{1} G_{1}\left(\text { Treat }_{c}-p\left(Z_{i c s}\right)\right)+\gamma_{2} G_{2}\left(\text { Treat }_{c}-p\left(Z_{i c s}\right)\right) \\
& +\gamma_{3} G_{3}\left(\text { Treat }_{c}-p\left(Z_{i c s}\right)\right)+u_{i c s}
\end{aligned}
$$

where $G_{1}$ is an indicator variable equal to one for observations in the lowest tercile of $S\left(Z_{i c s}\right)$, and $G_{2}$ and $G_{3}$ are indicators for the middle and top terciles of $S\left(Z_{i c s}\right)$, respectively. If $S\left(Z_{i c s}\right)$ approximates the true conditional intent-to-treat effect accurately, then $\gamma_{1}, \gamma_{2}$, and $\gamma_{3}$ will closely correspond to the

\footnotetext{
${ }^{6}$ In our application, subtracting the propensity score from the treatment indicator has no effect on our results since the propensity score does not vary. However, for research designs where the probability of treatment depends on observed characteristics, failing to difference out the propensity score can result in substantial bias (Chernozhukov et al., 2018a).
} 
average intent-to-treat effects among households or children least affected, moderately affected, and most affected by the program. We refer to $\gamma_{1}, \gamma_{2}$, and $\gamma_{3}$ as group average intent-to-treat effects.

Finally, we have:

$$
Z_{i c s}^{k}=\delta_{1} G_{1}+\delta_{2} G_{2}+\delta_{3} G_{3}+e_{i c s}
$$

where $Z_{i c s}^{k}$ represents a single covariate from $Z_{i c s}$. The parameters $\delta_{1}, \delta_{2}$, and $\delta_{3}$ are the means of $Z_{i c s}^{k}$ for the least, middle, and most affected observations. By testing whether $\delta_{1}=\delta_{3}$ we can check whether the most and least affected observations differ in their characteristics. We refer to the comparison of $\delta_{1}$ and $\delta_{3}$ as classification analysis, following Chernozhukov et al. (2018b). We limit the classification analysis presented in the main text to outcomes that exhibit evidence of treatment effect heterogeneity, i.e., where we can reject $\beta_{2}=0$ or $\gamma_{1}=\gamma_{3}$ after adjusting for multiple hypothesis testing.

The method of Chernozhukov et al. (2018b) avoids overfitting by using repeated sample splitting, i.e., randomly dividing the sample into an auxiliary part used for model selection and a main part used for estimation and hypothesis testing. We repeat the sample splitting procedure 199 times and report the median of each point estimate, $p$-value, and upper and lower confidence interval bound in our final results. Using medians generated by many sample splits increases robustness by avoiding "cherry picking" a favorable sample split. The cost of sample splitting is that a nominal significance level of $\alpha$ translates to a true significance level of $2 \alpha$ (Chernozhukov et al., 2018b).

We use two machine learning methods to create the proxy predictors (i.e., $S\left(Z_{i c s}\right)$ ): the elastic net (Zou and Hastie, 2005) and the random forest algorithm (Breiman, 2001). The elastic net is a penalized least squares method that arguably combines the best features of two other methods: LASSO and ridge regression. When predictors are not highly correlated with one another and the correct regression model has a relatively small number of non-zero parameters, then, just as in the LASSO. When a subset of predictors are highly correlated with one another, the elastic net will include them all in the final model, just as in ridge regression (Zou and Hastie, 2005). The random forest algorithm is an "ensemble" method that averages predictions generated by many "regression trees". Regression 
trees are grown by splitting the sample into "leaves" where observations in a leaf have similar values of covariates that are important for predicting the outcome. Each observation is assigned the average of the outcome within its leaf as its predicted value. The elastic net should provide a better fit for outcomes where the conditional mean is approximately linear in parameters whereas random forest may have more success for nonlinear conditional means. Both methods strong predictive accuracy while avoiding overfitting.

Since we are using two machine learning methods, we could potentially have two tests for every hypothesis of interest that should be accounted for when adjusting for multiple comparisons. We opt to present results from only one machine learning method per outcome. When deciding which set of results to select for a given outcome, we first check whether one of the machine learning methods strictly dominates based on two separate goodness-of-fit measures taken from Chernozhukov et al. (2018b) and described in appendix A.4. If the two goodness-of-fit measures disagree, then we select the set of results to report at random.

Note that we do not conduct separate heterogeneity analyses for boys and girls. Dividing the subsample of children by gender would cut the data too finely, limiting our ability to detect meaningful effect heterogeneity. Instead, we include gender as one of the characteristics that could shape treatment effect heterogeneity and estimate average intent-to-treat effects for boys and girls with machine learning as a check on our main results in section A.13 of the appendix. The results in the appendix are very similar to what we present in the main text, but estimated less precisely.

\section{Results}

\subsection{Average intent-to-treat effects on households}

Table 3 presents average intent-to-treat effect estimates for household-level outcomes. Virtually all intent-to-treat estimates are small and imprecisely estimated. Although the negative point estimates on number of chickens owned and naked-neck chickens owned are somewhat concerning, they are 
not significant and contradicted by a large positive effect on egg production. Overall, impacts on household-level outcomes are not estimated with enough precision to reach conclusions about program effects.

\subsection{Average intent-to-treat effects on children}

Table 4 shows average intent-to-treat effect estimates among children aged six to 60 months. Among girls, impacts on weight-for-age, height-for-age, stunting, and severe stunting are large, significant, and robust to adjustment for multiple comparisons. Estimated effects for boys are generally small and none are statistically significant. Impacts on consumption of animal source foods and the dietary diversity score are imprecisely estimated for both genders. As shown in the rightmost column of table 4, there are significant differences in intent-to-treat effects by gender for weight-for-age and stunting, although none of the differences in intent-to-treat effects by gender remain statistically significant after adjusting for multiple comparisons. In the appendix we check the robustness of our results to changes in the estimation sample, covariate set, mode of inference, and estimation method. We also check for spillovers and attrition bias. In all cases our results are unaffected. 
Table 3: Intent-to-treat effects, household-level outcomes

\begin{tabular}{|c|c|c|}
\hline & \multicolumn{2}{|c|}{ Intent-to-treat effect Control mean } \\
\hline Annual expenditure per adult male equivalent (log) & $\begin{array}{c}-0.008 \\
{[-0.434,0.418]} \\
(-0.511,0.494)\end{array}$ & 9.087 \\
\hline Annual food expenditure per adult male equivalent (log) & $\begin{array}{c}0.004 \\
{[-0.290,0.298]} \\
(-0.290,0.298)\end{array}$ & 8.364 \\
\hline Daily calories per adult male equivalent (log) & $\begin{array}{c}-0.001 \\
{[-0.250,0.248]} \\
(-0.250,0.248)\end{array}$ & 8.075 \\
\hline Daily grams of animal protein per adult male equivalent (log) & $\begin{array}{c}0.007 \\
{[-0.870,0.884]} \\
(-0.922,0.935)\end{array}$ & 2.545 \\
\hline Daily servings of eggs & $\begin{array}{c}-0.024 \\
{[-0.243,0.195]} \\
(-0.295,0.247)\end{array}$ & 0.439 \\
\hline Eggs consumed per day per adult male equivalent & $\begin{array}{c}0.013 \\
{[-0.865,0.890]} \\
(-0.982,1.008)\end{array}$ & 1.766 \\
\hline Food consumption score & $\begin{array}{c}-1.046 \\
{[-7.336,5.245]} \\
(-9.971,7.880)\end{array}$ & 33.269 \\
\hline Chickens owned (log) & $\begin{array}{c}-0.130 \\
{[-0.534,0.274]} \\
(-0.631,0.371)\end{array}$ & 2.140 \\
\hline Naked-neck chickens owned (log) & $\begin{array}{c}-0.017 \\
{[-0.511,0.477]} \\
(-0.511,0.477)\end{array}$ & 0.964 \\
\hline Uses poultry registry $(\mathrm{o} / 1)$ & $\begin{array}{c}0.026 \\
{[-0.008,0.060]} \\
(-0.022,0.075)\end{array}$ & 0.015 \\
\hline Eggs produced in last six months (log) & $\begin{array}{c}0.203 \\
{[-0.503,0.910]} \\
(-0.598,1.005)\end{array}$ & 2.600 \\
\hline Sold at least one egg in last six months $(\mathrm{o} / \mathrm{1})$ & $\begin{array}{c}0.004 \\
{[-0.050,0.059]} \\
(-0.054,0.062)\end{array}$ & 0.075 \\
\hline Observations & 791 & \\
\hline
\end{tabular}

Notes: ${ }^{*} p<0.10,{ }^{* *} p<0.05,{ }^{* * *} p<0.01 ;{ }^{+} q<0.10,{ }^{++} q<0.05,{ }^{+++} q<0.01$, where $q$ is the false discovery rate. $95 \%$ confidence intervals in brackets, $95 \%$ false discovery rate-adjusted confidence intervals in parentheses. Standard errors and degrees of freedom estimated as in Young (2016). See equation 1 for the regression specification. 
Table 4: Intent-to-treat effects for children, ages 6 to 60 months

\begin{tabular}{|c|c|c|c|c|c|}
\hline & \multicolumn{2}{|l|}{ Girls } & \multicolumn{2}{|l|}{ Boys } & \multirow[b]{2}{*}{ Difference } \\
\hline & Intent-to-treat effect & Control mean & Intent-to-treat effect & Control mean & \\
\hline Weight-for-age (Z-score) & $\begin{array}{c}0.349 \\
{[0.111,0.587]^{* * *}} \\
(0.068,0.629)^{++}\end{array}$ & -1.305 & $\begin{array}{c}0.027 \\
{[-0.397,0.450]} \\
(-0.397,0.450)\end{array}$ & -1.163 & $\begin{array}{c}0.322 \\
{[-0.050,0.694]^{*}} \\
(-0.154,0.798)\end{array}$ \\
\hline Not underweight $(\mathrm{o} / 1)$ & $\begin{array}{c}0.090 \\
{[-0.021,0.202]} \\
(-0.027,0.207)\end{array}$ & 0.773 & $\begin{array}{c}0.023 \\
{[-0.098,0.143]} \\
(-0.120,0.165)\end{array}$ & 0.802 & $\begin{array}{c}0.068 \\
{[-0.113,0.249]} \\
(-0.122,0.257)\end{array}$ \\
\hline Not severely underweight (o/1) & $\begin{array}{c}0.054 \\
{[-0.013,0.120]} \\
(-0.013,0.120)\end{array}$ & 0.938 & $\begin{array}{c}0.032 \\
{[-0.022,0.087]} \\
(-0.048,0.112)\end{array}$ & 0.954 & $\begin{array}{c}0.021 \\
{[-0.081,0.124]} \\
(-0.081,0.124)\end{array}$ \\
\hline Height-for-age (Z-score) & $\begin{array}{c}0.539 \\
{[0.203,0.875]^{* * *}} \\
(0.106,0.972)^{++}\end{array}$ & -2.209 & $\begin{array}{c}0.065 \\
{[-0.631,0.762]} \\
(-0.706,0.836)\end{array}$ & -1.997 & $\begin{array}{c}0.474 \\
{[-0.178,1.125]} \\
(-0.295,1.242)\end{array}$ \\
\hline Not stunted $(\mathrm{o} / 1)$ & $\begin{array}{c}0.235 \\
{[0.103,0.366]^{* * *}} \\
(0.041,0.428)^{++}\end{array}$ & 0.412 & $\begin{array}{c}0.038 \\
{[-0.121,0.196]} \\
(-0.166,0.242)\end{array}$ & 0.420 & $\begin{array}{c}0.197 \\
{[-0.029,0.423]^{*}} \\
(-0.132,0.526)\end{array}$ \\
\hline Not severely stunted (o/1) & $\begin{array}{c}0.143 \\
{[0.025,0.261]^{* *}} \\
(0.012,0.274)^{++}\end{array}$ & 0.784 & $\begin{array}{c}0.012 \\
{[-0.115,0.139]} \\
(-0.121,0.145)\end{array}$ & 0.794 & $\begin{array}{c}0.131 \\
{[-0.064,0.326]} \\
(-0.085,0.347)\end{array}$ \\
\hline Consumed animal-source foods in past day $(\mathrm{o} / 1)$ & $\begin{array}{c}-0.039 \\
{[-0.339,0.260]} \\
(-0.394,0.315)\end{array}$ & 0.598 & $\begin{array}{c}0.061 \\
{[-0.210,0.331]} \\
(-0.259,0.380)\end{array}$ & 0.547 & $\begin{array}{c}-0.100 \\
{[-0.294,0.094]} \\
(-0.329,0.129)\end{array}$ \\
\hline One-day dietary diversity score & $\begin{array}{c}-0.014 \\
{[-1.049,1.021]} \\
(-1.049,1.021)\end{array}$ & 5.649 & $\begin{array}{c}-0.041 \\
{[-1.272,1.190]} \\
(-1.272,1.190)\end{array}$ & $5 \cdot 484$ & $\begin{array}{c}0.027 \\
{[-0.626,0.680]} \\
(-0.626,0.680)\end{array}$ \\
\hline Observations & 195 & & 241 & & 436 \\
\hline
\end{tabular}

Notes: ${ }^{*} p<0.10,{ }^{* *} p<0.05,{ }^{* * *} p<0.01 ;{ }^{+} q<0.10,{ }^{++} q<0.05,{ }^{+++} q<0.01$, where $q$ is the false discovery rate. $95 \%$ confidence intervals in brackets, $95 \%$ false discovery rate-adjusted confidence intervals in parentheses. Standard errors and degrees of freedom estimated as in Young (2016). Z-scores and indicators for stunting and underweight based on standards from World Health Organization (2011). See equation 2 for the regression specification. 


\subsection{Heterogeneous intent-to-treat effects}

The first two columns of results in table 5 show estimates of the average intent-to-treat effect and the heterogeneity parameter (i.e., $\beta_{2}$ ) from equation 3 . The last three columns show the average intentto-treat effects for the most affected and least affected groups as well as their difference. At the household level, log grams of animal protein and the food consumption score have statistically significant treatment effect heterogeneity. ${ }^{7}$ Although the impact on the least affected tercile for the food consumption score suggests a negative average effect, the estimated difference is consistent with positive effects equal to a $5 \%$ increase relative to the overall sample average after adjusting for multiple hypothesis testing (see the 90\% confidence interval in the appendix). Still, it is possible that the least affected tercile experienced negative effects because of the Marek's disease outbreak. The indicator for having consumed animal source foods in the past day is the lone outcome exhibiting detectable treatment effect heterogeneity among children.

The classification analysis presented table 6 shows that households with the largest intent-totreat effects on animal protein consumption are at higher altitudes, suggesting they are poorer and more isolated. But indicators associated with poverty and isolation show no significant differences in means. Households experiencing the largest impacts on the food consumption score are less educated, have less wealth, have adult female members with relatively few group memberships (suggesting that they have low social capital), and consume less animal protein at baseline than the least affected households.

Table 7 shows estimated differences in means for the children with the largest and smallest impacts on the probability of consuming animal protein the past day. Children enjoying the largest impacts on having consumed animal source foods in the past day are from households that are relatively poor, less likely to be connected to an electricity grid, more likely to have given their children

\footnotetext{
${ }^{7} \mathrm{~A}$ draft of this paper that circulated under a different title did not show evidence of treatment effect heterogeneity for households outcomes. This changed once we fixed a small number of coding errors that affected indicators of diet and food consumption and applied the inverse hyperbolic sine transformation to baseline animal protein and nakedneck chickens owned. The latter two variables are highly skewed, and transforming them to reduce skewness strongly improved the performance of the elastic net. The elastic net fits a penalized linear regression model and is therefore sensitive to observations with outlying values of covariates.
} 
micronutrient supplements, and less likely to have a loan at baseline than the least affected households. Other baseline characteristics showing significant differences include the dependency ratio and having a dirt floor, but these additional differences are sensitive to adjusting for multiple comparisons. 
Table 5: Machine learning estimates of average impacts and effect heterogeneity

\begin{tabular}{|c|c|c|c|c|c|c|}
\hline & \multicolumn{2}{|c|}{ Best linear predictor } & \multicolumn{3}{|c|}{ Group average intent-to-treat } & \multirow[b]{2}{*}{$\begin{array}{c}\text { Machine learning } \\
\text { method }\end{array}$} \\
\hline & $\begin{array}{c}\text { Average } \\
\text { intent-to-treat }\end{array}$ & Heterogeneity & $\begin{array}{c}\text { Most } \\
\text { affected }\end{array}$ & $\begin{array}{c}\text { Least } \\
\text { affected }\end{array}$ & (Most-Least) & \\
\hline \multicolumn{7}{|l|}{ Household outcomes } \\
\hline Annual expenditure per adult male equivalent $(\log )$ & 0.002 & 0.526 & 0.136 & -0.090 & 0.222 & Elastic net \\
\hline Annual food expenditure per adult male equivalent $(\log )$ & 0.023 & 0.367 & 0.081 & -0.068 & 0.151 & Elastic net \\
\hline Daily calories per adult male equivalent (log) & 0.017 & $0.733^{*}$ & 0.142 & -0.119 & 0.281 & Elastic net \\
\hline Animal protein (log grams) & 0.063 & $0.886^{* *+}$ & 0.628 & -0.598 & $1.222^{* *}$ & Elastic net \\
\hline Daily servings of eggs & -0.032 & 0.412 & 0.064 & -0.105 & 0.155 & Random forest \\
\hline Eggs consumed per day per adult male equivalent & 0.094 & 0.266 & 0.279 & -0.104 & 0.338 & Elastic net \\
\hline Food consumption score & -0.699 & $0.830^{* * *+}$ & 2.410 & -4.235 & $6.752^{* *+}$ & Elastic net \\
\hline Chickens owned (log) & -0.119 & 0.660 & 0.103 & -0.416 & 0.541 & Elastic net \\
\hline Naked-neck chickens owned (log) & -0.018 & $0.985^{*}$ & 0.228 & -0.342 & 0.564 & Elastic net \\
\hline Eggs produced in last six months (log) & 0.188 & 0.657 & 0.408 & -0.167 & 0.604 & Elastic net \\
\hline \multicolumn{7}{|l|}{ Child outcomes } \\
\hline Weight-for-age (Z-score) & 0.154 & 0.572 & 0.360 & -0.022 & 0.411 & Elastic net \\
\hline Not underweight $(\mathrm{o} / 1)$ & 0.017 & 0.239 & 0.061 & -0.018 & 0.066 & Random forest \\
\hline Height-for-age (Z-score) & 0.245 & 0.213 & 0.316 & 0.307 & 0.036 & Elastic net \\
\hline Not stunted $(\mathrm{o} / \mathbf{1})$ & $0.111^{* *}$ & -0.566 & -0.001 & 0.212 & -0.207 & Random forest \\
\hline Consumed animal-source foods in past day $(\mathrm{o} / \mathrm{1})$ & 0.075 & $1.028^{* *+}$ & $0.279^{* *}$ & -0.084 & 0.353 & Random forest \\
\hline One-day dietary diversity score & 0.174 & $0.917^{* *}$ & $0.854^{*}$ & -0.409 & 1.231 & Random forest \\
\hline
\end{tabular}

Notes: ${ }^{*} p<0.10,{ }^{* *} p<0.05,{ }^{* * *} p<0.01 ;{ }^{+} q<0.10,{ }^{++} q<0.05,{ }^{+++} q<0.01$, where $q$ is the false discovery rate. Standard errors and degrees of freedom estimated as in Young (2016). Results for the "Best linear predictor" are estimates from equation 3. Results for the "Group average intent-to-treat" are estimates from equation 4 . See the appendix for $90 \%$ confidence intervals around each parameter. 
Table 6: Classification analysis for household outcomes

\begin{tabular}{lccc}
\hline & & \multicolumn{2}{c}{ (Most affected) - (Least affected) } \\
\cline { 2 - 4 } & $\begin{array}{c}\text { Sample } \\
\text { average }\end{array}$ & $\begin{array}{c}\text { Animal protein } \\
\text { (log grams) }\end{array}$ & $\begin{array}{c}\text { Food consumption } \\
\text { score }\end{array}$ \\
\hline Meters above sea level & 746.487 & $137.014^{* * *+++}$ & 51.688 \\
Rainfall (millimeters) & 499.457 & -60.658 & -23.058 \\
Days with extreme temperatures & 171.750 & 12.238 & -4.962 \\
Household size & 4.022 & 0.134 & 0.161 \\
Dependency ratio & 0.393 & -0.024 & -0.029 \\
Average education (years) & 2.535 & -0.808 & $-1.208^{* * *+}$ \\
Wealth (log) & 9.514 & -0.163 & $-0.506^{* * *+}$ \\
Dwelling has dirt floor (o/1) & 0.633 & -0.092 & 0.069 \\
Women's share of wealth & 0.363 & -0.026 & -0.034 \\
Had credit at baseline (o/1) & 0.110 & -0.069 & $-0.085^{*}$ \\
Distance to market (minutes) & 58.436 & 4.223 & $13.000^{*}$ \\
Connected to water network (o/1) & 0.695 & 0.062 & $0.123^{*}$ \\
Connected to electricity network (o/1) & 0.584 & -0.031 & -0.108 \\
Social capital index, household & 1.564 & 0.000 & $-0.585^{* *}$ \\
Social capital, women (count) & 0.925 & -0.038 & $-0.477^{* * *+}$ \\
Calories (log) & 8.402 & -0.041 & -0.100 \\
Animal protein (log grams) & 1.883 & -0.038 & $-0.448^{* *+}$ \\
Food consumption score & 21.075 & -1.285 & -1.519 \\
Egg unit value (quetzales/egg) & 1.174 & 0.018 & 0.001 \\
Eggs produced (units in last six months) & 1.475 & 0.518 & $0.656^{*}$ \\
Chickens owned (log) & 2.382 & 0.231 & $0.51^{* * *}$ \\
\hline
\end{tabular}

Notes: ${ }^{*} p<0.10,{ }^{* *} p<0.05,{ }^{* * *} p<0.01 ;{ }^{+} q<0.10,{ }^{++} q<0.05,{ }^{+++} q<0.01$, where $q$ is the false discovery rate. Standard errors are of the "HC1" type (MacKinnon and White, 1985). All characteristics are measured at baseline except for weather variables and altitude of the dwelling. See the appendix for a full description of all variables and $90 \%$ confidence intervals around each difference in characteristics. 
Table 7: Classification analysis for child outcomes

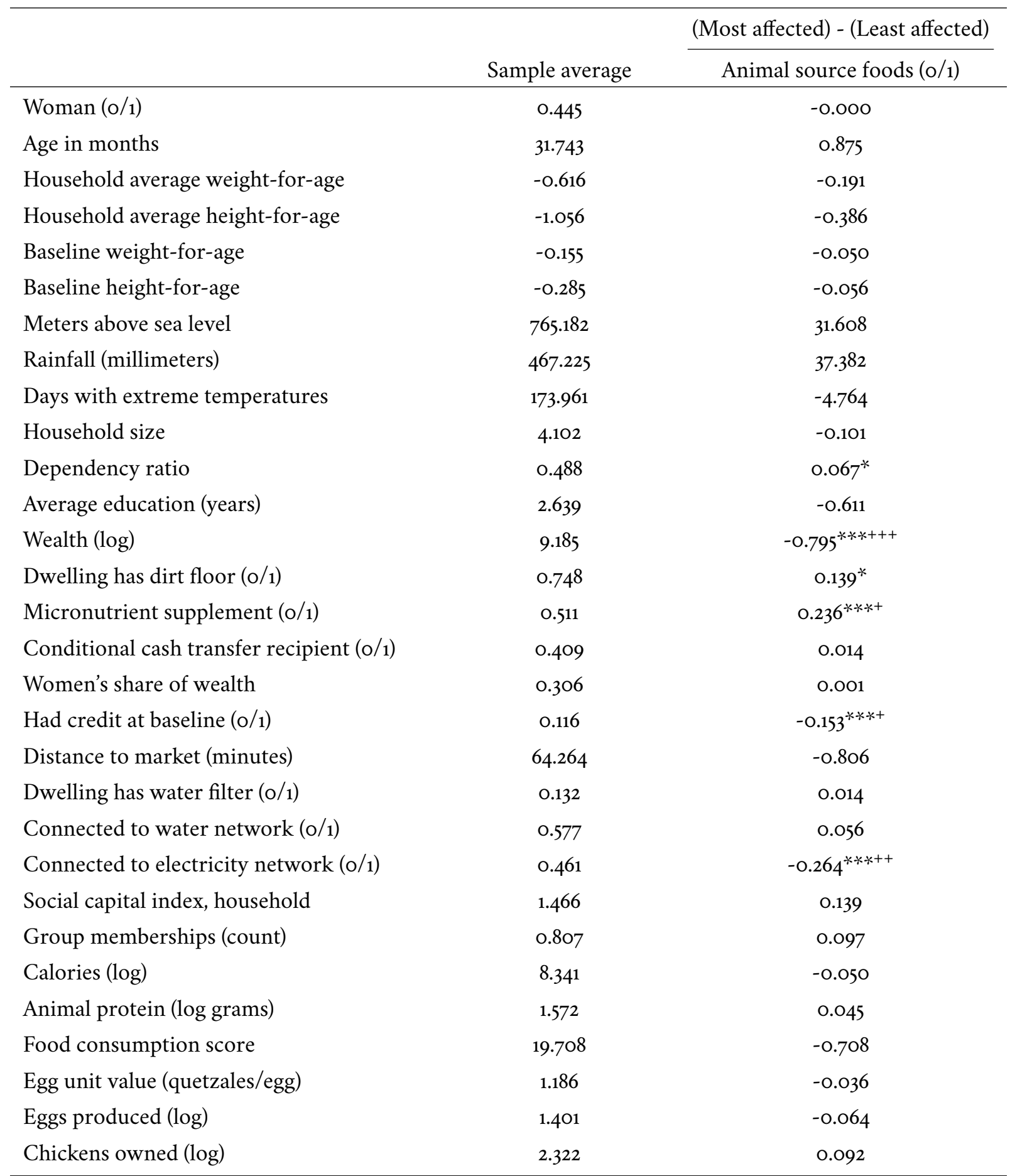

Notes: ${ }^{*} p<0.10,{ }^{* *} p<0.05,{ }^{* * *} p<0.01{ }^{+} q<0.10,{ }^{++} q<0.05,{ }^{+++} q<0.01$, where $q$ is the false discovery rate. Standard errors are of the "HC1" type (MacKinnon and White, 1985). All characteristics are measured at baseline except for gender, age, weather variables, and altitude of the dwelling. See the appendix for a full description of all variables and 90\% confidence intervals around each difference in characteristics. 


\section{Discussion}

\subsection{Are our household-level results consistent with an effective program?}

Our household-level analysis did not uncover clear evidence of program impacts. But there are several mitigating factors that could explain this result. First, the Marek's outbreak likely made impacts on chicken ownership short lived for some households. Second, the power analysis in appendix A.7 shows that minimum detectable effects for most household-level outcomes are somewhat large. Third, the program was rolled out over the course of a year and eight months in the treatment group and follow-up data were collected about two and a half years after the start of implementation. As noted earlier, naked-neck chickens have a productive life of two to three years. We do not know whether offspring of program chickens produced eggs. But if program chickens are not eventually replaced, outcomes like the number of chickens owned and egg production might only be temporarily affected. Most other household-level outcomes also seem likely to be affected temporarily by the program if transferred chickens were not replaced. The potentially transitory nature of household-level program effects stands in contrast to impacts on stunting (and to a lesser degree underweight), which can be permanently improved through proper nutrition in early childhood (Choudhury, Headey, and Masters, 2019), although gains in height from increased animal protein consumption are not guaranteed to persist over time (Iannotti et al., 2020).

\subsection{Explaining larger average impacts on girls than boys}

Our results from section 5.2 show a clear pattern of larger impacts on girls. A first possible explanation for this pattern is survivor effects. That is, the program could have allowed boys with relatively low Z-scores to survive until the follow-up survey. Two children who were young enough at baseline to later be included in our impact analysis did not survive to the follow-up survey, and the program had no impact on the number of boys or girls under 60 months of age at the household level (see appendix A.22). Survivor effects therefore seem unlikely to explain our results. A second explanation is that our 
results reflect gender-specific differences in anthropometric indicators in the absence of treatment, or in the treatment group prior to intervention. We examine the first possibility by comparing Z-scores for boys and girls in the control group at follow-up and the second possibility by comparing boys and girls in the treatment group at baseline. Kolmogorov-Smirnov tests and $t$-tests fail to reject the null of no difference by gender in all cases, regardless of whether we condition on being stunted when testing height-for-age or underweight when testing weight-for-age. A third possible explanation is that girls were more likely to receive chickens within the first 1,ooo days of life. We show in appendix table A.2 that this is not the case.

Alternatively, it could be that boys are more likely than girls to suffer from intestinal illness, undermining gains in height and weight through poor absorption of nutrients (Guerrant et al., 2012). As mentioned earlier, the program itself could increase intestinal illness by worsening exposure to pathogens in animal waste. We explore whether the program affected intestinal illness among children as well as differences in intestinal illness by gender in table 8 . The first and second columns of table 8 show no evidence that the program had deleterious effects on child intestinal health. But in the three rightmost columns we see that the incidence and average duration of intestinal illness are substantially higher among boys, where the latter is calculated using all children, not just those who were sick. ${ }^{8}$

If we could identify the mechanism that is driving higher rates of intestinal illness among boys, then we might be able to propose a complementary intervention that could raise the effectiveness of future livestock transfer programs. One possible explanation is greater exposure to pathogens among infant boys through consumption of drinks mixed with unclean water, e.g., infant formula (AnttilaHughes et al., 2018). In our data, boys between the ages of six and 60 months are more than twice as likely to consume infant formula than girls at follow-up $(p<0.005)$, but consumption is small overall (5.8\% of boys versus $2.6 \%$ of girls). There are no significant differences by gender in the probability of

\footnotetext{
${ }^{8}$ Note that the $q$-values and confidence intervals shown in table 8 do not incorporate the hypothesis tests for our main outcomes of interest shown in table 4. We consider the tests in each table to represent different families of hypotheses. The tests in table 4 each give us a separate chance to determine whether the program had a positive effect on children, whereas the tests in table 8 all relate to potential negative effects of the program.
} 
consuming any other drinks that might deliver pathogens.

Another explanation is that girls are favored by households in the distribution of eggs or meat. Regressing a series of binary indicators for having consumed different animal source foods in the past 24 hours on gender and age in months reveals no pattern of favoritism towards girls or boys. Differences could be with respect to quantity, however. But any existing bias in food distribution in the Guatemalan context seems more likely to favor boys than girls (Frongillo and Begín, 1993). Our results could also be explained by differences in breastfeeding patterns. For example, girls might stop exclusively breastfeeding earlier than boys, and move on to complementary foods. Our data do not have detailed information on breastfeeding, so we turn to the the 2014-2015 National Survey of Maternal and Child Health (NSMCH), which includes a random sample of 566 children between the ages of zero and 60 months from Chiquimula. The NSMCH data show that conditional on age in months, gender is uncorrelated with current breastfeeding or duration of breastfeeding. Overall, differences in breastfeeding and consumption of complementary foods do not seem to provide an explanation for higher rates of intestinal illness among boys. We do not have the data needed to consider other channels of pathogen exposure, such as differences in the play habits of boys and girls.

Finally, several previous studies have evaluated policy changes that increased asset ownership or control over income among women while affecting girls but not boys, positing improved women's bargaining strength as the mechanism driving gender differences in effects on children (Duflo, 2003; Qian, 2008; Matz and Narciso, 2010; de Carvalho Filho, 2012). Given our imprecise impact estimates on chicken ownership, we cannot rule out improved bargaining strength through greater asset ownership as a mechanism. 
Table 8: Intestinal illness, children ages 6 to 60 months

\begin{tabular}{|c|c|c|c|c|c|c|}
\hline & \multicolumn{3}{|c|}{ Intent-to-treat effects } & \multicolumn{3}{|c|}{ Sample averages } \\
\hline & Girls & Boys & Difference & Girls & Boys & Difference \\
\hline Animal feces in or around the dwelling $(\mathrm{o} / 1)$ & $\begin{array}{c}0.111 \\
{[-0.125,0.346]} \\
(-0.150,0.371)\end{array}$ & $\begin{array}{c}0.034 \\
{[-0.100,0.167]} \\
(-0.114,0.181)\end{array}$ & $\begin{array}{c}0.077 \\
{[-0.151,0.305]} \\
(-0.216,0.370)\end{array}$ & 0.438 & 0.412 & $\begin{array}{c}0.018 \\
{[-0.074,0.110]} \\
(-0.074,0.110)\end{array}$ \\
\hline Intestinal illness in past 30 days $(\mathrm{o} / 1)$ & $\begin{array}{c}0.067 \\
{[-0.056,0.189]} \\
(-0.091,0.225)\end{array}$ & $\begin{array}{c}0.082 \\
{[-0.144,0.308]} \\
(-0.209,0.373)\end{array}$ & $\begin{array}{c}-0.015 \\
{[-0.204,0.174]} \\
(-0.204,0.174)\end{array}$ & 0.304 & 0.395 & $\begin{array}{c}-0.098 \\
{[-0.183,-0.013]^{* *}} \\
(-0.190,-0.006)^{++}\end{array}$ \\
\hline Days with intestinal illness in past 30 days & $\begin{array}{c}0.356 \\
{[-0.706,1.418]} \\
(-0.706,1.418)\end{array}$ & $\begin{array}{c}0.202 \\
{[-1.662,2.065]} \\
(-1.662,2.065)\end{array}$ & $\begin{array}{c}0.154 \\
{[-1.454,1.761]} \\
(-1.624,1.931)\end{array}$ & 1.861 & 2.761 & $\begin{array}{c}-0.997 \\
{[-1.753,-0.241]^{* * *}} \\
(-1.922,-0.072)^{++}\end{array}$ \\
\hline Observations & 196 & 244 & 440 & 196 & 244 & 440 \\
\hline
\end{tabular}

Notes: ${ }^{*} p<0.10,{ }^{* *} p<0.05,{ }^{* * *} p<0.01{ }^{+} q<0.10,{ }^{++} q<0.05,{ }^{+++} q<0.01$, where $q$ is the false discovery rate. $95 \%$ confidence intervals in brackets, $95 \%$ false discovery rate-adjusted confidence intervals in parentheses. Standard errors and degrees of freedom estimated as in Young (2016). All regressions include an intercept, indicators for thirteen strata, and child age in months. The standard errors for the rightmost column are adjusted for clustering at the household level. 


\subsection{Heterogeneous impacts on diet among children}

Children in the poorest households enjoy the largest impacts on animal source foods consumption at follow-up, two and a half years after the start of the program. While we might expect higher current consumption of animal source foods to be accompanied by gains in height or weight, we do not have strong evidence for heterogeneous impacts on Z-scores, stunting, or underweight. One possible explanation for the disconnect between impacts on animal source foods and height and weight is that poorer households have had their chickens long enough to enjoy increased access to animal source foods, but not long enough for child height and weight to be affected. This situation could occur if the Mancomunidad opted to treat wealthier clusters first, conditional on treatment assignment. We check this possibility by regressing the chicken set delivery date (specified as the number of days between an arbitrary date and the date of the chicken transfer) on baseline household wealth and find no relationship $(p=0.566)$.

Another explanation is that the poorest children face additional constraints that prevent them from transforming higher animal source foods consumption into anthropometric gains. Oral-fecal contamination, for example, has been blamed for the failure of nutritional interventions and oral vaccines in other contexts (Ngure et al., 2014), motivating the incorporation of water, sanitation, and hygiene components into nutrition interventions (e.g., Tofail et al. (2018)). As shown in table 8, 35\% of children in our data set between the ages of six and 60 months had diarrhea in the 30 days prior to follow-up interviews, suggesting that oral-fecal contamination is common in the program's intervention area.

Access to clean water was scarce in the Mancomunidad during the study period, and was likely a problem for households of all wealth levels. But hygiene appears to be positively correlated with wealth in our data. Enumerators confirmed the presence of a hand-washing station with soap in about $50 \%$ of households at follow-up. ${ }^{9}$ Baseline wealth is $41 \%$ higher among households with a handwashing station than in households without. The correlation between wealth and hygiene is also

\footnotetext{
${ }^{9}$ Note that we did not ask this question at baseline so it was not included in our machine learning analysis.
} 
present in the NSMCH data from Chiquimula, where the probability of having a hand washing station with running water and soap is 32 percentage points lower for households in the lowest wealth quintile (according to the wealth index included in the NSMCH data set) than households in the second lowest quintile. In our data set, children who reported having diarrhea in the 30 days prior to follow-up data collection are from households with 10\% less wealth on average than their counterparts who did not report having diarrhea. Although household wealth could be correlated with a variety of factors that mediate program impacts, it is plausible that hygiene and sanitation considerations are partly responsible for the patterns we see in impacts on anthropometrics and consumption of animal source foods among children.

\section{Conclusion}

We evaluated the chicken transfer and training component of a program seeking to build resilience in rural Guatemala using a cluster-randomized phase-in design. We estimate program average intentto-treat effects by comparing 14 clusters of communities assigned to receive the program in its second year to 14 clusters assigned to receive the program in year four. At follow-up, $46.6 \%$ of households assigned to treatment had participated in the program long enough to plausibly have experienced impacts, whereas the same was true of $13.5 \%$ of households assigned to the control group.

We find no statistically significant average intent-to-treat effects on household-level measures of expenditure, nutrient intake, diet quality, chicken ownership, egg consumption, egg production and sales, and chicken management. We acknowledge that low power hampers our ability to detect household-level effects. Furthermore, the slow pace of program rollout and the typical productive lifespan of a naked-neck chicken may have resulted in household-level impacts dissipating before follow-up data were collected. Despite no evidence for positive average effects on household outcomes, we find significant treatment effect heterogeneity for grams of animal protein consumed and the food consumption score. Poorer and more isolated households appear to have experienced the largest impacts on these outcomes. 
In contrast, we find clear evidence for large average intent-to-treat effects on weight and height among girls who were between the ages of six and 6o months at follow-up. Most notably, stunting fell by 23.5 percentage points ( \pm 19.4 ) among girls, an improvement of $57 \%$ relative to the control group. We find no statistically significant average intent-to-treat effects on height or weight among boys. Differences in height and weight impacts by gender could be a product of higher rates of intestinal illness among boys. The program does not appear to have increased the rate or severity of intestinal illness among children, which could have reduced health improvements. Among children, we find evidence of heterogeneous effects on having consumed animal source foods in the past day, and the poorest households appear to have enjoyed the largest impacts. But we find no corresponding heterogeneity in height or weight impacts by wealth. Descriptive evidence suggests that differences in hygiene by wealth could be to blame, as poor hygiene can lead to increased intestinal illness and reduced absorption of nutrients.

The main policy implication of our results is that livestock transfer programs can have dramatic impacts on child health even when undermined by shocks like disease outbreaks. But program modifications might increase the effectiveness of livestock transfers while sustaining impacts over time. Adding training modules on nutrition, intrahousehold food distribution, animal waste management, and hygiene could improve program impacts on health outcomes. Larger positive impacts on households could feed back into program sustainability by demonstrating to beneficiaries that chickens are valuable assets. Livestock transfer programs might be able to encourage animal reproduction by offering households explicit incentives for getting program chickens to successfully produce offspring, and additional incentives if those offspring go on to produce eggs. The additional egg and meat production generated by new chicks may not be sufficient incentives by themselves if villages are poorly integrated into surrounding markets. These additional incentives could be paired with monitoring of households who may be novice chicken breeders. Disease outbreaks could be mitigated by building incentives for animal health professionals into program design if beneficiaries are unable to pay for vaccination and other services. Future research could test the efficacy of complementary interventions by building them into randomized trials. 


\section{References}

Abadie, A., S. Athey, G. Imbens, and J. Wooldridge. 2017. "When Should You Adjust Standard Errors for Clustering?” Working paper, National Bureau of Economic Research.

Adesogan, A.T., A.H. Havelaar, S.L. McKune, M. Eilittä, and G.E. Dahl. 2020. "Animal source foods: Sustainability problem or malnutrition and sustainability solution? Perspective matters." Global Food Security 25:100325.

Anttila-Hughes, J., L. Fernald, P. Gertler, P. Krause, and B. Wydick. 2018. "Mortality from Nestlé’s Marketing of Infant Formula in Low and Middle-Income Countries." Working paper No. 24452, National Bureau of Economic Research.

Athey, S., J. Tibshirani, and S. Wager. 2019. “Generalized Random Forests.” The Annals of Statistics 47:1148-1178.

Attanasio, O., H. Baker-Henningham, R. Bernal, C. Meghir, D. Pineda, and M. Rubio-Codina. 2018. "Early Stimulation and Nutrition: The Impacts of a Scalable Intervention." Working paper No. 25059, National Bureau of Economic Research.

Attanasio, O., C. Meghir, and E. Nix. 2019. "Human Capital Development and Parental Investment in India." Unpublished.

Balehegn, M., Z. Mekuriaw, L. Miller, S. Mckune, and A.T. Adesogan. 2019. "Animal-sourced foods for improved cognitive development." Animal Frontiers 9:50-57.

Bandiera, O., R. Burgess, N. Das, S. Gulesci, I. Rasul, and M. Sulaiman. 2013. “Can Basic Entrepreneurship Transform the Economic Lives of the Poor?” IZA Discussion Paper No. 7386.

Banerjee, A., E. Duflo, N. Goldberg, D. Karlan, R. Osei, W. Pariente, J. Shapiro, B. Thuysbaert, and C. Udry. 2015. "A Multifaceted Program Causes Lasting Progress for the Very Poor: Evidence from Six Countries." Science 348:1260799-1260799. 
Bellemare, M.F., and C.J. Wichman. 2019. "Elasticities and the Inverse Hyperbolic Sine Transformation." Oxford Bulletin of Economics and Statistics 82:50-61.

Belloni, A., V. Chernozhukov, and C. Hansen. 2014. "High-Dimensional Methods and Inference on Structural and Treatment Effects." Journal of Economic Perspectives 28(2):29-50.

Benjamini, Y., and Y. Hochberg. 1995. "Controlling the False Discovery Rate: A Practical and Powerful Approach to Multiple Testing." Journal of the Royal Statistical Society SeriesB 57:289-300.

Benjamini, Y., and D. Yekutieli. 2005. "False Discovery Rate-Adjusted Multiple Confidence Intervals for Selected Parameters." Journal of the American Statistical Association 100:71-81.

Borazjani, F., K.A. Angali, and S.S. Kulkarni. 2014. "Milk and Protein Intake by Pregnant Women Affects Growth of Foetus." Journal of Health, Population and Nutrition 31.

Breiman, L. 2001. "Random Forests.” Machine Learning 45:5.

Central Intelligence Agency. 2016. “The World Factbook.” Web page.

Chen, C.F., A. Bordas, D. Gourichon, and M. Tixier-Boichard. 2004. "Effect of High Ambient Temperature and Naked Neck Genotype on Performance of Dwarf Brown-Egg Layers Selected for Improved Clutch Length." British Poultry Science 45:346-354.

Chernozhukov, V., D. Chetverikov, M. Demirer, E. Duflo, C. Hansen, W. Newey, and J. Robins. $2018 \mathrm{.}$ “Double/Debiased Machine Learning for Treatment and Structural Parameters." The Econometrics Journal 21:C1-C68.

Chernozhukov, V., M. Demirer, E. Duflo, and I. Fernández-Val. 2018b. "Generic Machine Learning Inference on Heterogeneous Treatment Effects in Randomized Experiments." Working paper, National Bureau of Economic Research.

Choudhury, S., D.D. Headey, and W.A. Masters. 2019. "First Foods: Diet Quality Among Infants Aged 6-23 Months in 42 Countries." Food Policy, sep, pp. 101762. 
CNN. 2016. “Can Bill Gates' donation of 100.000 chickens help Africa’s poorest?”

Darrouzet-Nardi, A.F., L.C. Miller, N. Joshi, S. Mahato, M. Lohani, and B.L. Rogers. 2016. “Child Dietary Quality in Rural Nepal: Effectiveness of a Community-Level Development Intervention.” Food Policy 61:185-197.

de Carvalho Filho, I.E. 2012. "Household Income as a Determinant of Child Labor and School Enrollment in Brazil: Evidence from a Social Security Reform.” Economic Development and Cultural Change 60:399-435.

Duflo, E. 2003. "Grandmothers and Granddaughters: Old-Age Pensions and Intrahousehold Allocation in South Africa." The World Bank Economic Review 17:1-25.

El Nuevo Diario. 2016. “The Dry Corridor of Central America, Facing its Worst Drought in the last 30 Years (El Corredor Seco de Centroamérica, ante la Peor Sequía de los Últimos 30 Años).” El Nuevo Diario, May, pp. .

Emran, M.S., V. Robano, and S.C. Smith. 2014. "Assessing the Frontiers of Ultrapoverty Reduction: Evidence from Challenging the Frontiers of Poverty Reduction/Targeting the Ultra-poor, an Innovative Program in Bangladesh." Economic Development and Cultural Change 62:339-380.

FAO. 2017. "Chronology of the Dry Corridor: The Impetus for Resilience in Central America." Food and Agriculture Organization of the United Nations.

Figlio, D., J. Guryan, K. Karbownik, and J. Roth. 2014. “The Effects of Poor Neonatal Health on Children's Cognitive Development." The American Economic Review 104:3921-3955.

Frongillo, E., and F. Begín. 1993. "Gender Bias in Food Intake Favors Male Preschool Guatemalan Children." Journal of Nutrition, pp. .

Gates, B. 2016. "Why I Would Raise Chickens." GatesNotes: The Blog of Bill Gates.

Ghosh, S. 2016. "Protein Quality in the First Thousand Days of Life." Food and Nutrition Bulletin 37:S14S21. 
Gillespie, B. 2018. "Sprinkles and Spacing." Anthropology in Action 25:24-35.

Glass, N., N.A. Perrin, A. Kohli, J. Campbell, and M.M. Remy. 2017. "Randomised Controlled Trial of a Livestock Productive Asset Transfer Programme to Improve Economic and Health Outcomes and Reduce Intimate Partner Violence in a Postconflict Setting." BMJ Global Health 2:eooo165.

Government of Guatemala. 2013. "Impact of the Extended Summer on the Marginal and Subsistence Population of the Dry Corredor in Guatemala (Impacto de la Canícula Prolongada en La Población de Infra y Subsistencia del Corredor Seco de Guatemala).”

Guatemala National Institute of Statistics. 2015. "Republic of Guatemala: National Survey of Living Standards 2014." Working paper, Guatemala National Institute of Statistics, Guatemala.

Guerrant, R.L., M.D. DeBoer, S.R. Moore, R.J. Scharf, and A.A.M. Lima. 2012. "The Impoverished Gut-a Triple Burden of Diarrhoea, Stunting and Chronic Disease." Nature Reviews Gastroenterology er Hepatology 10:220-229.

Headey, D., and K. Hirvonen. 2016. "Is Exposure to Poultry Harmful to Child Nutrition? An Observational Analysis for Rural Ethiopia." PLOS ONE 11:1-16.

Headey, D., K. Hirvonen, and J. Hoddinott. 2018. “Animal Sourced Foods and Child Stunting.” American Journal of Agricultural Economics 100:1302-1319, IFPRI Discussion Paper 01695.

Headey, D., R. Rawat, S. Kim, P. Menon, M. Ruel, and P. Nguyen. 2017. "Is Exposure to Animal Feces Harmful to Child Nutrition and Health Outcomes? A Multicountry Observational Analysis." The American Journal of Tropical Medicine and Hygiene 96:961-969.

Hoddinott, J., J. Maluccio, J. Behrman, R. Flores, and R. Martorell. 2008. "Effect of a Nutrition Intervention During Early Childhood on Economic Productivity in Guatemalan Adults." The Lancet 371:411-416.

Iannotti, L.L., M. Chapnick, J. Nicholas, C.A. Gallegos-Riofrio, P. Moreno, K. Douglas, D. Habif, Y. Cui, 
C. Stewart, C.K. Lutter, and W.F. Waters. 2020. "Egg intervention effect on linear growth no longer present after two years." Maternal \& Child Nutrition 16.

Iannotti, L.L., C.K. Lutter, D.A. Bunn, and C.P. Stewart. 2014. "Eggs: the uncracked potential for improving maternal and young child nutrition among the world's poor." Nutrition Reviews 72:355-368.

Iannotti, L.L., C.K. Lutter, C.P. Stewart, C.A.G. Riofrío, C. Malo, G. Reinhart, A. Palacios, C. Karp, M. Chapnick, K. Cox, and W.F. Waters. 2017a. "Eggs in Early Complementary Feeding and Child Growth: A Randomized Controlled Trial." Pediatrics 140:e20163459.

Iannotti, L.L., C.K. Lutter, W.F. Waters, C.A.G. Riofrío, C. Malo, G. Reinhart, A. Palacios, C. Karp, M. Chapnick, K. Cox, S. Aguirre, L. Narvaez, F. López, R. Sidhu, P. Kell, X. Jiang, H. Fujiwara, D.S. Ory, R. Young, and C.P. Stewart. 2017b. "Eggs Early in Complementary Feeding Increase Choline Pathway Biomarkers and DHA: a Randomized Controlled Trial in Ecuador.” The American Journal of Clinical Nutrition 106:1482-1489.

Imbens, G., and J. Angrist. 1994. "Identification and Estimation of Local Average Treatment Effects." Econometrica 62:467-475.

Imdad, A., and Z.A. Bhutta. 2011. "Effect of balanced protein energy supplementation during pregnancy on birth outcomes." BMC Public Health 11:S17.

INCAP. 2012. "Food Composition Table for Central America and Panama (Tabla de Composición de Alimentos de Centroamérica).” Working paper, Nutrition Institute of Central America and Panama (INCAP).

INE. 2015. "Republic of Guatemala: National Living Standards Survey of 2014 (República de Guatemala: Encuesta Nacional de Condiciones de Vida 2014)." National Institute of Statistics (Instituto Nacional de Estadística).

Janzen, S., N. Magnan, S. Sharma, and W. Thompson. 2018. "Short-Term Impacts of a Pay-It-Forward Livestock Transfer and Training Program in Nepal." AEA Papers and Proceedings 108:422-25. 
Jin, M., and L.L. Iannotti. 2014. "Livestock Production, Animal Source Food Intake, and Young Child Growth: The Role of Gender for Ensuring Nutrition Impacts." Social Science er Medicine 105:16-21.

Jodlowski, M., A. Winter-Nelson, K. Baylis, and P.D. Goldsmith. 2016. "Milk in the Data: Food Security Impacts from a Livestock Field Experiment in Zambia." World Development 77:99-114.

Kafle, K., A. Winter-Nelson, and P. Goldsmith. 2016. “Does 25 Cents More Per Day Make a Difference? The Impact of Livestock Transfer and Development in Rural Zambia." Food Policy 63:62-72.

Krishna, A., M. Poghosyan, and N. Das. 2012. "How Much Can Asset Transfers Help the Poorest? Evaluating the Results of BRAC's Ultra-Poor Programme (2002-2008)." Journal of Development Studies 48:254-267.

Lakens, D. 2016. “Why You Don't Need to Adjust Your Alpha Level for All Tests You'll Do In Your Lifetime." Web site.

Lee, D. 2009. “Training, Wages, and Sample Selection: Estimating Sharp Bounds on Treatment Effects.” The Review of Economic Studies 76:1071-1102.

Leroy, J.L., M. Ruel, J.P. Habicht, and E.A. Frongillo. 2014. "Linear Growth Deficit Continues to Accumulate beyond the First 1000 Days in Low- and Middle-Income Countries: Global Evidence from 51 National Surveys." The Journal of Nutrition 144:1460-1466.

Lobell, D.B., M. Bänziger, C. Magorokosho, and B. Vivek. 2011. "Nonlinear Heat Effects on African Maize as Evidenced by Historical Yield Trials." Nature Climate Change 1:42-45.

MacKinnon, J., and H. White. 1985. “Some Heteroskedasticity-Consistent Covariance Matrix Estimators with Improved Finite Sample Properties." Journal of Econometrics 29:305-325.

Mackinnon, J.G., and M.D. Webb. 2016. “Wild Bootstrap Inference for Wildly Different Cluster Sizes.” Journal of Applied Econometrics 32:233-254. 
Matz, J.A., and G. Narciso. 2010. “Does Reinforcing Spouses’ Land Rights Improve Children’s Outcomes? Evidence from a Quasi-Natural Experiment in Rural Vietnam.” Institute for International Integration Studies Discussion Paper 348.

Miller, L.C., N. Joshi, M. Lohani, B. Rogers, M. Kershaw, R. Houser, S. Ghosh, J.K. Griffiths, S. Mahato, and P. Webb. 2016. "Duration of Programme Exposure is Associated with Improved Outcomes in Nutrition and Health: The Case for Longer Project Cycles from Intervention Experience in Rural Nepal." Journal of Development Effectiveness 9:101-119.

Miller, L.C., N. Joshi, M. Lohani, B. Rogers, M. Loraditch, R. Houser, P. Singh, and S. Mahato. 2014. "Community Development and Livestock Promotion in Rural Nepal: Effects on Child Growth and Health.”, pp. .

Ministry of Public Health and Social Assistance. 2017. "National Survey of Maternal and Child Health 2014-2015: Final Report." Working paper, Ministry of Public Health and Assistance, National Institute of Statistics, and ICF International.

Misha, F.A., W.A. Raza, J. Ara, and E. van de Poel. 2019. "How Far Does a Big Push Really Push? LongTerm Effects of an Asset Transfer Program on Employment Trajectories." Economic Development and Cultural Change, sep, pp. ooo-ooo.

Moore, V.M., M.J. Davies, K.J. Willson, A. Worsley, and J.S. Robinson. 2004. "Dietary Composition of Pregnant Women Is Related to Size of the Baby at Birth.” The Journal of Nutrition 134:1820-1826.

Multilateral Investment Fund. 2018. "Project Status Report (Reporte de Estado del Proyecto).”

National Institute of Population Research and Training. 2016. "Bangladesh Demographic and Health Survey 2014." Working paper, NIPORT, Mitra and Associates, and ICF International, Dhaka, Bangladesh.

National Institute of Statistics of Rwanda. 2015. “2014-2015 RDHS Key Findings.” Working paper, NISR, Ministry of Health, and ICF International, Rockville, MD. 
Nepal Ministry of Health. 2016. “Nepal: 2016 Demographic and Health Survey Key Findings.” Working paper, Ministry of Health, Nepal, Kathmandu.

Ngure, F., B. Reid, J. Humphrey, M. Mbuya, G. Pelto, and R. Stoltzfus. 2014. "Water, Sanitation, and Hygiene (WASH), Environmental Enteropathy, Nutrition, and Early Child Development: Making the Links." Annals of the New York Academy of Sciences 1308:118-128.

Padilla, V.F. 2017. "Comsultancy for the Description of Regional Mechanisms for the Marketing of Basic Grains and the Efficiency of the Production Systems of CUNORI: Final Report." Working paper, Opportunities and New Businesses.

Qian, N. 2008. "Missing Women and the Price of Tea in China: The Effect of Sex-Specific Earnings on Sex Imbalance." Quarterly Journal of Economics 123:1251-1285.

Rawlins, R., S. Pimkina, C.B. Barrett, S. Pedersen, and B. Wydick. 2014. "Got Milk? The Impact of Heifer International's Livestock Donation Programs in Rwanda on Nutritional Outcomes." Food Policy 44:202-213.

Raza, W.A., E.V. de Poel, and T.V. Ourti. 2018. "Impact and Spill-Over Effects of an Asset Transfer Program on Child Undernutrition: Evidence from a Randomized Control Trial in Bangladesh.” Journal of Health Economics 62:105-120.

Roodman, D., M.Ø. Nielsen, J.G. MacKinnon, and M.D. Webb. 2019. "Fast and Wild: Bootstrap Inference in Stata Using Boottest.” The Stata Journal: Promoting communications on statistics and Stata 19:4-6o.

Roy, S., J. Ara, N. Das, and A.R. Quisumbing. 2015. “"Flypaper Effects” in Transfers Targeted to Women: Evidence from BRAC's “Targeting the Ultra Poor” Program in Bangladesh.” Journal of Development Economics 117:1-19.

Shrimpton, R., C.G. Victora, M. de Onis, R.C. Lima, M. Blossner, and G. Clugston. 2001. "Worldwide Timing of Growth Faltering: Implications for Nutritional Interventions." Pediatrics 107:e75-e75. 
Sonaiya, E., and S. Swan. 2004. Small-Scale Poultry Poultry Production: Technical Guide. Food and Agriculture Organization of the United Nations.

Tofail, F., L. Fernald, K. Das, M. Rahman, T. Ahmed, K. Jannat, L. Unicomb, B. Arnold, S. Ashraf, P. Winch, P. Kariger, C. Stewart, J. Colford, and S. Luby. 2018. "Effect of Water Quality, Sanitation, Hand Washing, and Nutritional Interventions on Child Development in Rural Bangladesh (WASH Benefits Bangladesh): a Cluster-Randomised Controlled Trial.” The Lancet Child er Adolescent Health 2:255-268.

Victora, C.G., M. de Onis, P.C. Hallal, M. Blossner, and R. Shrimpton. 2010. "Worldwide Timing of Growth Faltering: Revisiting Implications for Interventions.” Pediatrics 125:e473-e480.

Wong, J., J. de Bruyn, B. Bagnol, H. Grieve, M. Li, R. Pym, and R. Alders. 2017. "Small-Scale Poultry and Food Security in Resource-Poor Settings: A Review." Global Food Security 15:43-52.

World Bank. 2019a. “GDP per capita, PPP." Accessed October 1, 2019.

—. 2019b. "GINI index (World Bank estimate)." Accessed October 1, 2019.

—. 2019c. "Rural population (\% of total population)." Accessed October 1, 2019.

World Food Program. 20o8. "Food Consumption Analysis: Calculation and Use of the Food Consumption Socre in Food Security Analysis." Working paper, World Food Program.

-. 2018. "Guatemala."

World Health Organization. 2011. "WHO Anthro version 3.2.2."

Young, A. 2016. "Improved, Nearly Exact, Statistical Inference with Robust and Clustered Covariance Matrices using Effective Degrees of Freedom Corrections." Unpublished.

Zou, H., and T. Hastie. 2005. "Regularization and Variable Selection Via the Elastic Net." Journal of the Royal Statistical Society: Series B (Statistical Methodology) 67:301-320. 


\section{A Appendix}

\section{A.1 Implementation challenges}

For the program cohort studied in this article, the farmer field schools used to train future chicken recipients as well as the program poultry breeding and health were initially managed by a local agricultural university. The university in question had never before managed anything approaching the scale of the chicken breeding and health program required for the program, and it struggled to provide an adequate supply of birds in the program's initial stages. In response, the program expanded its breeding stock by purchasing birds from non-program areas, sometimes from households, with inadequate quarantine procedures. All birds were kept at the same facility, creating a situation where chickens raised without regular veterinary care mixed with the overall population of program chickens. The result was a major outbreak of Marek's disease, a virus that is both contagious and deadly to chickens. In personal communications, program technicians indicated that affected chickens died within two or three weeks of delivery to beneficiary households while the outbreak of Marek's disease was ongoing. Sick chickens received from the program could have affected healthy chickens already owned by the household. In our sample, 17 total households received more than one chicken set, and four of these were households that received chickens before and after the Marek's vaccine was introduced.

A vaccine against Marek's was added to the prophylactic plan used by program technicians in August 2015, stabilizing the population of chickens distributed by the program. But the vaccine program had challenges of its own. Extension agents trained women from the communities to provide vaccination services, but their spouses sometimes would not let newly-trained animal health providers go from house to house vaccinating chickens in the community. These problems were eventually addressed by seeking additional outside expert advice from animal health professionals and revising management of the program. But the spread of the disease could have been limited had an animal health care team been in place from the beginning of the program. 
Figure A.1 and table A.1 capture the respective situations of beneficiaries receiving chickens before and after the Marek's vaccine was added to the program. The horizontal axis of figure A.1 shows the time horizon over which treatment group households included in the sample used for this paper received their chickens. The gray bar graph (measured by the vertical axis on the left side of figure A.1) shows the cumulative number of chicken set delivered to treatment households in our sample. The scatter plot (measured by the vertical axis on the right of figure A.1) graphs the average number of chickens owned at follow-up by chicken set recipients against the date that chickens were distributed. There are more points in the graph than there are clusters in the data because a single cluster could have multiple delivery dates. There is a jump in the average number of chickens owned once the Marek vaccine is put in place, and the average number of chickens owned is about $48 \%$ higher for households receiving the vaccine (9.633 versus 6.522 chickens owned on average). We note that the difference is not statistically significant.

Figure A.1: Timing of chicken transfers and number of chickens owned, treatment group

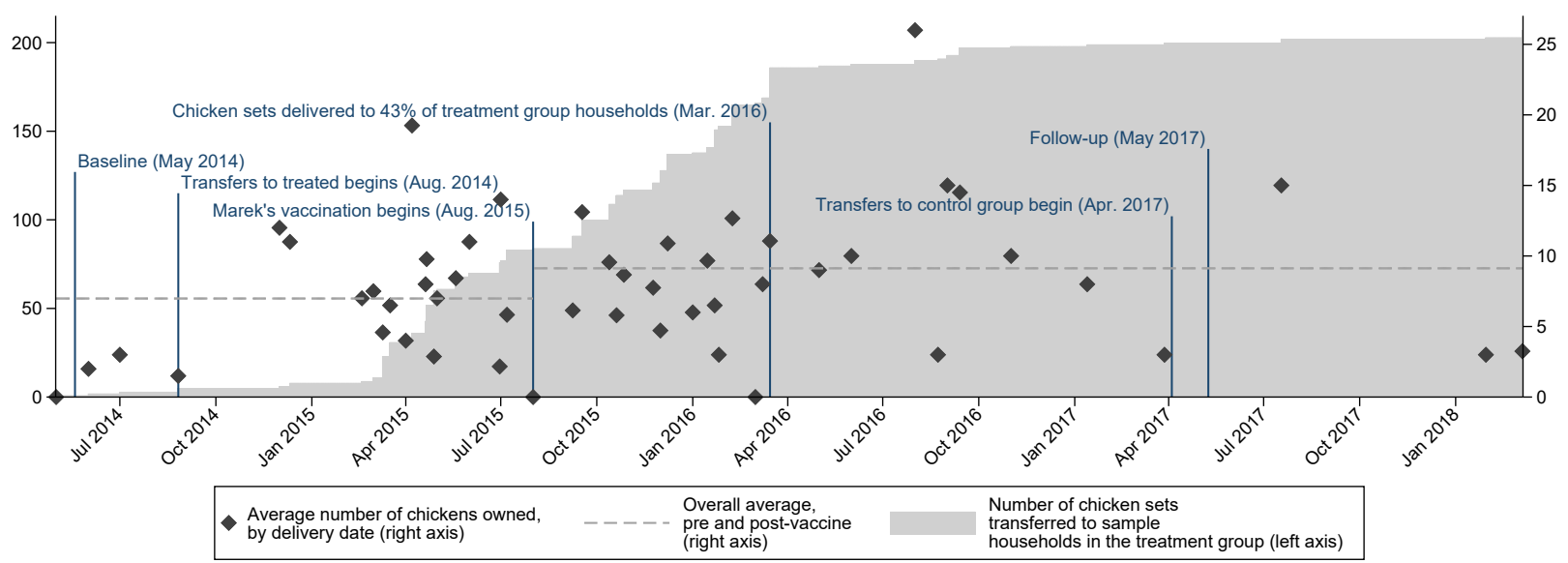

Additional differences are given in table A.1. Households receiving multiple chicken sets are included in the post-vaccine group if at least one chicken set was received after August 2015. Households receiving the vaccine own $86 \%$ more naked-neck chickens on average than other program participants. Indicators for whether chickens received from the program produced eggs or chicks, eggs produced, and chicken ownership (naked-neck or otherwise) all suggest that the Marek's outbreak 
strongly affected program performance. But since the order of chicken transfers was the product of administrative concerns and variation in ease of implementation across clusters, none of the differences in means shown in table A.1 are necessarily causal. Most differences in means have the expected sign if we expect households receiving chickens before the vaccine to be worse off. Exceptions include egg production and having sold chickens or eggs, although the latter could reflect distress sales of chickens among non-vaccine households. Overall, we interpret table A.1 as suggesting that disease management can have a strong effect on the performance of livestock transfer programs, a fact not emphasized in prior evaluations. At the same time, the lack of any association between timing of chicken delivery and detectable difference in consumption, production, or marketing at follow-up may indicate that improved implementation does not guarantee sustained program impacts.

The Mancomunidad confronted implementation challenges in addition to the Marek's outbreak. As already mentioned, participation in program components other than poultry training and transfers was initially quite low. Program technicians also struggled to identify the gender of chicks. Commercial layer operations use specialized equipment to identify the gender of young birds. But a lack of uniformity in appearance makes this same equipment ineffective for naked-neck chickens. According to Mancomunidad technicians, the chicken sets delivered to early program participants sometimes had less than the desired 5:1 ratio of females to males.

As a result of the Marek's outbreak and other challenges, the program's cost of producing a nineweek old male chick was over twice the market price in Chiquimula through early 2017 (Padilla, 2017). The Mancomunidad responded to the above challenges by revising its implementation model for subsequent program cohorts. First, the Mancomunidad centralized management of the various program components rather than using a scheme where separate teams administered different program features. Second, the Mancomunidad took control over the chicken breeding and health program, hired its own technicians and started its own breeding facility with assistance from outside organizations. In the wake of these changes, the cost of production per bird fell to around one quarter of the market price by late 2017 . 
Table A.1: Differences in means among beneficiaries, before and after introduction of Marek's vaccine

\begin{tabular}{|c|c|c|c|}
\hline & Marek's vaccine & No Marek's vaccine & Difference \\
\hline Program chickens produced eggs $(\mathrm{o} / \mathrm{1})$ & $\begin{array}{c}0.819 \\
\{0.387\}\end{array}$ & $\begin{array}{l}0.323 \\
\{0.471\}\end{array}$ & $\begin{array}{c}0.496 \\
{[0.297,0.695]^{\text {*** }}} \\
(0.172,0.820)^{+++}\end{array}$ \\
\hline Program chickens produced chicks $(\mathrm{o} / \mathrm{1})$ & $\begin{array}{l}0.506 \\
\{0.503\}\end{array}$ & $\begin{array}{l}0.108 \\
\{0.312\}\end{array}$ & $\begin{array}{c}0.398 \\
{[0.222,0.575]^{* * *}} \\
(0.144,0.652)^{+++}\end{array}$ \\
\hline Daily servings of eggs & $\begin{array}{l}0.295 \\
\{0.501\}\end{array}$ & $\begin{array}{l}0.246 \\
\{0.332\}\end{array}$ & $\begin{array}{c}0.049 \\
{[-0.072,0.169]} \\
(-0.083,0.180)\end{array}$ \\
\hline Sold eggs or chickens in last six months $(\mathrm{o} / \mathrm{1})$ & $\begin{array}{l}0.209 \\
\{0.409\}\end{array}$ & $\begin{array}{l}0.408 \\
\{0.495\}\end{array}$ & $\begin{array}{c}-0.199 \\
{[-0.376,-0.022]^{* *}} \\
(-0.419,0.021)^{+}\end{array}$ \\
\hline Eggs produced in last six months & $\begin{array}{c}127.855 \\
\{243.600\}\end{array}$ & $\begin{array}{l}148.073 \\
\{302.967\}\end{array}$ & $\begin{array}{c}-20.219 \\
{[-112.106,71.669]} \\
(-114.679,74.242)\end{array}$ \\
\hline Chickens eaten in last six months & $\begin{array}{c}1.800 \\
\{2.080\}\end{array}$ & $\begin{array}{c}1.513 \\
\{1.880\}\end{array}$ & $\begin{array}{c}0.287 \\
{[-0.582,1.155]} \\
(-0.633,1.207)\end{array}$ \\
\hline Chickens owned & $\begin{array}{c}9.127 \\
\{7.894\}\end{array}$ & $\begin{array}{l}6.987 \\
\{6.309\}\end{array}$ & $\begin{array}{c}2.140 \\
{[-0.958,5.239]} \\
(-1.377,5.658)\end{array}$ \\
\hline Naked-neck chickens owned & $\begin{array}{c}3.182 \\
\{3.494\}\end{array}$ & $\begin{array}{c}1.711 \\
\{2.308\}\end{array}$ & $\begin{array}{c}1.471 \\
{[0.442,2.501]^{* * *}} \\
(0.114,2.828)^{++}\end{array}$ \\
\hline Owns chickens $(\mathrm{o} / 1)$ & $\begin{array}{l}0.918 \\
\{0.275\}\end{array}$ & $\begin{array}{l}0.803 \\
\{0.401\}\end{array}$ & $\begin{array}{c}0.116 \\
{[-0.001,0.232]^{*}} \\
(-0.022,0.253)\end{array}$ \\
\hline Eggs consumed per day per adult male equivalent & $\begin{array}{c}1.171 \\
\{2.335\}\end{array}$ & $\begin{array}{l}1.202 \\
\{2.136\}\end{array}$ & $\begin{array}{c}-0.031 \\
{[-0.878,0.816]} \\
(-0.878,0.816)\end{array}$ \\
\hline Observations & 110 & 76 & 186 \\
\hline
\end{tabular}

Notes: ${ }^{*} p<0.10,{ }^{* *} p<0.05,{ }^{* * *} p<0.01 ;{ }^{+} q<0.10,{ }^{++} q<0.05,{ }^{+++} q<0.01$, where $q$ is the false discovery rate. Standard deviations in curly braces, $95 \%$ confidence intervals in brackets, $95 \%$ false discovery rate-adjusted confidence intervals in parentheses. See the appendix for an explanation of the false discovery rate. Standard errors and degrees of freedom for the last column were estimated as in Young (2016). Four households received chicken set before and after the Marek's vaccine was introduced. We consider them to be post-vaccine households in this table. 


\section{A.2 Timing of program implementation and follow-up data collection}

When deciding at what moment to collect follow-up data, the research team had to take several factors into consideration. First, the amount of time needed for program impacts to occur will vary across outcomes. Second, some program impacts can be sustained over time while others might dissipate. Third, the timing of program implementation was somewhat unpredictable. The implementation challenges discussed in section A.1 drastically slowed down rollout in treatment clusters. But once these issues were addressed, the Mancomunidad accelerated the pace of implementation to stay on schedule with deadlines set by donors, including starting the program in a randomly selected subset of communities from cohort three (i.e., the randomized cohort not included in the evaluation) while farmer field schools were still being set up in cohort two (the treatment group). ${ }^{10}$ The expected start date of the program in cohort four became hard to predict as a result of these changes.

Recall that our household-level outcomes include measures of chicken ownership and management, egg production, expenditure, diet, and nutrient intake, and that we also estimate individuallevel impacts on indicators or height, weight, and diet for children. Chickens received through the program would need approximately 80 days to begin producing eggs after delivery to a household, followed by a productive life of two to three years that would hopefully include giving birth to chicks that go on to lay their own eggs. For the evaluation to find impacts on egg production, expenditure (e.g., through the value of home egg and meat production), diet, and nutrient intake, households would therefore need to have received their chickens sets 8 o days or more prior to follow-up. For impacts on child health, appropriate timing of follow-up data collection is less clear, but we can turn to the literature for guidance. A six-month randomized trial in Ecuador where infants aged 6-9 months received one egg per day reduced stunting by $47 \%$ and underweight by $74 \%$ (Iannotti et al., 2017a,b). When factoring in the 80 days needed for the start of egg production, the results of Iannotti et al. (2017a,b) suggest that around 260 days (80 days plus six months) from chicken set delivery to follow-up data

\footnotetext{
${ }^{10}$ Seven communities from cohort three were brought into the program while the intervention was still underway in cohort two. The seven communities were randomly selected by the research team at the request of the Mancomunidad Copan Ch'orti', who made the change to stay on track to meet donor targets. These additional communities are not included in the impact evaluation, as the change in the timing of intervention was made after baseline data were collected.
} 
collection would be adequate for detection of impacts on child health. We discuss the duration of overlap between the productive life of program chickens and critical moments for child nutrition in appendix A.3 below.

Collecting follow-up data before any control group households had received their chickens would have been preferred. But we expect minimal bias arising from control group households with short-term exposure to the program. The possible exceptions to this assumption are impacts on chicken ownership or using a registry to keep production records. The former would show effects immediately after receipt of the chicken set, while the latter might be affected even earlier once control group households began to attend their farmer field schools. We also cannot rule out anticipatory effects (as is the case in any randomized phase-in), but communities were not told far in advance about when to expect the program's arrival. Since the exact timing of program rollout was often in flux, it is not clear that the Mancomunidad could have told communities when to expect the program, even if they had wanted to do so.

\section{A.3 The timing of chicken transfers and the first 1,000 days of life}

Child nutrition during the first 1,000 days of life (from the estimated date of conception to the second birthday) can have strong effects on later health outcomes, including height (Victora et al., 2010; Shrimpton et al., 2001). Animal source foods can improve diet quality when children begin to incorporate solids into their diets at around six months of age (Headey, Hirvonen, and Hoddinott, 2018; Adesogan et al., 2020; Balehegn et al., 2019). At younger ages, children may benefit from improved maternal nutrition during pregnancy and breastfeeding. In a survey of the literature, Imdad and Bhutta (2011) find that balanced protein supplementation during pregnancy reduces the risk of smallfor-gestational-age babies and low birth weight. Five of the eleven studies included in Imdad and Bhutta's 2011 meta-analysis use dairy products as diet supplements. Ghosh (2016) surveys the experimental and observational literature on maternal diet and child health outcomes, and the available evidence shows that animal protein consumption and infant health outcomes are associated. Among 
the studies cited by Ghosh (2016), Moore et al. (2004) find that the proportion of calories coming from protein during pregnancy is associated with birth weight and placental weight among women in South Australia after adjusting for several potential confounders, with protein from dairy showing the strongest association relative to protein from cereals and meat. Borazjani, Angali, and Kulkarni (2014) (also cited by Ghosh (2016)) finds that fetal measurements are positively associated with daily milk consumption in Maharashtra state, India.

The nutrient profile of dairy products differs from that of eggs. But the literature showing positive effects of maternal dairy consumption on child health outcomes tends to cite increased protein consumption as the mechanism. Low-protein diets suppress the production of insulin-like growth factor-1, increasing the likelihood of stunting (Ghosh, 2016). Relative to dairy, eggs are a superior source of protein and micronutrients in many respects, as discussed in Iannotti et al. (2014). Therefore it at least seems plausible that eggs consumption could have effects similar to that of dairy consumption on child health. A caveat to the above evidence is that it is not drawn from studies on in-home production of animal source foods. But regardless of study design, the available evidence suggests a plausible link between maternal consumption of animal protein and child health outcomes.

If we make assumptions about the productive life of naked-neck chickens (i.e., how long they can lay eggs), we can estimate the number of days that overlap between the productive life of program chickens and the first 1,00o days of life for each child in our data set. The Mancomunidad Copan Ch'orti' estimates that the productive life of a naked-neck chicken will last two to three years. We use an estimate of two years while assuming zero egg production for households who stated that their program chickens never laid eggs. We also assume that the first 1,00o days of life begin 280 days before birth and end 720 days afterwards. When estimating overlap between the first 1,ooo days of life and access to program chickens, we add 80 days to the chicken delivery date to account for the delay before the start of egg production.

There are 212 children in the treatment group between the ages of six and 60 months at followup. 115 treatment group children are from households that received their chickens before the follow- 
up survey. 54 of these same children were still in their first 1,000 of life while their program chickens were of productive age, and their households reported that their program chickens laid eggs. In other words, $47 \%$ of treatment group children in chicken recipient households had productive program chickens in their first 1,000 days of life, as well as $25 \%$ of children in treatment group households overall. The median age 80 days after delivery for children with chickens during their first 1,0oo days is 447 , with a median overlap of 449 days between the first 1,00o days of life and the productive life of their naked-neck chickens.

There are 61 treatment group children aged six to 60 months at follow-up who did not have productive program chickens during their first 1,00o days of life, despite their households receiving chicken sets before follow-up. Among these households, only ten reported that their program chickens laid eggs. Most children in this group are older and more likely to be in households receiving chickens early in the program, before the Marek's vaccine was being administered.

In contrast to the treatment group, only 14 children in the control group had received program chickens within their first 1,00o days of life at follow-up and were in households reporting that the chickens received laid eggs. The distribution of age at the date of chicken delivery for the treatment group is shown in figure A.2.

In table A.2 we report estimated intent-to-treat effects for the effect of assignment to treatment on overlap between the first 1,00o days of life and the productive life of program chickens. We also present local average treatment effects estimated by two-stage least squares where we define being treated as having program chickens for at least six months at follow-up, just as we do in appendix A.19 when estimating local average treatment effects on all outcomes. Under th assumptions described in Imbens and Angrist (1994), the local average treatment effect is the average impact of having program chickens for at least six months before follow-up for the subpopulation of compliers, i.e., households that would have program chickens for at least six months if assigned to cohort 1 but not otherwise. We instrument receipt of treatment using the indicator for random assignment to the treatment group. The results in table A.2 suggest that assignment to treatment strongly affected exposure to program 
Figure A.2: Age in days when program chickens were received, treatment group children ages six to 60 months

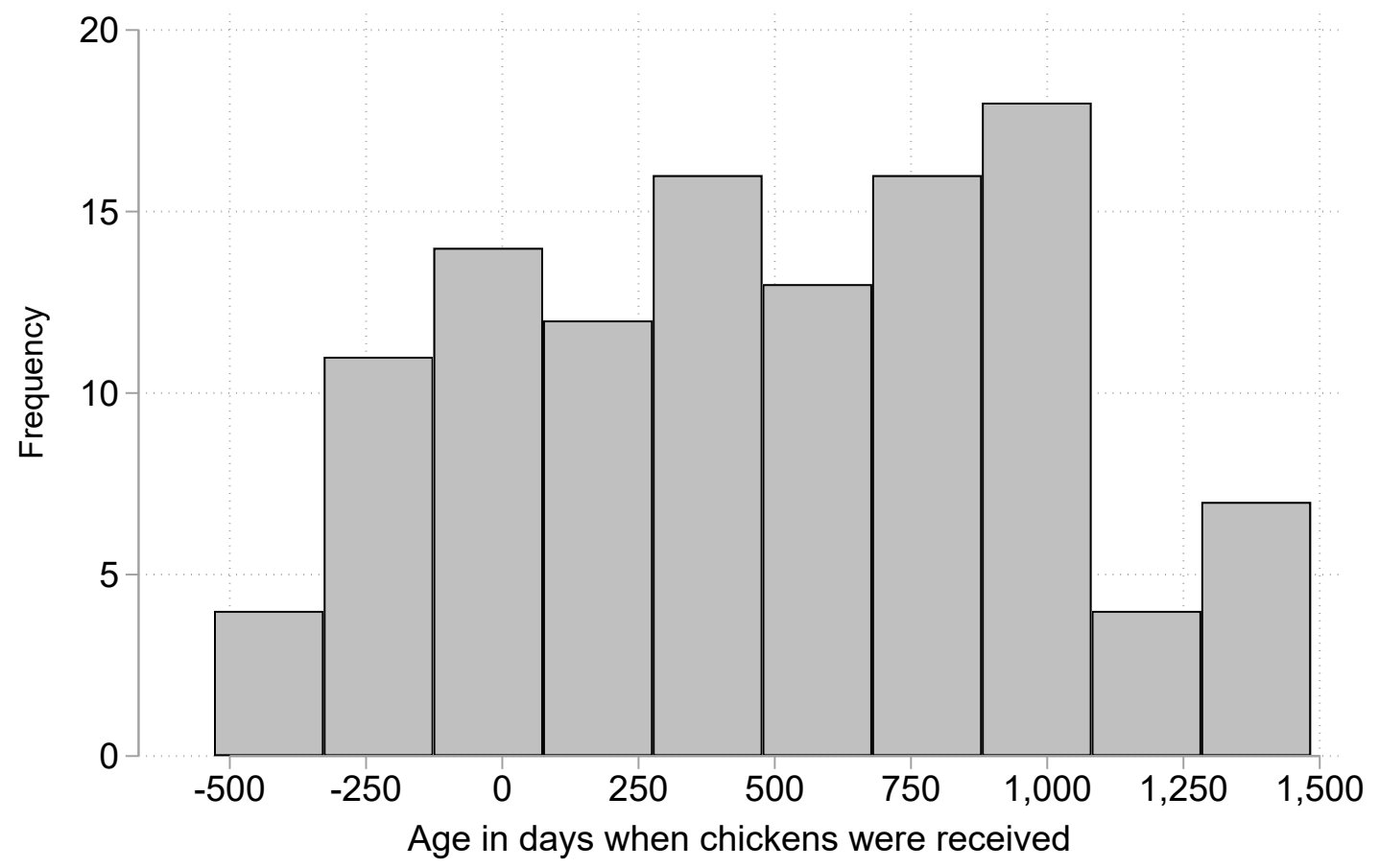

Notes: 115 children in the treatment group are in households that had received chickens at follow-up. The first 1,00o days of life are assumed to occur between ages - 
Table A.2: Impact of assignment to treatment on overlap between the first 1,00o days of life and the productive life of program chickens

\begin{tabular}{lcc}
\hline & \multicolumn{3}{c}{ Intent-to-treat effects } & Boys \\
\cline { 2 - 3 } Number of days & Girls & 109.7 \\
Observations & 72.7 & {$[40.4,178.9]^{* * *}$} \\
& {$[9.3,136.1]^{* *}$} & 244 \\
\hline & 196 & Boys \\
\cline { 2 - 3 } Number of days & \multicolumn{2}{c}{ Local average treatment effects } \\
Girls & 187.7 & 210.1 \\
Observations & {$[87.7,314.6]^{* * *}$} & {$[118.6,301.9]^{* * *}$} \\
\hline
\end{tabular}

Notes: ${ }^{*} p<0.10,{ }^{* *} p<0.05,{ }^{* * *} p<0.01 .95 \%$ confidence intervals in brackets. See the text for how we estimate the productive lifespan of program chickens. Confidence intervals and degrees of freedom estimated as in Young (2016) for the intent-to-treat effects. Confidence intervals for local average treatment effects were obtained through the wild cluster bootstrap (Mackinnon and Webb, 2016). All regressions include an intercept, indicators for thirteen strata, and child age in days at follow-up.

chickens in the first 1,000 days of life for children in our sample.

Given that the median age when chickens were delivered to treatment group households is 447 days, a significant portion of the productive life of program chickens could have occurred beyond the first 1,00o days of life for many treatment group children. Increased animal source food production likely has weaker effects on child health after the second birthday, as most growth faltering occurs during the first 1,000 day window (Victora et al., 2010; Shrimpton et al., 2001). But additional evidence supports the idea that further growth faltering can occur beyond the first 1,ooo days of life, although this does not imply that animal source food consumption can increase height beyond the first 1,000 days. Using DHS data from 51 countries, Leroy et al. (2014) find that around $30 \%$ of the height deficit relative to a healthy population occurs between the second and fifth birthdays. It is important to note that Leroy et al. (2014) rely on height-for-age differences in centimeters relative to health population rather than Z-scores, while showing that Z-scores can mask growth faltering after the second birthday. More recent analysis of DHS data by Headey et al. (2017) using Z-scores to calculate stunting prevalence suggests that children in Latin America and the Caribbean may be an exception to 
this rule, with growth faltering are especially likely experience continued growth faltering beyond 24 months of age. ${ }^{11}$

Regardless, we expect that the strongest effects on height will be felt by children receiving chickens during the first 1,00o days of life. In our sample, no one older than 54 months of age received chickens during their first 1,00o days of life. If we were to find that our results are not robust to excluding children older than 54 months, we might be concerned that a mechanism other than program chickens is driving impacts, or that our results are spurious. In table A.3, we show results obtained by re-estimating our main regression model after dropping children older than 54 months of age. Precision drops slightly because of the decrease in sample size, but none of our conclusions are affected.

\footnotetext{
${ }^{11}$ See figure $S_{1}$ in the supplementary appendix to Headey et al. (2017), which shows that predicted stunting prevalence continues to increase in Latin America beyond 24 months age.
} 
Table A.3: Intent-to-treat effects for children ages 6 to 54 months

\begin{tabular}{|c|c|c|c|c|c|}
\hline & \multicolumn{2}{|l|}{ Girls } & \multicolumn{2}{|l|}{ Boys } & \multirow[b]{2}{*}{ Difference } \\
\hline & Intent-to-treat effect & Control mean & Intent-to-treat effect & Control mean & \\
\hline Weight-for-age (Z-score) & $\begin{array}{c}0.344 \\
{[0.105,0.582]^{* * *}} \\
(0.062,0.625)^{++}\end{array}$ & -1.307 & $\begin{array}{c}-0.028 \\
{[-0.480,0.424]} \\
(-0.480,0.424)\end{array}$ & -1.136 & $\begin{array}{c}0.372 \\
{[-0.046,0.790]^{*}} \\
(-0.238,0.982)\end{array}$ \\
\hline Not underweight $(\mathrm{o} / \mathbf{1})$ & $\begin{array}{c}0.097 \\
{[-0.029,0.222]} \\
(-0.035,0.228)\end{array}$ & 0.773 & $\begin{array}{c}0.014 \\
{[-0.108,0.136]} \\
(-0.121,0.149)\end{array}$ & 0.805 & $\begin{array}{c}0.083 \\
{[-0.096,0.262]} \\
(-0.115,0.280)\end{array}$ \\
\hline Not severely underweight $(\mathrm{o} / \mathrm{1})$ & $\begin{array}{c}0.019 \\
{[-0.045,0.084]} \\
(-0.045,0.084)\end{array}$ & 0.955 & $\begin{array}{c}0.036 \\
{[-0.017,0.089]} \\
(-0.042,0.115)\end{array}$ & 0.958 & $\begin{array}{c}-0.017 \\
{[-0.106,0.073]} \\
(-0.106,0.073)\end{array}$ \\
\hline Height-for-age (Z-score) & $\begin{array}{c}0.502 \\
{[0.170,0.834]^{* * *}} \\
(0.072,0.931)^{++}\end{array}$ & -2.197 & $\begin{array}{c}0.067 \\
{[-0.653,0.787]} \\
(-0.687,0.821)\end{array}$ & -1.978 & $\begin{array}{c}0.435 \\
{[-0.254,1.124]} \\
(-0.379,1.249)\end{array}$ \\
\hline Not stunted $(\mathrm{o} / \mathrm{1})$ & $\begin{array}{c}0.214 \\
{[0.088,0.340]^{* * *}} \\
(0.028,0.400)^{++}\end{array}$ & 0.409 & $\begin{array}{c}0.033 \\
{[-0.131,0.197]} \\
(-0.179,0.244)\end{array}$ & 0.432 & $\begin{array}{c}0.181 \\
{[-0.035,0.398]^{*}} \\
(-0.097,0.459)\end{array}$ \\
\hline Not severely stunted $(\mathrm{o} / \mathrm{1})$ & $\begin{array}{c}0.106 \\
{[-0.016,0.228]^{*}} \\
(-0.030,0.241)\end{array}$ & 0.807 & $\begin{array}{c}0.019 \\
{[-0.109,0.148]} \\
(-0.133,0.172)\end{array}$ & 0.788 & $\begin{array}{c}0.086 \\
{[-0.115,0.288]} \\
(-0.125,0.298)\end{array}$ \\
\hline Consumed animal-source foods in past day $(\mathrm{o} / 1)$ & $\begin{array}{c}-0.001 \\
{[-0.351,0.349]} \\
(-0.351,0.349)\end{array}$ & 0.557 & $\begin{array}{c}0.054 \\
{[-0.211,0.319]} \\
(-0.259,0.368)\end{array}$ & 0.548 & $\begin{array}{c}-0.055 \\
{[-0.275,0.165]} \\
(-0.315,0.205)\end{array}$ \\
\hline One-day dietary diversity score & $\begin{array}{c}0.045 \\
{[-1.056,1.147]} \\
(-1.258,1.349)\end{array}$ & 5.545 & $\begin{array}{c}-0.025 \\
{[-1.323,1.273]} \\
(-1.323,1.273)\end{array}$ & 5.426 & $\begin{array}{c}0.070 \\
{[-0.627,0.767]} \\
(-0.627,0.767)\end{array}$ \\
\hline Observations & 174 & & 216 & & 390 \\
\hline
\end{tabular}

Notes: ${ }^{*} p<0.10,{ }^{* *} p<0.05,{ }^{* * *} p<0.01{ }^{+} q<0.10,{ }^{++} q<0.05,{ }^{+++} q<0.01$, where $q$ is the false discovery rate. $95 \%$ confidence intervals in brackets, $95 \%$ false discovery rate-adjusted confidence intervals in parentheses. Standard errors and degrees of freedom estimated as in Young (2016). Z-scores and indicators for stunting and underweight based on standards from World Health Organization (2011). 
We offer one last piece of evidence for chicken transfers as the mechanism driving program impacts. Recall that each stratum in our data set includes one cluster from the treatment group and one from control, and that each cluster consists of no more than two neighboring communities. Stratumlevel variation in chicken delivery timing is observed for all households and may capture spillover effects within the treatment group from chicken deliveries to neighboring communities, unlike the household-level chicken delivery date. Stratum-level variation in chicken deliveries is also unaffected by treatment status, whereas the chicken delivery date is, making the latter inappropriate for a model of heterogeneous treatment effects. Estimates of the variation in treatment effects explained by differences in delivery timing across strata should also not be affected by spillovers bias, because clusters were not matched into strata on the basis of geographic proximity. We re-estimate our main equation for the subsample of children in strata where the first delivery of chickens occurred during the first 1,000 days of life, adding 80 days to the chicken delivery date to adjust for the lag before egg production (6o\% of girls and $59 \%$ boys fall within this subsample). The median treatment group child in this subsample was slightly over 8 months old when her strata received its first chicken transfer. We repeat this estimation step for remaining children and test the null hypothesis of equal intent-to-treat effects in the two subsamples.

The resulting intent-to-treat effects and the 90\% confidence intervals for their differences are shown in figure A.3. Differences in intent-to-treatment effects for weight-for-age, underweight, and stunting among girls are positive and significant at the $10 \%$ level. Among boys, all differences in intentto-treat effects are imprecisely estimated. While none of the estimated differences in intent-to-treat effects remain significant after adjusting for multiple comparisons, we interpret figure figure A.3 as supporting the hypothesis that chicken transfers drove program effects on girls.

\section{A.4 Explanation of machine learning methods}

As discussed in the main text, we estimate heterogeneous intent-to-treat effects using a method created by Chernozhukov et al. (2018b). We implement the method of using the following steps: 
Figure A.3: Comparing intent-to-treat effects by timing of chicken transfers

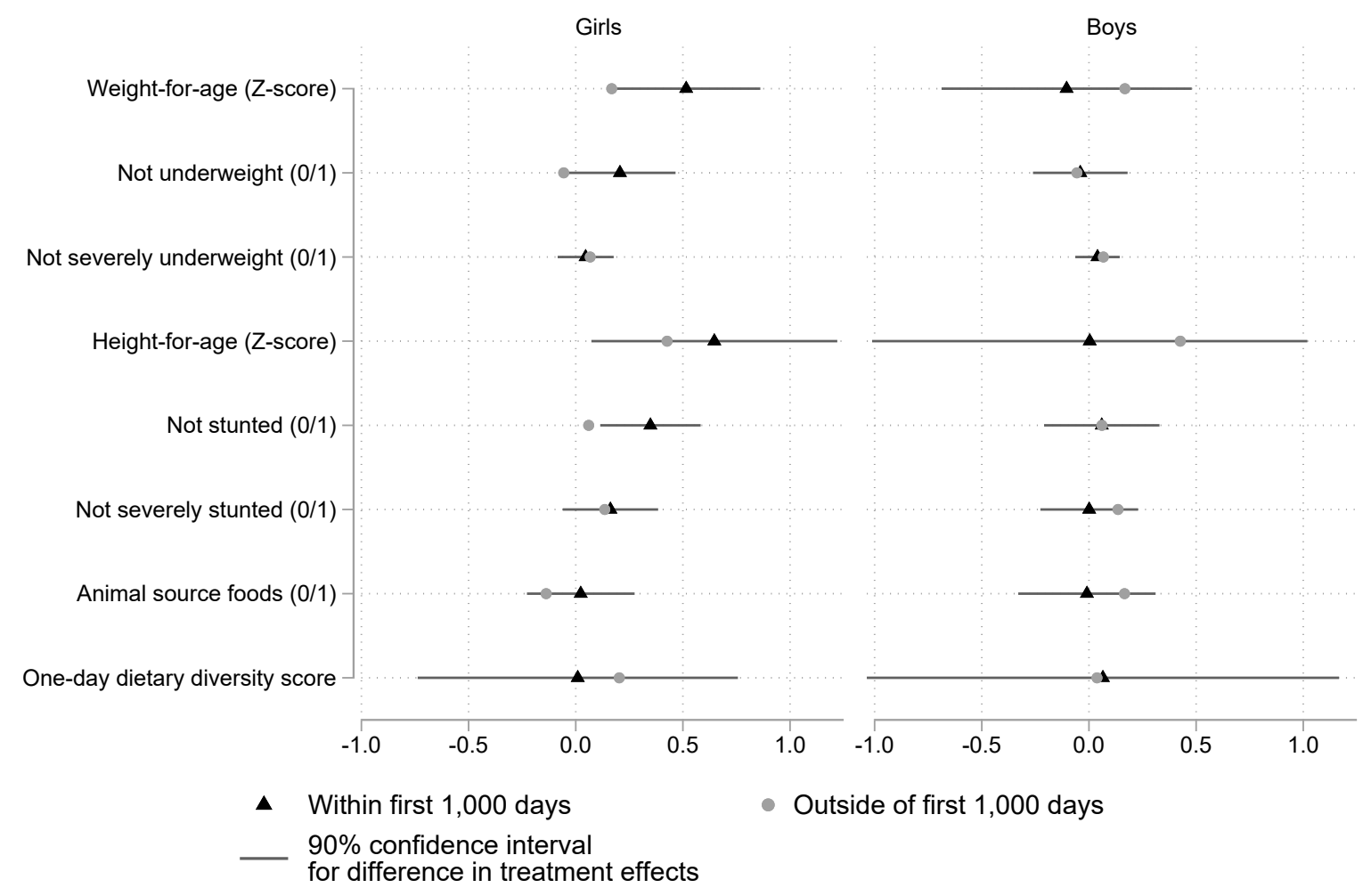

Notes: Point estimates were generated by allowing intent-to-treat effects to depend on whether the first chickens delivered to a child's stratum reached egg-laying age during a child's first 1,0oo days of life. Differences in treatment effects for girls are significant at the $10 \%$ level for Weight-for-age, Not underweight, and Not stunted. None of the differences in treatment effects are significant after adjusting for multiple comparisons.

1. We randomly split our data in half into a main sample $(M)$ and an auxiliary sample $(A)$. We stratify on cluster when splitting the sample, so that each cluster is evenly split between the main and auxiliary samples.

2. Let $Z_{i c s}$ be a vector of characteristics observed at baseline or otherwise unaffected by treatment for unit (household or child) $i$ in cluster $c$ from stratum $s$. We compute the propensity score, $p\left(\boldsymbol{Z}_{i c s}\right)$, i.e., the conditional probability of being assigned to treatment, for the program. Since all households in our initial roster had an equal chance of being assigned to the treatment group, we set the propensity score to 0.50 .

3. Let $s_{0}\left(Z_{i c s}\right)$ be the conditional intent-to-treat effect, i.e., the average impact of being assigned 
to treatment for units with characteristics $Z_{i c s}$. Let $b_{0}\left(Z_{i c s}\right)$ be the conditional mean of the outcome in the absence of treatment. Using the auxiliary sample, we use ML methods to obtain proxy predictors of $s_{0}\left(Z_{i c s}\right)$ and $b_{0}\left(Z_{i c s}\right)$. The proxy predictor for $b_{0}\left(Z_{i c s}\right)$ is the fitted value from a ML model of the outcome estimated using units assigned to control, while the proxy predictor for $s_{0}\left(Z_{i c s}\right)$ is the fitted value from a ML model of the outcome estimated using treated units minus the predicted proxy for $b_{0}\left(Z_{i c s}\right)$. The proxy predictors for the conditional intent-to-treat and conditional mean of the outcome in the absence of treatment are given by $S\left(Z_{i c s}\right)$ and $B\left(Z_{i c s}\right)$, respectively.

4. The results of the previous step are used to generate predicted proxies $B\left(Z_{i c s}\right)$ and $S\left(Z_{i c s}\right)$ for the main sample.

5. We next estimate the following regression by OLS using the main sample:

$$
y_{i c s}=\alpha^{\prime} \boldsymbol{X}_{i c s}+\beta_{1}\left(\text { Treat }_{c}-p\left(\boldsymbol{Z}_{i c s}\right)\right)+\beta_{2}\left(\text { Treat }_{c}-p\left(\boldsymbol{Z}_{i c s}\right)\right)\left(S\left(\boldsymbol{Z}_{i c s}\right)-\bar{S}\right)+\varepsilon_{i c s}
$$

where $\boldsymbol{X}_{i c s}$ includes the stratum indicators, $B\left(\boldsymbol{Z}_{i c s}\right)$, and $S\left(\boldsymbol{Z}_{i c s}\right)$. The latter two terms are included to improve model fit. The $\bar{S}$ term is the mean of $S\left(Z_{\text {ics }}\right)$ and is replaced with the average of the $S\left(Z_{i c s}\right)$ from the main sample in estimation. Other details of this equation are discussed in the main text.

6. Observations in the main sample are then sorted by their values of the best linear predictor for $s_{0}\left(Z_{i c s}\right)$, i.e., $\left(\beta_{1}+\beta_{2}\left(S\left(Z_{i c s}\right)-\bar{S}\right)\right)$. Note that this is equivalent to sorting on $S\left(Z_{i c s}\right)$. After sorting, observations in the main sample are split into terciles with high, middle, and low values of $S\left(Z_{i c s}\right)$. If $S\left(Z_{i c s}\right)$ is a high-quality proxy predictor of $s_{0}\left(Z_{i c s}\right)$, then the terciles of $S\left(Z_{i c s}\right)$ should closely correspond to units with high, middle, and low impacts of being assigned to treatment. 
7. Next we estimate the group average intent-to-treat effects:

$$
\begin{aligned}
y_{i c s} & =\alpha^{\prime} \boldsymbol{X}_{i c s}+\gamma_{1} G_{1}\left(\text { Treat }_{c}-p\left(Z_{\text {ics }}\right)\right)+\gamma_{2} G_{2}\left(\text { Treat }_{c}-p\left(Z_{\text {ics }}\right)\right) \\
& +\gamma_{3} G_{3}\left(\text { Treat }_{c}-p\left(Z_{i c s}\right)\right)+u_{i c s}
\end{aligned}
$$

Details of this equation are described in the main text.

8. Next, we estimate the classification analysis parameters:

$$
Z_{i c s}^{k}=\delta_{1} G_{1}+\delta_{2} G_{2}+\delta_{3} G_{3}+e_{i c s}
$$

Details of this equation are described in the main text.

9. Lastly, we calculate two goodness-of-fit measures for each combination of outcome and ML method: one measure that maximizes the variation in the outcome explained by equation A.2, which we will refer to as "Best GITTs", and a second measure that maximizes the correlation between $S\left(Z_{i c s}\right)$ and $s_{0}\left(Z_{i c s}\right)$, which we will refer to as "Best best linear predictor".

Within each split of the data, we estimate standard errors and degrees of freedom as in Young (2016) for equations A.1 and A.2. We use heteroskedasticity-robust "HC1" standard errors (MacKinnon and White, 1985) for equation A.3. ${ }^{12}$ We do not cluster our standard errors when performing inference on the classification analysis parameters because we do not view our sample as being multi-stage and we do not purposefully assign individuals to $G_{1}, G_{2}$, or $G_{3}$ in a way that is correlated with cluster membership; Abadie et al. (2017) prove that cluster-based assignment or two-stage sampling are necessary for clustering in a randomized trial. We do not use an effective degrees of freedom correction or bias-reduced standard errors for the classification analysis standard errors because these adjustments have no effect when the parameter of interest is a simple comparison of means.

\footnotetext{
${ }^{12}$ The random number generator driving the choice of sample splits as well as all other results in this paper that rely on random number generation was seeded using the closing value of the Dow Jones Industrial Average on a pre-specified date (December 20, 2018). Pre-specification can be verified at the Github site of one of the co-authors and will be made available at the conclusion of the blind review process.
} 
The algorithm described above is repeated for 199 random splits of the data. The final estimate for each object of interest (parameter point estimates, $p$-values, goodness-of-fit measures, etc.) is its median from the 199 sample splits as in Chernozhukov et al. (2018b). We base hypothesis testing on $90 \%$ confidence intervals constructed using the median upper and lower bounds from the $95 \%$ confidence intervals estimated in each sample split, and two times the median $p$-values generated by the sample splits. We correct for multiple comparisons by reporting $q$-values and confidence intervals adjusted for the false discovery rate. Corrections for multiple comparisons are made within families of hypotheses described in section A.6 of the appendix. Table A.4 presents goodness-of-fit measures by outcome for our selected machine learning methods.

The method of Chernozhukov et al. (2018b) has several appealing features. To estimate the parameters of equations 3 through 5, observations are randomly divided in half between an auxiliary sample and a main sample, where the former is used to build the model for the proxy predictors and the latter is used in estimating parameters from equations 3, 4, and 5. By using sample splitting, Chernozhukov et al. (2018b) avoid "overfitting" even when including many covariates in $Z_{i c s}$. In addition, we are able to exploit the predictive power of machine learning methods without placing any distributional assumptions on the proxy predictor $S\left(\boldsymbol{Z}_{i c s}\right)$ and without having to assume that $S\left(\boldsymbol{Z}_{i c s}\right)$ is an unbiased or consistent estimator of the conditional intent-to-treat effect. This is achieved by estimating the best linear predictor of the conditional intent-to-treat effect and comparing differences in the average intent-to-treat effect across terciles formed by sorting on $S\left(Z_{i c s}\right)$, rather than attempting to directly estimate and then sort on the conditional intent-to-treat effect itself. By focusing on the best linear predictor, we can conduct hypothesis testing for each parameter of interest just as we would in any other application of linear regression, conditional on how the sample is split into main and auxiliary parts.

We pair two machine learning methods with the algorithm of Chernozhukov et al. (2018b): the elastic net (Zou and Hastie, 2005) and the random forest algorithms (Breiman, 2001). The elastic net 
Table A.4: Goodness of fit for machine learning methods

\begin{tabular}{|c|c|c|c|c|}
\hline \multirow[b]{3}{*}{$\underline{\text { Household-level outcomes }}$} & \multicolumn{2}{|c|}{ Best GITTs } & \multicolumn{2}{|c|}{ Best BLP } \\
\hline & Elastic net & Random forest & Elastic net & Random forest \\
\hline & & & & \\
\hline Expenditure (log) & 0.013 & 0.007 & 0.110 & 0.044 \\
\hline Food expenditure (log) & 0.011 & 0.007 & 0.061 & 0.052 \\
\hline Calories (log) & 0.019 & 0.008 & 0.116 & 0.051 \\
\hline Animal protein (log grams) & 0.312 & 0.209 & 0.528 & 0.445 \\
\hline Daily servings of eggs & 0.008 & 0.008 & 0.054 & 0.065 \\
\hline Eggs consumed per day per AME & 0.147 & 0.114 & 0.206 & 0.163 \\
\hline Food consumption score & 9.561 & 5.486 & 3.020 & 2.039 \\
\hline Chickens (log) & 0.086 & 0.046 & 0.214 & 0.098 \\
\hline Naked-neck chickens (log) & 0.071 & 0.026 & 0.264 & 0.085 \\
\hline Eggs produced & 0.242 & 0.235 & 0.362 & 0.277 \\
\hline \multicolumn{5}{|l|}{ Child-level outcomes } \\
\hline Weight-for-age (Z-score) & 0.083 & 0.057 & 0.172 & 0.162 \\
\hline Not underweight $(\mathrm{o} / \mathrm{1})$ & 0.006 & 0.007 & 0.035 & 0.043 \\
\hline Height-for-age (Z-score) & 0.123 & 0.079 & 0.134 & 0.200 \\
\hline Not stunted $(\mathrm{o} / \mathrm{1})$ & 0.027 & 0.028 & 0.062 & 0.094 \\
\hline Consumed animal-source foods in past day $(\mathrm{o} / \mathrm{1})$ & 0.025 & 0.036 & 0.120 & 0.194 \\
\hline One-day dietary diversity score & 0.376 & 0.396 & 0.576 & 0.703 \\
\hline
\end{tabular}

Notes: "Best GITTs" measures goodness-of-fit by how well the division of the sample into terciles of predicted intent-to-treat effects (most, middle, and least affected) explains the outcome. "Best BLP" measures goodness-of-fit by the correlation between the true conditional intent-to-treat effects and the estimated conditional intent-to-treat effects.

minimizes the following objective function:

$$
\sum_{i=1}^{N}\left(\tilde{y}_{i c s}-\beta_{p}^{\prime} \tilde{Z}_{i c s}\right)^{2}+\lambda\left(\alpha \sum_{p=1}^{P}\left(\left|\beta_{p}\right|\right)+(1-\alpha) \sum_{p=1}^{P}\left(\beta_{p}^{2}\right)\right)
$$

where $\alpha \leq 1$ and $\tilde{y}_{i c s}$ and $\tilde{Z}_{i c s}$ are the outcomes and a set of predictors, respectively, that have been standardized to have averages of zero and variances of one. For a given random split of the data into main and auxiliary samples, we choose $\alpha$ and $\lambda$ by twice-repeated, two-fold cross validation within the auxiliary sample (i.e., randomly split the data into main and auxiliary samples, reverse the roles of the samples, and then repeat with another random split), performing a grid search over 100 randomly 
chosen values of each parameter.

As is clear from equation A.4, the elastic net is a penalized least squares method where the penalty depends on $\lambda, \alpha$, and two functions of the regression coefficients: the square root of the sum of the absolute value of the regression coefficients (i.e., the L1 norm, as in the LASSO algorithm) and the square root of the sum of squared regression coefficients (the L2 norm, as in ridge regression). Penalized least squares methods can outperform ordinary least squares in prediction by avoiding overfitting. In effect, penalized methods improve mean-squared prediction error by trading lower variance for increased bias. The L1 norm constraint used in the LASSO forces many regression coefficient to zero, resulting in better predictive performance than ridge regression when the true conditional mean function has relatively few nonzero coefficients. However, when a group of predictors is highly correlated, the LASSO will tend to include just one predictor from the group, resulting in worse predictive performance than ridge regression. Ridge regression would instead include all predictors in the group and assign them similar coefficients (recall that all predictors are standardized to be on the same scale). The elastic net improves on LASSO and ridge regression by selecting a parsimonious model when predictors are not highly correlated (as in the LASSO) and including all predictors from highly correlated groups (as in ridge regression) (Zou and Hastie, 2005).

The random forest algorithm is an "ensemble" method that generates predictions by averaging many estimated "regression trees". Regression trees do not impose structure on the conditional mean as in a linear model like the elastic net, and the random forest algorithm will tend to outperform the elastic net if the conditional mean of the outcome is highly non-linear. A single regression tree is fit as follows. For a given predictor, the sample is split in two at each possible predictor value, and each observation is assigned the average value of the outcome within its sample split as its predicted value. This process is repeated for all predictors, and the sample split that results in the smallest sum of squared prediction errors is retained. This process is repeated, searching for the sample split that results in the smallest sum of squared prediction errors conditional on existing sample splits until a stopping criterion is reached or no more sample splits are possible. This process forms a regression tree with branches created by sample splits and "leaves" containing groups of observations formed 
by the sample splits at the end of each branch. Each observation's predicted value is set equal to the average within its leaf.

Individual regression trees are highly vulnerable to overfitting, and random forests improve performance in two ways. First, a large number of separate regression trees are fit, and each observation's prediction is the average prediction across the trees. But each tree is estimated using a separate bootstrap sample with size equal to two-thirds of the overall sample. For a given observation, the predicted value is calculated using the regression trees where the observation in question was not part of the bootstrap sample. Using separate data for estimation and prediction reduced overfitting. Second, each time a new split in a given tree is considered, the algorithm only considers a random subset of the available predictors. This last feature has the effect of decorrelating predictions across trees, so that modeling errors in each separate tree tend to cancel out when averaging their predicted values.

When using the random forest algorithm, we used a minimum leaf size of one grew 1,ooo trees. We choose the number of predictors considered at each sample split by repeated two-fold cross validation. We compared ten different randomly-selected values for the number of predictors. The elastic net and the random forest algorithm were implemented in $\mathrm{R}$ with the glmnet and randomForest packages, respectively, while tuning was carried out using the CARET package.

Note that several of our outcomes are binary (e.g., whether a child is not stunted) or count variables (e.g., number of chickens owned). The elastic net can be used as a penalized logistic or Poisson regression in such cases. For binary outcomes, random forest predictions can assign a predicted class (i.e., o or 1) based on a majority vote of observations in the same node. For example, if a majority of observations in your node have a value of 1 for the binary outcome, your prediction is set equal to 1. For the results presented in this article, we used penalized OLS for all outcomes and generated fitted values from the random forest as the average fitted value within each observation's node. But we did check sensitivity to using a penalized logit or Poisson regression where appropriate and taking the classification approach to prediction using the random forest algorithm. There was no noticeable 
difference in our goodness of fit measures and our overall results were nearly the same.

\section{A.5 Predictor selection for analysis of heterogeneous treatment effects}

We use the characteristics listed below as predictor variables when estimating the predicted proxies to the true heterogeneous treatment effects. We use the same set of characteristics when describing differences between the most and least affected, i.e., in our classification analysis:

1. Demographics (household size in AMEs, the dependency ratio, average years of education among household members ages twelve and older).

2. Geographic and weather information at follow-up (altitude of the dwelling, millimeters of rain measured during the 2015 maize and bean season at the nearest weather station, number of days where the maximum temperature recorded at the nearest weather station was over $30^{\circ} \mathrm{C}$ during the 2015 maize and bean season).

3. Wealth and credit (the combined value of land, livestock, tools, consumer durables, cash and grain savings, and the annual rental value of housing; an indicator for whether the dwelling has a dirt floor; an indicator for whether the household had a loan from a formal lender).

4. Several lagged household outcomes: log calories, the food consumption score, log grams of animal protein, log number of chickens owned, log of eggs produced. We dropped food expenditure because it was highly correlated with calories and naked-neck chickens because of high correlation with total chickens. We exclude lagged indicators for whether the household kept poultry production records or sold any eggs because they exhibited little variation in the sample. Note that we approximate the log transformation using the inverse hyperbolic sine function (Bellemare and Wichman, 2019).

5. Access to services and markets (separate indicators for being connected to a water network, being connected to an electricity network, time to nearest market, and unit value per egg consumed) 
6. Group memberships for the household as a whole.

7. Indicators of women's empowerment (the share of household wealth controlled by women either jointly or independently and group memberships among adult women.

When modeling variation in impacts on child-level outcomes, we include all of the above characteristics as well as the following:

1. Age in months at follow-up

2. Gender

3. The relevant lagged outcome (specified as in equation 2 of the main text, including dummy variables for availability of lagged outcome data)

4. Whether the household participated in the "Mi Bono Seguro" conditional cash transfer program at baseline

5. Whether the household administered a government-supplied micronutrient supplement to its children at baseline

Finally, we also include stratum dummies and distance to the nearest weather station as measured at follow-up in the predictor set for equations A.1 and A.2, but do not include them in our classification analysis. Distance to the nearest station may control for a portion of the measurement error associated with using data from the nearest station as a measure of weather conditions on the farm. The stratum dummies and the additional covariates just described are not included when estimating the classification analysis parameters.

Although the elastic net and random forest algorithms remove much of the guesswork from model selection, we used theory and knowledge of the program to choose the initial pool of predictors listed above. We include demographics in the set of baseline predictors because knowing whether program impacts are correlated with information that is easily observed could be useful for targeting. 
Several variables included in our set of baseline predictors will let us examine whether the largest program benefits were enjoyed by the most or least affluent households in the study area, including wealth, having a formal loan, access to services and markets, social capital, and receiving conditional cash transfers. Better-off households may experience larger effects if they are able to avoid selling or eating chickens when suffering negative shocks, or smaller effects if the marginal improvement in diet is greater among relatively poor program participants.

Our weather data cover the 2015-2016 agricultural year and are drawn from six weather stations constructed as part of the program. Alternative weather data sources showed poor correlation with the station data. Although our data do not allow for credible identification of causal weather effects, examining the correlation of program impacts with weather conditions is interesting because of the robustness of naked-neck chickens to heat and drought (Chen et al., 2004). For our measure of exposure to extreme temperatures, we use the total number of days with maximum temperatures above $30^{\circ} \mathrm{C} .30^{\circ} \mathrm{C}$ is a commonly used cutoff when studying the sensitivity of crop yields or livestock to extreme heat (see Lobell et al. (2011) and Chen et al. (2004)). We use maximum rather than average temperatures because there is little variation across stations in the number of days with average temperatures over $30^{\circ} \mathrm{C}$. Higher altitudes will be associated with cooler temperatures, but along with distance to the closest market and egg units value, may also indicate greater geographic isolation. We would expect low supply of animal protein at baseline to be more of a concern for relatively isolated communities.

Women's standing in the household, as captured by women's share of wealth and women's social capital, could play an important role in shaping impacts. For example, a woman with a strong bargaining position in the household may be able to dissuade her husband from selling or eating chickens received through the program before they begin to reproduce. Clusters assigned to treatment in which women have relatively high social capital might enjoy large program benefits if more social ties lead to increased trade or transfer of eggs or chickens from program households to their neighbors. If women have a greater preference for child welfare than their spouses, then households in which women have a strong bargaining position might enjoy relatively large impacts on child health and 
diet, particularly if these same households are constrained in access to animal source foods at baseline. On the other hand, if children in households where women have a relatively strong influence on decision making tend to be healthy and eat a diverse diet at baseline, we might instead see the largest effects in households where women have a low share of assets or poor social capital prior to receiving their chicken sets. ${ }^{13}$

Participation in Guatemala's "Mi Bono Seguro” conditional cash transfer program functions as a poverty indicator. But cash transfers could indicate that some of the constraints preventing improved child health are being addressed by other interventions. The same argument could be made for provision of micronutrients to children. If regular health clinic visits (as stipulated by Mi Bono Seguro for families with children under six years of age) and micronutrients are needed to convert greater consumption of animal source foods into height and weight gains, then households answering affirmatively to each of these indicators might enjoy the largest program impacts. Research elsewhere in Guatemala suggests that parents can sprinkle micronutrient powder on eggs, making the former more palatable and potentially increasing supplement intake (Gillespie, 2018).

Note that we drop two household-level outcomes (indicators for maintaining a poultry registry and having sold eggs in the six months prior to follow-up) and two child-level outcomes (indicators for not being severely underweight and not being severely stunted) prior to our analysis of heterogeneous effects. Each of these outcomes exhibited little variation in the sample, making it difficult to split the sample in two while preserving at least some outcome variation in each subsample as required by the method of Chernozhukov et al. (2018b). Finally, as noted in the main text, we do not conduct separate heterogeneity analyses for boys and girls. Results obtained when splitting the sample of children by gender are similar but less precise than what we obtain by pooling the sample of children.

\footnotetext{
${ }^{13}$ Note that detailed questions on intrahousehold ownership and control over assets and social capital were only asked at baseline to reduce the length of the follow-up survey. Therefore we do not include indicators of social capital or women's relative standing in the household in our set of outcomes.
} 


\section{A.6 Adjusting for multiple hypothesis testing: the false discovery rate}

Throughout the main text (except for our balance test tables) we report $q$-values, i.e., the estimated false discovery rate, alongside $p$-values for each hypothesis of interest. If a hypothesis test yields a $p$-value of 0.05 and a $q$-value of 0.10 , this implies that rejecting all null hypotheses with $p$-values of 0.05 or less would result in $10 \%$ of rejected nulls being true in expectation. The $q$-values are calculated as follows (Benjamini and Hochberg, 1995):

$$
q=M p_{m} / m
$$

where $p_{m}$ is the $m^{\text {th }}$ smallest $p$-value when all $p$-values are ordered from smallest (i.e., $m=1$ ) to largest (i.e., $m=M$ ) and $M$ is the number of tests being performed in the relevant "family of hypotheses". We define each family of hypotheses as including all tests that give us a chance to answer the same question (Lakens, 2016). For example, in table A.1, each of the ten tests in the "Difference" column gives us a chance to say whether households receiving their chickens before the Marek vaccine was put in place and households receiving their chickens afterwards differ in their average characteristics. To compute the $q$-values reported in table A.1, we therefore used equation A.5 with $M=10$ and $m \in[1, \ldots, 10]$.

We also report 95\% confidence intervals adjusted for the false discovery rate in parentheses below the unadjusted 95\% confidence intervals shown in square brackets. The adjusted intervals ensure that $95 \%$ of intervals for tests in a family of hypotheses cover their true parameter values in repeated samples. In contrast, each of the unadjusted $95 \%$ confidence intervals shown in parentheses is meant to ensure a 95\% coverage rate for a single parameter (Benjamini and Yekutieli, 2005). To compute the intervals adjusted for the false discovery rate, we increase the critical values of the $t$-statistics used to compute the unadjusted intervals. The $95 \%$ confidence interval adjusted to control the false discovery rate uses the $[1-(\alpha m / 2 M)]^{\text {th }}$ percentile of the same $t$-distribution, where $m$ and $M$ are defined as in equation A.5 (Benjamini and Yekutieli, 2005).

At the household level, tests of the null hypothesis that the average intent-to-treat effect is equal 
to zero are grouped into three families:

1. Expenditure impacts (includes tests of impacts on expenditure and food expenditure per adult male equivalent)

2. Household diet impacts (daily calories per adult male equivalent, daily grams of animal source foods protein per adult male equivalent, daily servings of eggs for the houseold, daily eggs consumed per adult male equivalent, and the food consumption score)

3. Impacts on poultry outcomes (chickens owned, naked-neck chickens owned, using a poultry registry, eggs produced in the last six months, and having sold an egg in the last six months)

For children, we divide outcomes into health impacts (weight and height indicators) and diet impacts (animal source foods consumption indicator, individual dietary diversity score). Tests of the null of a zero average intent-to-treat effect are then split into six families: health and diet impacts among girls, health and diet impacts among boys, and differences in health and diet impacts by gender.

When estimating heterogeneous intent-to-treat effects, we seek to answer the following questions:

1. Which outcomes exhibit heterogeneity in the conditional intent-to-treat effect?

2. For the outcomes where we have evidence of impact heterogeneity, are there any differences in the average characteristics of the most and least affected households or children?

For a given outcome, we conclude that there is treatment effect heterogeneity if we can reject $\beta_{2}=0$ (from equation A.1) or $\gamma_{1}=\gamma_{3}$ (from equation A.2) after adjusting for multiple comparisons. In adjusting for multiple comparisons, we divide outcomes just as described above. For each outcome, we have separate tests of whether $\beta_{2}=0$ and whether $\gamma_{1}=\gamma_{3}$. Therefore we have four hypothesis tests in the family. The adjusted 90\% confidence intervals and $q$-values are obtained by applying the formula given in equation A.5 to the four corresponding unadjusted 90\% confidence intervals and $p$-values, respectively. 
If our tests of $\beta_{2}=0$ and $\gamma_{1}=\gamma_{3}$ lead us to conclude that a particular outcome variable exhibits impact heterogeneity, then we report classification analysis results for that outcome in the main text. That is, we present a set of equality of means tests to determine whether the units that were most and least affected by the program exhibit differences in characteristics. The question being asked by the classification analysis tests is outcome specific. For example, do the children who enjoyed the largest and smallest impacts with respect to animal source foods consumption differ in their characteristics? Therefore we adjust for multiple comparisons within each outcome when reporting our classification analysis results.

For the sake of completeness, we report our estimates of $\beta_{1}$ (the average intent-to-treat obtained from equation A.1) as well as $\gamma_{1}$ and $\gamma_{3}$ from equation A.2, although these parameters do not factor into our decision rules. For each parameter we adjust for multiple comparisons within the families described above. In addition, any classification analysis and group average intent-to-treat effects results not shown in the main text are reported in sections A.15 and ?? of this appendix.

\section{A.7 Power calculations}

In this section we estimate minimum detectable effects for the impact of being assigned to the treatment group (i.e., the intent-to-treat effect). The minimum detectable effect (MDE) is the smallest program effect size that, if true, would allow us to reject the hypothesis of a zero effect in $80 \%$ of the samples that we could draw from our population of interest. The smaller the MDE for a given outcome, the more likely we are to correctly conclude that the program had a non-zero effect on that outcome.

Let $\delta_{M D E}$ represent the minimum detectable effect. Let $s e_{\hat{\delta}}$ be the standard error for the causal effect of interest (i.e., intent-to-treat or local average treatment effect). The minimum detectable effect is given by:

$$
\delta_{M D E}=\left(t_{\alpha / 2}+t_{1-\beta}\right) s e_{\hat{\delta}}
$$

The parameters $\alpha$ and $\beta$ represent the probability of making a Type 1 error (rejecting a false null 
Table A.5: Minimum detectable effects for intent-to-treat effects on household-level outcomes

\begin{tabular}{lccc}
\hline Outcome & Original units & Percent of mean & Standard deviations \\
\hline Annual expenditure per adult male equivalent (log) & 0.594 & 6.537 & 0.856 \\
Annual food expenditure per adult male equivalent (log) & 0.410 & 4.906 & 0.658 \\
Daily calories per adult male equivalent (log) & 0.347 & 4.301 & 0.553 \\
Daily grams of animal protein per adult male equivalent (log) & 1.224 & 48.100 & 0.635 \\
Daily servings of eggs & 0.305 & 69.595 & 0.543 \\
Eggs consumed per day per adult male equivalent & 1.225 & 69.341 & 0.494 \\
Food consumption score & 8.779 & 26.389 & 0.857 \\
Chickens owned (log) & 0.564 & 26.376 & 0.412 \\
Naked-neck chickens owned (log) & 0.689 & 71.445 & 0.609 \\
Uses poultry registry (o/1) & 0.048 & 318.425 & 0.392 \\
Eggs produced in last six months (log) & 0.986 & 37.926 & 0.350 \\
Sold at least one egg in last six months (o/1) & 0.076 & 101.696 & 0.289 \\
Observations & 791 & 791 & 791 \\
\hline
\end{tabular}

Notes: The mean and standard deviation used to compute minimum detectable effects in the second and third columns of results are from the control group at follow up. All regression used to estimate the standard errors used in estimating minimum detectable effects are taken from a regression of the outcome on its lag, the treatment indicator, and indicators for thirteen strata. Standard errors and degrees of freedom were estimated as in Young (2016). Continuous outcomes winsorized at the first and 99th percentiles of each variable.

hypothesis) and the probability of making a Type 2 error (failing to reject a false null hypothesis), respectively. We set $\alpha$ to 0.05 and $\beta$ to o.8o for all estimated minimum detectable effects. We present all minimum detectable effects in each outcome's original units, in standard deviations of the control groups's observed distribution at follow-up, and as a perecent of the average in the control group follow-up.

When estimating the minimum detectable intent-to-treat effect for a given outcome, we use the standard error from equation 1 for household-level outcomes and equation 2 for child-level outcomes. We use effective degrees of freedom calculated as in Young (2016) to obtain the critical values (from a $t$-distribution) for the minimum detectable intent-to-treat effect. Note that we drop the contaminated strata before running our power calculations. Results are given in tables A.5 through A.7.

When looking at household-level outcomes, power looks fair for naked-neck chickens owned. The minimum detectable effect for the intent-to-treat impact on naked-neck chickens corresponds 
Table A.6: Minimum detectable effects for intent-to-treat effects on girls

\begin{tabular}{lccc}
\hline Outcome & Original units & Percent of mean & Standard deviations \\
\hline Weight-for-age (Z-score) & 0.332 & 25.406 & 0.329 \\
Not underweight (o/1) & 0.156 & 20.128 & 0.370 \\
Not severely underweight (o/1) & 0.093 & 9.951 & 0.386 \\
Height-for-age (Z-score) & 0.468 & 21.186 & 0.333 \\
Not stunted (o/1) & 0.184 & 44.609 & 0.372 \\
Not severely stunted (o/1) & 0.165 & 21.019 & 0.398 \\
Consumed animal-source foods in past day (o/1) & 0.418 & 69.851 & 0.847 \\
One-day dietary diversity score & 1.443 & 25.541 & 0.712 \\
Observations & 195 & 195 & 195 \\
\hline
\end{tabular}

Notes: The mean and standard deviation used to compute minimum detectable effects in the second and third columns of results are from the control group at follow up. All regression used to estimate the standard errors used in estimating minimum detectable effects are taken from a regression of the outcome on its lag, the treatment indicator, and indicators for thirteen strata. Standard errors and degrees of freedom were estimated as in Young (2016). Continuous outcomes winsorized at the first and 99th percentiles of each variable.

Table A.7: Minimum detectable effects for intent-to-treat effects on boys

\begin{tabular}{lccc}
\hline Outcome & Original units & Percent of mean & Standard deviations \\
\hline Weight-for-age (Z-score) & 0.591 & 50.849 & 0.437 \\
Not underweight (o/1) & 0.168 & 20.977 & 0.420 \\
Not severely underweight (o/1) & 0.076 & 7.983 & 0.363 \\
Height-for-age (Z-score) & 0.972 & 48.649 & 0.636 \\
Not stunted (o/1) & 0.221 & 52.739 & 0.447 \\
Not severely stunted (o/1) & 0.177 & 22.256 & 0.435 \\
Consumed animal-source foods in past day (o/1) & 0.377 & 67.617 & 0.756 \\
One-day dietary diversity score & 1.717 & 31.015 & 0.848 \\
Observations & 241 & 241 & 241 \\
\hline
\end{tabular}

Notes: The mean and standard deviation used to compute minimum detectable effects in the second and third columns of results are from the control group at follow up. All regression used to estimate the standard errors used in estimating minimum detectable effects are taken from a regression of the outcome on its lag, the treatment indicator, and indicators for thirteen strata. Standard errors and degrees of freedom were estimated as in Young (2016). Continuous outcomes winsorized at the first and 99th percentiles of each variable. 
to a $88 \%$ increase, which seems large but is less dramatic when one considers that control group households owned 2.425 naked-neck chickens on average at follow-up, while the baseline sample average was about 1.3 naked-neck chickens owned. The minimum detectable effect for using a poultry registry also appears reasonable, at 4.8 percentage points. Other household-level outcomes are underpowered. When looking at child outcomes, minimum detectable effects for the intent-to-treat effect look reasonable as long as positive spillovers are likely.

\section{A.8 Comparison of estimation sample and dropped strata}

In tables A.8 through A.10 we present differences in baseline characteristics between our main sample and the strata that were dropped because of control group contamination. There are no significant differences between the two groups.

\section{A.9 Randomization inference}

In tables A.11, A.12, and A.13 we check the robustness of the estimated average intent-to-treat effects to mode of inference. Specifically, we compare inference based on analytic $p$-values and $q$-values to what we obtain through randomization inference (RI).

Let $\hat{\beta}_{0}$ be the intent-to-treat effect estimated using the observed vector of treatment assignments.

We use the same estimating equation used in the main text. Let $\hat{\beta}_{b}$ be the intent-to-treat estimate obtained when applying alternative-stratified randomization $b$ to the data set. The RI $p$-value for a two-tailed test is given by:

$$
\frac{1}{B}\left(\sum_{b=1}^{B} I\left(\left|\hat{\beta}_{b}\right| \geq\left|\hat{\beta}_{0}\right|\right)\right)
$$

where $I(\cdot)$ is an indicator function equal to one if the condition in parentheses is true and zero otherwise, and $B$ is the number of permutations. We set $B=999$. We compute RI $q$-values by applying equation A.5 the RI $p$-values.

Results are given in tables A.11, A.12, and A.13 below. None of our conclusions with respect to 
Table A.8: Comparison of main sample and contaminated strata: baseline household characteristics

\begin{tabular}{|c|c|c|c|}
\hline & $\begin{array}{c}\text { Estimation } \\
\text { strata }\end{array}$ & $\begin{array}{c}\text { Contaminated } \\
\text { strata }\end{array}$ & Difference \\
\hline Household size (adult male equivalents) & 4.025 & 4.054 & 0.029 \\
\hline Dependency ratio & 0.413 & 0.378 & -0.034 \\
\hline Woman-headed household (o/1) & 0.173 & 0.162 & -0.011 \\
\hline Wealth (log) & 9.443 & 9.508 & 0.064 \\
\hline Annual food expenditure per adult male equivalent (log) & 7.332 & 7.294 & -0.038 \\
\hline Daily calories per adult male equivalent (log) & 8.379 & 8.404 & 0.024 \\
\hline Daily grams of animal protein per adult male equivalent (log) & 1.760 & 1.938 & 0.178 \\
\hline Daily servings of eggs & 0.379 & 0.427 & 0.048 \\
\hline Eggs consumed per day per adult male equivalent & 1.187 & 1.497 & 0.310 \\
\hline Food consumption score & 20.393 & 21.267 & 0.874 \\
\hline Chickens owned (log) & 2.354 & 2.435 & 0.081 \\
\hline Naked-neck chickens owned (log) & 0.482 & 0.599 & 0.116 \\
\hline Uses poultry registry $(\mathrm{o} / 1)$ & 0.095 & 0.106 & 0.011 \\
\hline Eggs produced in last six months (log) & 1.383 & 1.623 & 0.241 \\
\hline Sold at least one egg in last six months $(\mathrm{o} / 1)$ & 0.035 & 0.042 & 0.008 \\
\hline Observations & 462 & 377 & 839 \\
\hline
\end{tabular}

Notes: ${ }^{*} p<0.10,{ }^{* *} p<0.05,{ }^{* * *} p<0.01 ;{ }^{+} q<0.10,{ }^{++} q<0.05,{ }^{+++} q<0.01$, where $q$ is the false discovery rate. Cluster-robust standard errors and degrees of freedom for differences in means estimated as in Young (2016). 
Table A.9: Comparison of main sample and contaminated strata: baseline characteristics, girls ages six to 60 months

\begin{tabular}{lccc}
\hline & Estimation & Contaminated & \\
& strata & strata & Difference \\
\hline Age in months & 32.035 & 28.190 & -3.845 \\
Height-for-age (Z-score) & -1.605 & -2.053 & -0.448 \\
Not stunted (o/1) & 0.502 & 0.524 & 0.022 \\
Not severely stunted (o/1) & 0.802 & 0.667 & -0.135 \\
Weight-for-age (Z-score) & -0.938 & -0.520 & 0.417 \\
Not underweight $(\mathrm{o} / 1)$ & 0.797 & 0.762 & -0.035 \\
Not severely underweight $(\mathrm{o} / 1)$ & 0.947 & 1.000 & $0.053^{*}$ \\
Observations & 227 & 21 & 248 \\
\hline Notes: ${ }^{*} p<0.10,{ }^{* *} p<0.05,{ }^{* * *} p<0.01 ;{ }^{+} q<0.10,{ }^{++} q<0.05,{ }^{+++} q<0.01$, \\
where $q$ is the false discovery rate. Cluster-robust standard errors and de- \\
grees of freedom for differences in means estimated as in Young $(2016)$.
\end{tabular}

Table A.10: Comparison of main sample and contaminated strata: baseline characteristics, boys ages six to 60 months

\begin{tabular}{lccc}
\hline & Estimation & Contaminated & \\
& strata & strata & Difference \\
\hline Age in months & 31.199 & 33.250 & 2.051 \\
Height-for-age (Z-score) & -1.699 & -1.675 & 0.025 \\
Not stunted (o/1) & 0.541 & 0.450 & -0.091 \\
Not severely stunted (o/1) & 0.807 & 0.800 & -0.007 \\
Weight-for-age (Z-score) & -0.922 & -0.884 & 0.038 \\
Not underweight $(\mathrm{o} / 1)$ & 0.797 & 0.850 & 0.053 \\
Not severely underweight $(\mathrm{o} / 1)$ & 0.949 & 1.000 & 0.051 \\
Observations & 296 & 20 & 316 \\
\hline Notes: ${ }^{*} p<0.10,{ }^{* *} p<0.05,{ }^{* * *} p<0.01 ;$ \\
where $q$ is the false discovery rate. Cluster-robust standard errors and de- \\
grees of freedom for differences in means estimated as in Young $(2016)$.
\end{tabular}


household-level outcomes or impacts on boys is altered. For impacts on girls, there is no clear pattern that $p$-values and $q$-values obtained through permuting treatment assignments are larger than what we obtained using analytic standard errors. None of our conclusions regarding impacts on girls or boys are affected by using randomization inference. 
Table A.11: Model-based versus randomization inference: intent-to-treat effects for household-level outcomes

\begin{tabular}{|c|c|c|c|c|c|}
\hline & $\begin{array}{c}\text { Intent-to-treat } \\
\text { effect }\end{array}$ & $\begin{array}{c}\text { Model-based } \\
p \text {-value }\end{array}$ & $\begin{array}{c}\text { Randomization } \\
p \text {-value }\end{array}$ & $\begin{array}{c}\text { Model-based } \\
q \text {-value }\end{array}$ & $\begin{array}{c}\text { Randomization } \\
q \text {-value }\end{array}$ \\
\hline Annual expenditure per adult male equivalent (log) & -0.008 & 0.967 & 0.970 & 1.000 & 1.000 \\
\hline Daily calories per adult male equivalent (log) & -0.001 & 0.992 & 0.985 & 0.992 & 0.985 \\
\hline Daily grams of animal protein per adult male equivalent (log) & 0.007 & 0.987 & 0.985 & 1.000 & 1.000 \\
\hline Food consumption score & -1.046 & 0.720 & 0.716 & 1.000 & 1.000 \\
\hline Chickens owned (log) & -0.130 & 0.492 & 0.503 & 1.000 & 1.000 \\
\hline Naked-neck chickens owned (log) & -0.017 & 0.941 & 0.949 & 0.941 & 0.949 \\
\hline Uses poultry registry $(\mathrm{o} / \mathrm{1})$ & 0.026 & 0.119 & 0.105 & 0.597 & 0.526 \\
\hline
\end{tabular}

Notes: See section 4.1 for the estimating equation. Model-based $p$-values and $q$-values calculated using standard errors and degrees of freedom estimated as in Young (2016). 
Table A.12: Model-based versus randomization inference: intent-to-treat effects for girls, ages 6 to 60 months

\begin{tabular}{lccccc}
\hline & Intent-to-treat & Model-based & Randomization & Model-based & Randomization \\
& effect & $p$-value & $p$-value & $q$-value & $q$-value \\
\hline Weight-for-age (Z-score) & 0.349 & 0.008 & 0.031 & 0.017 & 0.047 \\
Not underweight (o/1) & 0.090 & 0.102 & 0.095 & 0.122 & 0.095 \\
Not severely underweight (o/1) & 0.054 & 0.105 & 0.081 & 0.105 & 0.097 \\
Height-for-age (Z-score) & 0.539 & 0.005 & 0.022 & 0.015 & 0.044 \\
Not stunted (o/1) & 0.235 & 0.003 & 0.004 & 0.016 & 0.024 \\
Not severely stunted (o/1) & 0.143 & 0.023 & 0.012 & 0.034 & 0.036 \\
Consumed animal-source foods in past day (o/1) & -0.039 & 0.775 & 0.804 & 1.000 & 1.000 \\
One-day dietary diversity score & -0.014 & 0.976 & 0.980 & 0.976 & 0.980 \\
\hline
\end{tabular}

Notes: See section 4.1 for the estimating equation. Z-scores and indicators for stunting and underweight based on standards from World Health Organization (2011). Model-based $p$-values and $q$-values calculated using standard errors and degrees of freedom estimated as in Young (2016). 
Table A.13: Model-based versus randomization inference: intent-to-treat effects for boys, ages 6 to 60 months

\begin{tabular}{lccccc}
\hline & Intent-to-treat & Model-based & Randomization & Model-based Randomization \\
& effect & $p$-value & $p$-value & $q$-value & $q$-value \\
\hline Weight-for-age (Z-score) & 0.027 & 0.891 & 0.880 & 0.891 & 1.000 \\
Not underweight (o/1) & 0.023 & 0.687 & 0.659 & 1.000 & 1.000 \\
Not severely underweight (o/1) & 0.032 & 0.220 & 0.233 & 1.000 & 1.000 \\
Height-for-age (Z-score) & 0.065 & 0.839 & 0.931 & 1.000 & 0.931 \\
Not stunted (o/1) & 0.038 & 0.609 & 0.633 & 1.000 & 1.000 \\
Not severely stunted (o/1) & 0.012 & 0.840 & 0.898 & 1.000 & 1.000 \\
Consumed animal-source foods in past day (o/1) & 0.061 & 0.627 & 0.613 & 1.000 & 1.000 \\
One-day dietary diversity score & -0.041 & 0.942 & 0.955 & 0.942 & 0.955 \\
\hline
\end{tabular}

Notes: ${ }^{*} p<0.10,{ }^{* *} p<0.05,{ }^{* * *} p<0.01$. See section 4.1 for the estimating equation. Z-scores and indicators for stunting and underweight based on standards from World Health Organization (2011). Model-based $p$-values and $q$-values calculated using standard errors and degrees of freedom estimated as in Young (2016). 
Table A.14: Model-based versus randomization inference: differences in intent-to-treat effects by gender, ages 6 to 60 months

\begin{tabular}{lccccc}
\hline & Intent-to-treat & Model-based & Randomization & Model-based Randomization \\
& effect & $p$-value & $p$-value & $q$-value & $q$-value \\
\hline Weight-for-age (Z-score) & 0.322 & 0.083 & 0.098 & 0.249 & 0.294 \\
Not underweight (o/1) & 0.068 & 0.427 & 0.480 & 0.513 & 0.577 \\
Not severely underweight (o/1) & 0.021 & 0.654 & 0.656 & 0.654 & 0.656 \\
Height-for-age (Z-score) & 0.474 & 0.138 & 0.119 & 0.275 & 0.238 \\
Not stunted (o/1) & 0.197 & 0.081 & 0.074 & 0.487 & 0.444 \\
Not severely stunted (o/1) & 0.131 & 0.167 & 0.169 & 0.251 & 0.254 \\
Consumed animal-source foods in past day (o/1) & -0.100 & 0.280 & 0.308 & 0.559 & 0.617 \\
One-day dietary diversity score & 0.027 & 0.929 & 0.904 & 0.929 & 0.904 \\
\hline
\end{tabular}

Notes: ${ }^{*} p<0.10,{ }^{* *} p<0.05,{ }^{* * *} p<0.01$. See section 4.1 for details on the estimating equation. Z-scores and indicators for stunting and underweight based on standards from World Health Organization (2011). Model-based $p$-values and $q$-values calculated using standard errors and degrees of freedom estimated as in Young (2016). 


\section{A.10 Bias from spillovers across communities}

Communities in the program's intervention area are poorly connected by infrastructure and mostly located in rugged terrain. Therefore spillovers across communities are unlikely, but we formally test for them below. To estimate spillovers for household-level outcomes, we exploit random variation in the density of households assigned to treatment and estimate the following equation:

$$
y_{h c s t}=\gamma_{s}+\rho y_{h c s t-1}+\delta \text { Treat }_{c}+\beta_{1} P_{d h c s}^{T}+\beta_{2}\left(\text { Treat }_{c} \times P_{d h c s}^{T}\right)+\varepsilon_{h c s t}
$$

where $\gamma_{s}$ is a stratum fixed effect, $P_{d h c s}^{T}$ is the proportion of households within distance $d$ of household $i$ in cluster $c$ from stratum $s$ that was assigned to treatment, $\delta$ is the average intent-to-treat effect in the absence of externalities, $\beta_{1}$ is the average marginal spillover effect among controls, and $\beta_{1}+\beta_{2}$ is the average marginal spillover effect among treated households. The estimating equation for spillover effects on children is similar to equation A.8 but modified to include lagged outcomes and dummy variables for availability of lagged outcome data as descrbied in section 4.1 of the main text.

We focus on spillover effects onto the control group since any program effects on the controls would bias the intent-to-treat estimates presented in the main text. The average spillover effect on control households is given by:

$$
\beta_{1} \bar{P}_{d}^{T}
$$

where $\bar{P}_{d}^{T}$ is the proportion of households assigned to treatment within a distance $d$, averaged over all control group observations. We estimate the effect given in equation A.9 for distances of one and two kilometers. Allowing for spillovers over greater distances results in little variation in the density of treated households.

Table A.15 gives our estimate of equation A.9 for household-level outcomes, while table A.16 does the same for impacts on children. At the household level, the spillover effect is negative and significant at the $10 \%$ level when allowing externalities across households up to two kilometers apart. There is no evidence for bias arising because of spillovers onto households assigned to the control group. 
Table A.15: Spillover effect on control households, household-level impacts

\begin{tabular}{|c|c|c|}
\hline & 1 kilometer & 2 kilometers \\
\hline Annual expenditure per adult male equivalent (log) & $\begin{array}{c}-0.099 \\
{[-0.367,0.170]} \\
(-0.367,0.170)\end{array}$ & $\begin{array}{c}-0.368 \\
{[-0.924,0.188]} \\
(-1.040,0.304)\end{array}$ \\
\hline Annual food expenditure per adult male equivalent (log) & $\begin{array}{c}-0.068 \\
{[-0.245,0.109]} \\
(-0.278,0.142)\end{array}$ & $\begin{array}{c}-0.207 \\
{[-0.611,0.197]} \\
(-0.611,0.197)\end{array}$ \\
\hline Daily calories per adult male equivalent (log) & $\begin{array}{c}-0.049 \\
{[-0.172,0.074]} \\
(-0.180,0.081)\end{array}$ & $\begin{array}{c}-0.145 \\
{[-0.405,0.116]} \\
(-0.405,0.116)\end{array}$ \\
\hline Daily grams of animal protein per adult male equivalent $(\log )$ & $\begin{array}{c}-0.147 \\
{[-0.751,0.458]} \\
(-0.751,0.458)\end{array}$ & $\begin{array}{c}-0.558 \\
{[-1.545,0.430]} \\
(-1.611,0.496)\end{array}$ \\
\hline Daily servings of eggs & $\begin{array}{c}-0.078 \\
{[-0.216,0.059]} \\
(-0.250,0.093)\end{array}$ & $\begin{array}{c}-0.209 \\
{[-0.474,0.056]} \\
(-0.547,0.129)\end{array}$ \\
\hline Eggs consumed per day per adult male equivalent & $\begin{array}{c}-0.277 \\
{[-0.900,0.347]} \\
(-0.986,0.432)\end{array}$ & $\begin{array}{c}-0.742 \\
{[-1.800,0.316]} \\
(-1.961,0.477)\end{array}$ \\
\hline Food consumption score & $\begin{array}{c}-2.203 \\
{[-5.916,1.510]} \\
(-7.530,3.124)\end{array}$ & $\begin{array}{c}-6.277 \\
{[-13.905,1.350]^{*}} \\
(-17.526,4.971)\end{array}$ \\
\hline Chickens owned (log) & $\begin{array}{c}0.046 \\
{[-0.278,0.371]} \\
(-0.297,0.390)\end{array}$ & $\begin{array}{c}0.164 \\
{[-0.739,1.067]} \\
(-0.876,1.205)\end{array}$ \\
\hline Naked-neck chickens owned (log) & $\begin{array}{c}0.093 \\
{[-0.235,0.421]} \\
(-0.280,0.465)\end{array}$ & $\begin{array}{c}0.232 \\
{[-0.691,1.155]} \\
(-0.946,1.410)\end{array}$ \\
\hline Uses poultry registry $(\mathrm{o} / 1)$ & $\begin{array}{c}0.004 \\
{[-0.022,0.030]} \\
(-0.022,0.030)\end{array}$ & $\begin{array}{c}0.038 \\
{[-0.021,0.096]} \\
(-0.050,0.126)\end{array}$ \\
\hline Eggs produced in last six months (log) & $\begin{array}{c}-0.211 \\
{[-0.715,0.293]} \\
(-0.839,0.417)\end{array}$ & $\begin{array}{c}-0.193 \\
{[-1.424,1.038]} \\
(-1.506,1.120)\end{array}$ \\
\hline Sold at least one egg in last six months $(\mathrm{o} / \mathrm{1})$ & $\begin{array}{c}0.021 \\
{[-0.023,0.065]} \\
(-0.043,0.085)\end{array}$ & $\begin{array}{c}0.009 \\
{[-0.075,0.093]} \\
(-0.075,0.093)\end{array}$ \\
\hline Observations & 791 & 791 \\
\hline
\end{tabular}

Notes: ${ }^{*} p<0.10,{ }^{* *} p<0.05,{ }^{* * *} p<0.01 ;{ }^{+} q<0.10,{ }^{++} q<0.05,{ }^{+++} q<0.01$, where $q$ is the false discovery rate. $95 \%$ confidence intervals in brackets, $95 \%$ false discovery rate-adjusted confidence intervals in parentheses. Each reported coefficient is an estimate of equation A.9, i.e., the average spillover effect on the control group of the proportion of households assigned to treatment within a specified vicinity. Standard errors and degrees of freedom estimated as in Young (2016). 
Table A.16: Spillover effect on control households, child-level impacts

\begin{tabular}{|c|c|c|c|c|}
\hline & \multicolumn{2}{|c|}{ Girls } & \multicolumn{2}{|c|}{ Boys } \\
\hline & 1 kilometer & 2 kilometers & 1 kilometer & 2 kilometers \\
\hline \multirow[t]{3}{*}{ Weight-for-age (Z-score) } & 0.012 & -0.019 & -0.087 & 0.010 \\
\hline & {$[-0.239,0.264]$} & {$[-0.502,0.465]$} & {$[-0.410,0.236]$} & {$[-0.426,0.446]$} \\
\hline & $(-0.239,0.264)$ & $(-0.502,0.465)$ & $(-0.447,0.274)$ & $(-0.426,0.446)$ \\
\hline \multirow[t]{3}{*}{ Not underweight (o/1) } & -0.019 & -0.096 & 0.023 & 0.083 \\
\hline & {$[-0.109,0.071]$} & {$[-0.248,0.056]$} & {$[-0.083,0.128]$} & {$[-0.108,0.274]$} \\
\hline & $(-0.119,0.081)$ & $(-0.330,0.138)$ & $(-0.088,0.134)$ & $(-0.146,0.312)$ \\
\hline \multirow[t]{3}{*}{ Not severely underweight (o/1) } & 0.031 & -0.025 & 0.002 & -0.028 \\
\hline & {$[-0.063,0.125]$} & {$[-0.135,0.085]$} & {$[-0.040,0.045]$} & {$[-0.099,0.043]$} \\
\hline & $(-0.091,0.153)$ & $(-0.157,0.107)$ & $(-0.040,0.045)$ & $(-0.108,0.051)$ \\
\hline \multirow[t]{3}{*}{ Height-for-age (Z-score) } & 0.054 & -0.131 & -0.187 & -0.359 \\
\hline & {$[-0.290,0.398]$} & {$[-0.868,0.607]$} & {$[-0.582,0.208]$} & {$[-0.944,0.226]$} \\
\hline & $(-0.307,0.415)$ & $(-0.955,0.694)$ & $(-0.792,0.418)$ & $(-1.129,0.412)$ \\
\hline \multirow[t]{3}{*}{ Not stunted (o/1) } & 0.028 & -0.060 & -0.027 & -0.127 \\
\hline & {$[-0.081,0.136]$} & {$[-0.247,0.128]$} & {$[-0.126,0.072]$} & {$[-0.274,0.020]^{*}$} \\
\hline & $(-0.101,0.157)$ & $(-0.308,0.188)$ & $(-0.146,0.092)$ & $(-0.351,0.098)$ \\
\hline \multirow[t]{3}{*}{ Not severely stunted (o/1) } & 0.049 & 0.026 & -0.035 & -0.054 \\
\hline & {$[-0.060,0.157]$} & {$[-0.216,0.268]$} & {$[-0.136,0.066]$} & {$[-0.217,0.109]$} \\
\hline & $(-0.114,0.211)$ & $(-0.229,0.281)$ & $(-0.168,0.098)$ & $(-0.226,0.117)$ \\
\hline \multirow[t]{3}{*}{ Consumed animal-source foods in past day $(\mathrm{o} / 1)$} & -0.073 & -0.300 & 0.030 & -0.190 \\
\hline & {$[-0.255,0.109]$} & {$[-0.744,0.144]$} & {$[-0.184,0.245]$} & {$[-0.499,0.119]$} \\
\hline & $(-0.255,0.109)$ & $(-0.744,0.144)$ & $(-0.227,0.288)$ & $(-0.561,0.181)$ \\
\hline \multirow[t]{3}{*}{ One-day dietary diversity score } & -0.311 & -0.895 & 0.066 & -0.188 \\
\hline & {$[-0.778,0.157]$} & {$[-2.180,0.389]$} & {$[-0.578,0.710]$} & {$[-1.666,1.289]$} \\
\hline & $(-0.869,0.247)$ & $(-2.442,0.652)$ & $(-0.578,0.710)$ & $(-1.666,1.289)$ \\
\hline Observations & 195 & 195 & 241 & 241 \\
\hline
\end{tabular}

Notes: ${ }^{*} p<0.10,{ }^{* *} p<0.05,{ }^{* * *} p<0.01 ;{ }^{+} q<0.10,{ }^{++} q<0.05,{ }^{++} q<0.01$, where $q$ is the false discovery rate. $95 \%$ confidence intervals in brackets, $95 \%$ false discovery rate-adjusted confidence intervals in parentheses. Each reported coefficient is an estimate of equation A.9, i.e., the average spillover effect on the control group of the proportion of households assigned to treatment within a specified vicinity. Estimation sample includes 196 girls ( 97 control) and 244 boys ( 131 control), all between the ages of 6 and 60 months. Standard errors and degrees of freedom estimated as in Young (2016). 


\section{A.11 Attrition bias}

In table A.17, we check the robustness of our estimated average household-level intent-to-treat effects to attrition. As described by Lee (2009), if we assume that assignment to treatment weakly affects attrition in the same direction for all households (e.g., for all households assignment to treatment either has no effect on attrition or induces attrition), then we can bound the intent-to-treat effect on the "never attriters", i.e., households that would always appear in both rounds of survey data regardless of treatment assignment. We bound the never-attriter effect using the method described in Lee (2009). None of our conclusions with respect to household-level outcomes is affected once we account for attrition as just described.

Among children, the assumptions needed to apply the "never-attriters" approach of Lee (2009) are inappropriate. Instead, we check for meaningful or statistically significant baseline differences in anthropometric indicators when comparing households that drop out of the sample to those that remain. Results are shown in table A.18. We see no evidence of potential bias in our estimated ITTs for children arising from attrition, and attrition bias does not seem to have differentially affected boys relative to girls. Note that we also check the robustness of our results for children to composition of the sample in appendices A.3, A.20, A.21, and A.22.

\section{A.12 Dropping covariates from child impact models}

In table A.19, we estimate average intent-to-treat effects on children without controlling for lagged outcomes, indicators for having children at baseline, or age. Impacts on weight-for-age, height-forage, and stunting among girls remain large and statistically significant. We continue to find no effect of the program on boys. While girls continue to exhibit larger intent-to-treat effects, we can no longer reject the null that the intent-to-treat effect is equal for boys and girls. Note that point esimates in table A.19 are all very similar to what we found in table 4 of the main text. Dropping lagged outcomes increases our standard errors. 
Table A.17: Bounds on household-level treatment effects accounting for attrition

\begin{tabular}{|c|c|c|}
\hline & Intent-to-treat effect & Control mean \\
\hline Annual expenditure per adult male equivalent (log) & $\begin{array}{c}-0.048 \\
\{-0.095,0.009\}\end{array}$ & 9.088 \\
\hline Annual food expenditure per adult male equivalent (log) & $\begin{array}{c}-0.053 \\
\{-0.106,-0.009\}\end{array}$ & 8.365 \\
\hline Daily calories per adult male equivalent (log) & $\begin{array}{c}-0.040 \\
\{-0.091,0.024\}\end{array}$ & 8.075 \\
\hline Daily grams of animal protein per adult male equivalent (log) & $\begin{array}{c}-0.135 \\
\{-0.647,-0.017\}\end{array}$ & 2.545 \\
\hline Daily servings of eggs & $\begin{array}{c}-0.056 \\
\{-0.225,-0.024\}\end{array}$ & 0.439 \\
\hline Eggs consumed per day per adult male equivalent & $\begin{array}{c}-0.071 \\
\{-0.902,0.197\}\end{array}$ & 1.766 \\
\hline Food consumption score & $\begin{array}{c}-1.333 \\
\{-2.220,-1.333\}\end{array}$ & 33.269 \\
\hline Chickens owned (log) & $\begin{array}{c}-0.162 \\
\{-0.783,-0.088\}\end{array}$ & 2.140 \\
\hline Naked-neck chickens owned (log) & $\begin{array}{c}-0.029 \\
\{-0.955,0.054\}\end{array}$ & 0.964 \\
\hline Uses poultry registry $(\mathrm{o} / 1)$ & $\begin{array}{c}0.028 \\
\{0.028,0.043\}\end{array}$ & 0.015 \\
\hline Eggs produced in last six months (log) & $\begin{array}{c}0.181 \\
\{-2.552,0.330\}\end{array}$ & 2.600 \\
\hline Sold at least one egg in last six months $(\mathrm{o} / 1)$ & $\begin{array}{c}0.002 \\
\{-0.001,0.035\}\end{array}$ & 0.075 \\
\hline Observations & 791 & \\
\hline
\end{tabular}

Notes: Bounds on the point estimate for the average intent-to-treat effect are in curly braces. The bounds bracket the average impact on "never attriters", i.e., households who would have been interviewed in both rounds regardless of treatment status, and were computed as in Lee (2009). All regressions include an intercept and an indicator for assignment to the treatment group. 
Table A.18: Differential attrition by treatment status

\begin{tabular}{lccc}
\hline & Girls & Boys & Difference \\
\hline Weight-for-age (Z-score) & 0.609 & 0.397 & 0.211 \\
& {$[-1.341,2.558]$} & {$[-1.711,2.506]$} & {$[-2.543,2.965]$} \\
Not underweight (o/1) & $(-1.736,2.954)$ & $(-1.813,2.607)$ & $(-2.543,2.965)$ \\
& -0.125 & 0.130 & -0.244 \\
Not severely underweight (o/1) & $-0.544,0.295]$ & {$[-0.156,0.417]$} & {$[-0.648,0.161]$} \\
& $(-0.594,0.344)$ & $(-0.239,0.500)$ & $(-0.767,0.280)$ \\
Height-for-age (Z-score) & $-0.458,0.148]$ & {$[-0.066,0.225]$} & {$[-0.553,0.098]$} \\
& $(-0.623,0.312)$ & $(-0.134,0.293)$ & $(-0.709,0.254)$ \\
Not stunted (o/1) & 0.753 & -0.086 & 0.790 \\
Observations & {$[-1.152,2.657]$} & {$[-3.130,2.958]$} & {$[-2.402,3.982]$} \\
\hline Not severely stunted (o/1) & $(-1.770,3.276)$ & $(-3.130,2.958)$ & $(-2.748,4.329)$ \\
& -0.121 & 0.112 & -0.254 \\
& {$[-0.873,0.630]$} & {$[-0.416,0.641]$} & {$[-1.027,0.518]$} \\
& $(-0.913,0.670)$ & $(-0.513,0.737)$ & $(-1.170,0.661)$ \\
& 0.028 & 0.079 & -0.061 \\
& $(-0.338,0.395)$ & $(-0.376,0.533)$ & $(-0.470,0.349)$ \\
& 257 & 327 & 584 \\
\hline
\end{tabular}

Notes: ${ }^{*} p<0.10,{ }^{* *} p<0.05,{ }^{* * *} p<0.01 ;{ }^{+} q<0.10,{ }^{++} q<0.05,{ }^{+++} q<0.01$, where $q$ is the false discovery rate. $95 \%$ confidence intervals in brackets, $95 \%$ false discovery rate-adjusted confidence intervals in parentheses. Standard errors and degrees of freedom estimated as in Young (2016). All regressions include an intercept, thirteen strata indicators, an indicator for not being interviewed in the follow-up survey round, an indicator for assignment to the treatment group, and the interaction between the attrition indicators and the treatment indicator. The "Difference" column includes all of these variables interacted with an indicator equal to one for girls. The first two columns show the coefficient on the interaction between the treatment and attrition indicators, while the third column shows the three-way interaction between gender, attrition, and treatment. 
Table A.19: Intent-to-treat effects for children: models that only adjust for stratum dummies

\begin{tabular}{|c|c|c|c|c|c|}
\hline & \multicolumn{2}{|l|}{ Girls } & \multicolumn{2}{|l|}{ Boys } & \multirow[b]{2}{*}{ Difference } \\
\hline & Intent-to-treat effect & Control mean & Intent-to-treat effect & Control mean & \\
\hline Weight-for-age (Z-score) & $\begin{array}{c}0.352 \\
{[0.050,0.653]^{* *}} \\
(-0.005,0.709)^{+}\end{array}$ & -1.305 & $\begin{array}{c}0.060 \\
{[-0.349,0.470]} \\
(-0.425,0.545)\end{array}$ & -1.163 & $\begin{array}{c}0.292 \\
{[-0.085,0.668]} \\
(-0.192,0.775)\end{array}$ \\
\hline Not underweight $(\mathrm{o} / \mathrm{1})$ & $\begin{array}{c}0.070 \\
{[-0.062,0.202]} \\
(-0.062,0.202)\end{array}$ & 0.773 & $\begin{array}{c}0.019 \\
{[-0.117,0.154]} \\
(-0.131,0.169)\end{array}$ & 0.802 & $\begin{array}{c}0.051 \\
{[-0.163,0.265]} \\
(-0.174,0.275)\end{array}$ \\
\hline Not severely underweight (o/1) & $\begin{array}{c}0.054 \\
{[-0.014,0.122]} \\
(-0.017,0.125)\end{array}$ & 0.938 & $\begin{array}{c}0.033 \\
{[-0.025,0.091]} \\
(-0.052,0.119)\end{array}$ & 0.954 & $\begin{array}{c}0.021 \\
{[-0.084,0.126]} \\
(-0.084,0.126)\end{array}$ \\
\hline Height-for-age (Z-score) & $\begin{array}{c}0.515 \\
{[0.112,0.917]^{* *}} \\
(-0.005,1.034)^{+}\end{array}$ & -2.209 & $\begin{array}{c}0.033 \\
{[-0.667,0.733]} \\
(-0.701,0.767)\end{array}$ & -1.997 & $\begin{array}{c}0.482 \\
{[-0.121,1.085]} \\
(-0.401,1.365)\end{array}$ \\
\hline Not stunted $(\mathrm{o} / \mathrm{1})$ & $\begin{array}{c}0.212 \\
{[0.096,0.327]^{* * *}} \\
(0.041,0.382)^{++}\end{array}$ & 0.412 & $\begin{array}{c}0.061 \\
{[-0.120,0.243]} \\
(-0.173,0.296)\end{array}$ & 0.420 & $\begin{array}{c}0.150 \\
{[-0.078,0.379]} \\
(-0.102,0.403)\end{array}$ \\
\hline Not severely stunted $(\mathrm{o} / \mathrm{1})$ & $\begin{array}{c}0.143 \\
{[-0.025,0.310]^{*}} \\
(-0.043,0.328)\end{array}$ & 0.784 & $\begin{array}{c}0.002 \\
{[-0.107,0.112]} \\
(-0.107,0.112)\end{array}$ & 0.794 & $\begin{array}{c}0.140 \\
{[-0.068,0.349]} \\
(-0.106,0.386)\end{array}$ \\
\hline Consumed animal-source foods in past day $(\mathrm{o} / 1)$ & $\begin{array}{c}-0.042 \\
{[-0.359,0.275]} \\
(-0.417,0.334)\end{array}$ & 0.598 & $\begin{array}{c}0.050 \\
{[-0.245,0.344]} \\
(-0.298,0.398)\end{array}$ & 0.557 & $\begin{array}{c}-0.092 \\
{[-0.289,0.105]} \\
(-0.324,0.141)\end{array}$ \\
\hline One-day dietary diversity score & $\begin{array}{c}-0.032 \\
{[-1.517,1.452]} \\
(-1.517,1.452)\end{array}$ & 5.649 & $\begin{array}{c}-0.179 \\
{[-1.788,1.430]} \\
(-1.788,1.430)\end{array}$ & 5.534 & $\begin{array}{c}0.147 \\
{[-0.576,0.869]} \\
(-0.576,0.869)\end{array}$ \\
\hline Observations & 196 & & 244 & & 440 \\
\hline
\end{tabular}

Notes: ${ }^{*} p<0.10,{ }^{* *} p<0.05,{ }^{* * *} p<0.01 ;{ }^{+} q<0.10,{ }^{++} q<0.05,{ }^{+++} q<0.01$, where $q$ is the false discovery rate. $95 \%$ confidence intervals in brackets, $95 \%$ false discovery rate-adjusted confidence intervals in parentheses. Standard errors and degrees of freedom estimated as in Young (2016). All regressions include an intercept, an indicator for assignment treatment, and indicators for thirteen strata. 


\section{A.13 Average intent-to-treat effects for children estimated with machine learning}

The method of Chernozhukov et al. (2018b) is useful as a robustness check because it is designed to mitigate overfitting. Checking whether the large impacts on girls show up when using the Chernozhukov et al. (2018b) to estimate average intent-to-treat effects rather than regression on the whole sample is therefore of interest. We present these results in table A.20 for girls and table A.21. Our results for girls and boys are robust to changing our estimation approach to one that is based on machine learning.

\section{A.14 Full machine learning results for child-level outcomes}

In this section we show full machine learning results for household-level outcomes. The full results include 90\% confidence intervals for the best linear prediction regression and group average intentto-treat effects, rather than only showing point estimates and indicators of statistical significance. We also show the results of classification analysis for all outcomes regardless of evidence for treatment effect heterogeneity. 
Table A.20: Best linear predictor of the average intent-to-treat effect and impact heterogeneity: outcomes for girls

\begin{tabular}{lccc}
\hline & Intent-to-treat & Heterogeneity & ML method \\
\hline Weight-for-age (Z-score) & 0.344 & -0.535 & Random forest \\
& {$[0.088,0.612]^{* *}$} & {$[-1.891,0.850]$} & \\
Not underweight $(\mathrm{o} / \mathrm{1})$ & $(0.047,0.658)^{+}$ & $(-2.050,0.975)$ & \\
& 0.080 & 0.594 & Elastic net \\
& {$[-0.058,0.209]$} & {$[-1.197,2.521]$} & \\
Height-for-age (Z-score) & $(-0.068,0.221)$ & $(-1.293,2.642)$ & \\
& 0.532 & -0.076 & Elastic net \\
& {$[0.151,0.900]^{* *}$} & {$[-1.242,1.147]$} & \\
Not stunted (o/1) & $(0.050,1.008)^{+}$ & $(-1.242,1.147)$ & \\
& 0.230 & -1.353 & Random forest \\
& {$[0.094,0.381]^{* * *}$} & {$[-2.891,0.136]$} & \\
Consumed animal-source foods in past day $(0 / 1)$ & $(0.044,0.435)^{++}$ & $(-3.338,0.532)$ & \\
& -0.020 & 0.854 & Random forest \\
& {$[-0.201,0.149]$} & {$[-0.388,2.028]$} & \\
One-day dietary diversity score & $(-0.201,0.149)$ & $(-0.769,2.363)$ & \\
& -0.041 & 0.410 & Elastic net \\
& {$[-0.719,0.641]$} & {$[-0.308,1.230]$} & \\
& $(-0.745,0.679)$ & $(-0.394,1.335)$ & \\
\hline
\end{tabular}

Notes: ${ }^{*} p<0.10,{ }^{* *} p<0.05,{ }^{* * *} p<0.01 ;{ }^{+} q<0.10,{ }^{++} q<0.05,{ }^{+++} q<0.01$, where $q$ is the false discovery rate. $90 \%$ confidence intervals in brackets, $90 \%$ false discovery rate-adjusted confidence intervals in parentheses. 
Table A.21: Best linear predictor of the average intent-to-treat effect and impact heterogeneity: outcomes for boys

\begin{tabular}{lccc}
\hline & Intent-to-treat & Heterogeneity & ML method \\
\hline Weight-for-age (Z-score) & 0.026 & 0.389 & Random forest \\
& {$[-0.357,0.370]$} & {$[-0.631,1.450]$} & \\
Not underweight $(\mathrm{o} / \mathrm{1})$ & $(-0.438,0.425)$ & $(-0.887,1.609)$ & \\
& 0.018 & -0.103 & Elastic net \\
& {$[-0.105,0.144]$} & {$[-2.220,2.062]$} & \\
Height-for-age (Z-score) & $(-0.117,0.157)$ & $(-2.220,2.062)$ & \\
& 0.089 & 0.274 & Elastic net \\
& {$[-0.457,0.611]$} & {$[-0.926,1.814]$} & \\
Not stunted (o/1) & $(-0.484,0.632)$ & $(-0.964,1.873)$ & \\
& 0.052 & 0.139 & Random forest \\
& {$[-0.085,0.200]$} & {$[-0.946,1.166]$} & \\
Consumed animal-source foods in past day $(0 / 1)$ & $(-0.120,0.233)$ & $(-1.071,1.272)$ & \\
& 0.090 & 0.824 & Elastic net \\
& {$[-0.086,0.269]$} & {$[-0.005,1.769]$} & \\
One-day dietary diversity score & $(-0.165,0.338)$ & $(-0.347,2.131)$ & \\
& 0.136 & 0.494 & Elastic net \\
& {$[-0.558,0.863]$} & {$[-0.133,1.215]$} & \\
& $(-0.558,0.863)$ & $(-0.213,1.443)$ & \\
\hline
\end{tabular}

Notes: ${ }^{*} p<0.10,{ }^{* *} p<0.05,{ }^{* * *} p<0.01{ }^{+} q<0.10,{ }^{++} q<0.05,{ }^{+++} q<0.01$, where $q$ is the false discovery rate. $90 \%$ confidence intervals in brackets, $90 \%$ false discovery rate-adjusted confidence intervals in parentheses. 
Table A.22: Best linear predictor of the average intent-to-treat effect and impact heterogeneity: child outcomes

\begin{tabular}{lcccc}
\hline & Intent-to-treat & Heterogeneity & ML method \\
\hline Weight-for-age (Z-score) & 0.154 & 0.572 & Elastic net \\
& {$[-0.086,0.388]$} & {$[-0.457,1.603]$} & \\
Not underweight (o/1) & $(-0.112,0.408)$ & $(-0.718,1.813)$ & \\
& 0.017 & 0.239 & Random forest \\
& {$[-0.054,0.090]$} & {$[-0.783,1.294]$} & \\
Height-for-age (Z-score) & $(-0.054,0.090)$ & $(-0.807,1.326)$ & \\
& 0.245 & 0.213 & Elastic net \\
& {$[-0.092,0.569]$} & {$[-1.052,1.410]$} & \\
Not stunted (o/1) & $(-0.153,0.654)$ & $(-1.095,1.475)$ & \\
& 0.111 & -0.566 & Random forest \\
& {$[0.029,0.198]^{* *}$} & {$[-1.513,0.373]$} & \\
Consumed animal-source foods in past day (o/1) & $(-0.010,0.234)$ & $(-1.992,0.953)$ & \\
& 0.075 & 1.028 & Random forest \\
& {$[-0.027,0.175]$} & {$[0.211,1.932]^{* *}$} & \\
One-day dietary diversity score & $(-0.039,0.189)$ & $(0.115,2.083)^{+}$ & \\
& 0.174 & 0.917 & Random forest \\
& {$[-0.220,0.552]$} & {$[0.209,1.635]^{* *}$} & \\
& $(-0.234,0.575)$ & $(-0.006,1.920)$ & \\
\hline
\end{tabular}

Notes: ${ }^{*} p<0.10,{ }^{* *} p<0.05,{ }^{* * *} p<0.01 ;{ }^{+} q<0.10,{ }^{++} q<0.05,{ }^{+++} q<0.01$, where $q$ is the false discovery rate. $90 \%$ confidence intervals in brackets, $90 \%$ false discovery rate-adjusted confidence intervals in parentheses. 
Table A.23: Intent-to-treat effects for most and least affected children

\begin{tabular}{lccc}
\hline & Most & Least & (Most - Least) \\
\hline Weight-for-age (Z-score) & 0.360 & -0.022 & 0.411 \\
& {$[-0.093,0.813]$} & {$[-0.544,0.509]$} & {$[-0.373,1.152]$} \\
Not underweight $(\mathrm{o} / 1)$ & $(-0.160,0.902)$ & $(-0.573,0.535)$ & $(-0.490,1.296)$ \\
& 0.061 & -0.018 & 0.066 \\
Height-for-age $(Z-$-score $)$ & {$[-0.126,0.236]$} & {$[-0.209,0.172]$} & {$[-0.232,0.364]$} \\
& $(-0.136,0.244)$ & $(-0.209,0.172)$ & $(-0.232,0.364)$ \\
Not stunted (o/1) & 0.316 & 0.307 & 0.036 \\
& {$[-0.414,1.057]$} & {$[-0.361,0.920]$} & {$[-1.043,1.058]$} \\
& $(-0.490,1.129)$ & $(-0.500,1.044)$ & $(-1.149,1.197)$ \\
Consumed animal-source foods in past day $(0 / 1)$ & -0.001 & 0.212 & -0.207 \\
& {$[-0.218,0.224]$} & {$[-0.018,0.438]$} & {$[-0.568,0.153]$} \\
& $(-0.218,0.224)$ & $(-0.132,0.539)$ & $(-0.704,0.257)$ \\
One-day dietary diversity score & $0.058,0.504]^{* *}$ & {$[-0.339,0.171]$} & {$[-0.038,0.739]$} \\
& $(-0.032,0.584)$ & $(-0.365,0.200)$ & $(-0.038,0.739)$ \\
& 0.854 & -0.409 & 1.231 \\
& {$[0.031,1.691]^{*}$} & {$[-1.233,0.438]$} & {$[-0.061,2.595]$} \\
& $(-0.235,1.904)$ & $(-1.450,0.709)$ & $(-0.167,2.697)$ \\
\hline
\end{tabular}

Notes: ${ }^{*} p<0.10,{ }^{* *} p<0.05,{ }^{* * *} p<0.01 ;{ }^{+} q<0.10,{ }^{++} q<0.05,{ }^{+++} q<0.01$, where $q$ is the false discovery rate. $90 \%$ confidence intervals in brackets, $90 \%$ false discovery rate-adjusted confidence intervals in parentheses. 
Table A.24: Classification analysis for child outcomes

\begin{tabular}{|c|c|c|c|c|}
\hline & \multirow[b]{2}{*}{$\begin{array}{l}\text { Sample } \\
\text { average }\end{array}$} & \multicolumn{3}{|c|}{ (Most - Least) } \\
\hline & & Weight-for-age & Not underweight $(\mathrm{o} / \mathrm{1})$ & Height-for-age \\
\hline Woman (o/1) & 0.445 & $\begin{array}{c}0.024 \\
{[-0.142,0.190]} \\
(-0.149,0.196)\end{array}$ & $\begin{array}{c}0.028 \\
{[-0.138,0.191]} \\
(-0.146,0.199)\end{array}$ & $\begin{array}{c}0.014 \\
{[-0.152,0.180]} \\
(-0.163,0.191)\end{array}$ \\
\hline Age in months & 31.743 & $\begin{array}{c}6.625 \\
{[1.625,11.637]^{* *}} \\
(0.595,12.612)^{++}\end{array}$ & $\begin{array}{c}7.264 \\
{[1.966,12.494]^{* *}} \\
(0.222,14.074)^{+}\end{array}$ & $\begin{array}{c}5.903 \\
{[0.296,11.154]^{*}} \\
(-1.158,12.687)\end{array}$ \\
\hline Household average weight-for-age & -0.616 & $\begin{array}{c}0.212 \\
{[-0.222,0.633]} \\
(-0.266,0.672)\end{array}$ & $\begin{array}{c}-0.135 \\
{[-0.613,0.358]} \\
(-0.623,0.369)\end{array}$ & $\begin{array}{c}-0.332 \\
{[-0.767,0.130]} \\
(-0.853,0.236)\end{array}$ \\
\hline Household average height-for-age & -1.056 & $\begin{array}{c}0.402 \\
{[-0.211,0.964]} \\
(-0.297,1.045)\end{array}$ & $\begin{array}{c}-0.009 \\
{[-0.616,0.622]} \\
(-0.644,0.658)\end{array}$ & $\begin{array}{c}-0.312 \\
{[-0.907,0.272]} \\
(-0.974,0.340)\end{array}$ \\
\hline Baseline weight-for-age & -0.155 & $\begin{array}{c}-0.115 \\
{[-0.434,0.226]} \\
(-0.459,0.251)\end{array}$ & $\begin{array}{c}-0.209 \\
{[-0.581,0.151]} \\
(-0.625,0.191)\end{array}$ & $\begin{array}{c}-0.604 \\
{[-0.961,-0.231]^{* * *}} \\
(-1.165,0.001)\end{array}$ \\
\hline Baseline height-for-age & -0.285 & $\begin{array}{c}-0.068 \\
{[-0.524,0.378]} \\
(-0.527,0.381)\end{array}$ & $\begin{array}{c}-0.153 \\
{[-0.648,0.354]} \\
(-0.664,0.370)\end{array}$ & $\begin{array}{c}-0.524 \\
{[-1.022,-0.034]^{*}} \\
(-1.183,0.129)\end{array}$ \\
\hline Meters above sea level & 765.182 & $\begin{array}{c}19.446 \\
{[-80.598,119.490]} \\
(-82.912,121.803)\end{array}$ & $\begin{array}{c}123.650 \\
{[25.835,220.286]^{* *}} \\
(-3.327,248.566)\end{array}$ & $\begin{array}{c}47.157 \\
{[-51.146,143.589]} \\
(-62.388,153.270)\end{array}$ \\
\hline Rainfall (millimeters) & 467.225 & $\begin{array}{c}-164.254 \\
{[-268.674,-59.920]^{* * *}} \\
(-297.185,-32.403)^{++}\end{array}$ & $\begin{array}{c}-194.514 \\
{[-297.616,-91.412]^{* * *}} \\
(-343.240,-45.788)^{+++}\end{array}$ & $\begin{array}{c}-153.964 \\
{[-263.822,-46.906]^{* * * *}} \\
(-319.923,7.456)\end{array}$ \\
\hline Days with extreme temperatures & 173.961 & $\begin{array}{c}-4.306 \\
{[-24.029,15.578]} \\
(-24.611,16.244)\end{array}$ & $\begin{array}{c}-9.125 \\
{[-28.523,10.630]} \\
(-30.217,12.445)\end{array}$ & $\begin{array}{c}-9.222 \\
{[-29.318,10.832]} \\
(-31.413,12.894)\end{array}$ \\
\hline Household size & 4.102 & $\begin{array}{c}-0.035 \\
{[-0.604,0.524]} \\
(-0.613,0.534)\end{array}$ & $\begin{array}{c}0.271 \\
{[-0.336,0.870]} \\
(-0.383,0.913)\end{array}$ & $\begin{array}{c}-0.036 \\
{[-0.627,0.525]} \\
(-0.644,0.541)\end{array}$ \\
\hline
\end{tabular}

Notes: ${ }^{*} p<0.10,{ }^{* *} p<0.05,{ }^{* *} p<0.01 ;{ }^{+} q<0.10,{ }^{++} q<0.05,{ }^{+++} q<0.01$, where $q$ is the false discovery rate. $90 \%$ confidence intervals in brackets, $90 \%$ false discovery rate-adjusted confidence intervals in parentheses. Standard errors are of the heteroskedasticity-robust "HC1" variety (MacKinnon and White, 1985). All characteristics displayed in the rows are measured at baseline except for gender, age, weather variables, and altitude of the dwelling. 
Table A.25: Classification analysis for child outcomes, continued

\begin{tabular}{|c|c|c|c|c|}
\hline & \multirow[b]{2}{*}{$\begin{array}{l}\text { Sample } \\
\text { average }\end{array}$} & \multicolumn{3}{|c|}{ (Most - Least) } \\
\hline & & Weight-for-age & Not underweight $(\mathrm{o} / 1)$ & Height-for-age \\
\hline Dependency ratio & 0.488 & $\begin{array}{c}-0.100 \\
{[-0.160,-0.039]^{* * *}} \\
(-0.180,-0.019)^{++}\end{array}$ & $\begin{array}{c}-0.041 \\
{[-0.100,0.018]} \\
(-0.109,0.027)\end{array}$ & $\begin{array}{c}-0.056 \\
{[-0.115,0.006]} \\
(-0.130,0.021)\end{array}$ \\
\hline Average education (years) & 2.639 & $\begin{array}{c}1.153 \\
{[0.020,2.257]^{*}} \\
(-0.176,2.442)\end{array}$ & $\begin{array}{c}0.986 \\
{[-0.158,2.087]} \\
(-0.416,2.320)\end{array}$ & $\begin{array}{c}0.736 \\
{[-0.336,1.891]} \\
(-0.546,2.103)\end{array}$ \\
\hline Wealth (log) & 9.185 & $\begin{array}{c}0.947 \\
{[0.543,1.344]^{* * *}} \\
(0.379,1.500)^{+++}\end{array}$ & $\begin{array}{c}0.583 \\
{[0.181,0.994]^{* * *}} \\
(0.025,1.152)^{+}\end{array}$ & $\begin{array}{c}0.113 \\
{[-0.311,0.552]} \\
(-0.313,0.555)\end{array}$ \\
\hline Dwelling has dirt floor (o/1) & 0.748 & $\begin{array}{c}-0.472 \\
{[-0.599,-0.343]^{* * *}} \\
(-0.677,-0.263)^{+++}\end{array}$ & $\begin{array}{c}-0.083 \\
{[-0.224,0.047]} \\
(-0.240,0.063)\end{array}$ & $\begin{array}{c}-0.125 \\
{[-0.268,0.027]} \\
(-0.301,0.062)\end{array}$ \\
\hline Micronutrient supplement (o/1) & 0.511 & $\begin{array}{c}-0.042 \\
{[-0.207,0.124]} \\
(-0.215,0.132)\end{array}$ & $\begin{array}{c}0.111 \\
{[-0.053,0.275]} \\
(-0.075,0.297)\end{array}$ & $\begin{array}{c}0.111 \\
{[-0.053,0.275]} \\
(-0.079,0.302)\end{array}$ \\
\hline Conditional cash transfer recipient (o/1) & 0.409 & $\begin{array}{c}-0.236 \\
{[-0.392,-0.080]^{* * *}} \\
(-0.428,-0.044)^{++}\end{array}$ & $\begin{array}{c}-0.125 \\
{[-0.286,0.036]} \\
(-0.319,0.069)\end{array}$ & $\begin{array}{c}-0.097 \\
{[-0.260,0.064]} \\
(-0.283,0.088)\end{array}$ \\
\hline Women's share of wealth & 0.306 & $\begin{array}{c}-0.001 \\
{[-0.102,0.105]} \\
(-0.110,0.112)\end{array}$ & $\begin{array}{c}-0.073 \\
{[-0.175,0.029]} \\
(-0.194,0.046)\end{array}$ & $\begin{array}{c}-0.004 \\
{[-0.107,0.098]} \\
(-0.112,0.103)\end{array}$ \\
\hline Had credit at baseline $(\mathrm{o} / \mathrm{1})$ & 0.116 & $\begin{array}{c}0.125 \\
{[0.015,0.224]^{*}} \\
(-0.004,0.246)\end{array}$ & $\begin{array}{c}0.083 \\
{[-0.026,0.181]} \\
(-0.046,0.202)\end{array}$ & $\begin{array}{c}0.042 \\
{[-0.075,0.143]} \\
(-0.085,0.152)\end{array}$ \\
\hline Distance to market (minutes) & 64.264 & $\begin{array}{c}-26.694 \\
{[-42.985,-9.979]^{* * *}} \\
(-47.665,-5.089)^{++}\end{array}$ & $\begin{array}{c}-8.472 \\
{[-25.140,8.148]} \\
(-26.783,9.821)\end{array}$ & $\begin{array}{c}-8.819 \\
{[-26.416,8.656]} \\
(-28.804,11.257)\end{array}$ \\
\hline Dwelling has water filter $(\mathrm{o} / 1)$ & 0.132 & $\begin{array}{c}0.069 \\
{[-0.044,0.176]} \\
(-0.058,0.189)\end{array}$ & $\begin{array}{c}-0.000 \\
{[-0.110,0.110]} \\
(-0.117,0.117)\end{array}$ & $\begin{array}{c}0.125 \\
{[0.013,0.235]^{*}} \\
(-0.031,0.274)\end{array}$ \\
\hline
\end{tabular}

Notes: ${ }^{*} p<0.10,{ }^{* *} p<0.05,{ }^{* * *} p<0.01 ;{ }^{+} q<0.10,{ }^{++} q<0.05,{ }^{+++} q<0.01$, where $q$ is the false discovery rate. $90 \%$ confidence intervals in brackets, $90 \%$ false discovery rate-adjusted confidence intervals in parentheses. Standard errors are of the heteroskedasticity-robust "HC1" variety (MacKinnon and White, 1985). 
Table A.26: Classification analysis for child outcomes, continued

\begin{tabular}{|c|c|c|c|c|}
\hline & \multirow[b]{2}{*}{$\begin{array}{l}\text { Sample } \\
\text { average }\end{array}$} & \multicolumn{3}{|c|}{ (Most - Least) } \\
\hline & & Weight-for-age & Not underweight (o/1) & Height-for-age \\
\hline Connected to water network $(\mathrm{o} / \mathbf{1})$ & 0.577 & $\begin{array}{c}0.125 \\
{[-0.038,0.284]} \\
(-0.061,0.307)\end{array}$ & $\begin{array}{c}-0.056 \\
{[-0.220,0.109]} \\
(-0.221,0.110)\end{array}$ & $\begin{array}{c}-0.056 \\
{[-0.216,0.109]} \\
(-0.216,0.109)\end{array}$ \\
\hline Connected to electricity network (o/1) & 0.461 & $\begin{array}{c}0.427 \\
{[0.276,0.577]^{* * *}} \\
(0.209,0.644)^{+++}\end{array}$ & $\begin{array}{c}0.111 \\
{[-0.051,0.276]} \\
(-0.074,0.300)\end{array}$ & $\begin{array}{c}0.222 \\
{[0.061,0.381]^{* *}} \\
(-0.011,0.451)\end{array}$ \\
\hline Social capital index, household & 1.466 & $\begin{array}{c}0.514 \\
{[-0.123,1.123]} \\
(-0.222,1.222)\end{array}$ & $\begin{array}{c}0.819 \\
{[0.237,1.386]^{* *}} \\
(0.042,1.576)^{+}\end{array}$ & $\begin{array}{c}-0.042 \\
{[-0.685,0.586]} \\
(-0.722,0.622)\end{array}$ \\
\hline Group memberships (count) & 0.807 & $\begin{array}{c}0.208 \\
{[-0.204,0.610]} \\
(-0.253,0.663)\end{array}$ & $\begin{array}{c}0.347 \\
{[-0.044,0.720]} \\
(-0.123,0.819)\end{array}$ & $\begin{array}{c}-0.083 \\
{[-0.504,0.332]} \\
(-0.513,0.342)\end{array}$ \\
\hline Calories (log) & 8.341 & $\begin{array}{c}0.508 \\
{[0.259,0.747]^{* * *}} \\
(0.168,0.838)^{+++}\end{array}$ & $\begin{array}{c}0.489 \\
{[0.239,0.736]^{* * *}} \\
(0.089,0.879)^{+++}\end{array}$ & $\begin{array}{c}0.236 \\
{[-0.017,0.495]} \\
(-0.079,0.559)\end{array}$ \\
\hline Animal protein (log grams) & 1.572 & $\begin{array}{c}1.239 \\
{[0.835,1.642]^{* * *}} \\
(0.621,1.848)^{+++}\end{array}$ & $\begin{array}{c}0.809 \\
{[0.383,1.240]^{* * *}} \\
(0.191,1.457)^{+++}\end{array}$ & $\begin{array}{c}0.579 \\
{[0.154,1.005]^{* *}} \\
(-0.013,1.172)\end{array}$ \\
\hline Food consumption score & 19.708 & $\begin{array}{c}4.007 \\
{[1.438,6.660]^{* * *}} \\
(0.785,7.319)^{++}\end{array}$ & $\begin{array}{c}3.104 \\
{[0.507,5.693]^{* *}} \\
(-0.192,6.438)\end{array}$ & $\begin{array}{c}1.785 \\
{[-0.762,4.424]} \\
(-1.167,4.919)\end{array}$ \\
\hline Egg unit value (quetzales/egg) & 1.186 & $\begin{array}{c}-0.008 \\
{[-0.046,0.030]} \\
(-0.048,0.032)\end{array}$ & $\begin{array}{c}0.003 \\
{[-0.036,0.042]} \\
(-0.036,0.042)\end{array}$ & $\begin{array}{c}0.001 \\
{[-0.037,0.038]} \\
(-0.038,0.039)\end{array}$ \\
\hline Eggs produced (log) & 1.401 & $\begin{array}{c}0.327 \\
{[-0.426,1.087]} \\
(-0.493,1.153)\end{array}$ & $\begin{array}{c}-0.047 \\
{[-0.796,0.695]} \\
(-0.808,0.706)\end{array}$ & $\begin{array}{c}-0.018 \\
{[-0.791,0.730]} \\
(-0.855,0.795)\end{array}$ \\
\hline Chickens owned (log) & 2.322 & $\begin{array}{c}0.049 \\
{[-0.412,0.509]} \\
(-0.412,0.509)\end{array}$ & $\begin{array}{c}0.115 \\
{[-0.333,0.570]} \\
(-0.351,0.589)\end{array}$ & $\begin{array}{c}-0.008 \\
{[-0.476,0.463]} \\
(-0.493,0.482)\end{array}$ \\
\hline
\end{tabular}

Notes: ${ }^{*} p<0.10,{ }^{* *} p<0.05,{ }^{* * *} p<0.01 ;{ }^{+} q<0.10,{ }^{++} q<0.05,{ }^{+++} q<0.01$, where $q$ is the false discovery rate. $90 \%$ confidence intervals in brackets, $90 \%$ false discovery rate-adjusted confidence intervals in parentheses. Standard errors are of the heteroskedasticity-robust "HC1" variety (MacKinnon and White, 1985). 
Table A.27: Classification analysis for child outcomes, continued

\begin{tabular}{|c|c|c|c|c|}
\hline & \multirow[b]{2}{*}{$\begin{array}{l}\text { Sample } \\
\text { average }\end{array}$} & \multicolumn{3}{|c|}{ (Most - Least) } \\
\hline & & Not stunted (o/1) & $\begin{array}{l}\text { Animal source foods } \\
(\mathrm{o} / \mathrm{1})\end{array}$ & $\begin{array}{c}\text { Dietary diversity } \\
\text { (count) }\end{array}$ \\
\hline Woman $(\mathrm{o} / \mathrm{i})$ & 0.445 & $\begin{array}{c}-0.006 \\
{[-0.172,0.160]} \\
(-0.179,0.166)\end{array}$ & $\begin{array}{c}-0.000 \\
{[-0.166,0.164]} \\
(-0.168,0.167)\end{array}$ & $\begin{array}{c}-0.014 \\
{[-0.178,0.152]} \\
(-0.180,0.154)\end{array}$ \\
\hline Age in months & 31.743 & $\begin{array}{c}8.597 \\
{[3.529,13.628]^{* * *}} \\
(0.379,16.815)^{+}\end{array}$ & $\begin{array}{c}0.875 \\
{[-4.288,6.018]} \\
(-4.943,6.644)\end{array}$ & $\begin{array}{c}2.528 \\
{[-2.680,7.615]} \\
(-3.455,8.376)\end{array}$ \\
\hline Household average weight-for-age & -0.616 & $\begin{array}{c}-0.136 \\
{[-0.568,0.302]} \\
(-0.620,0.353)\end{array}$ & $\begin{array}{c}-0.191 \\
{[-0.630,0.243]} \\
(-0.732,0.344)\end{array}$ & $\begin{array}{c}-0.138 \\
{[-0.594,0.301]} \\
(-0.598,0.304)\end{array}$ \\
\hline Household average height-for-age & -1.056 & $\begin{array}{c}-0.053 \\
{[-0.640,0.540]} \\
(-0.668,0.572)\end{array}$ & $\begin{array}{c}-0.386 \\
{[-0.980,0.196]} \\
(-1.132,0.349)\end{array}$ & $\begin{array}{c}-0.724 \\
{[-1.278,-0.149]^{* *}} \\
(-1.504,0.120)\end{array}$ \\
\hline Baseline weight-for-age & -0.155 & $\begin{array}{c}-0.255 \\
{[-0.602,0.083]} \\
(-0.736,0.192)\end{array}$ & $\begin{array}{c}-0.050 \\
{[-0.412,0.295]} \\
(-0.453,0.329)\end{array}$ & $\begin{array}{c}-0.021 \\
{[-0.381,0.316]} \\
(-0.412,0.346)\end{array}$ \\
\hline Baseline height-for-age & -0.285 & $\begin{array}{c}-0.309 \\
{[-0.772,0.144]} \\
(-0.886,0.255)\end{array}$ & $\begin{array}{c}-0.056 \\
{[-0.555,0.402]} \\
(-0.608,0.459)\end{array}$ & $\begin{array}{c}-0.359 \\
{[-0.830,0.105]} \\
(-0.911,0.179)\end{array}$ \\
\hline Meters above sea level & 765.182 & $\begin{array}{c}7.436 \\
{[-88.924,107.457]} \\
(-95.326,114.164)\end{array}$ & $\begin{array}{c}31.608 \\
{[-68.894,134.567]} \\
(-74.475,140.273)\end{array}$ & $\begin{array}{c}-1.286 \\
{[-102.302,97.459]} \\
(-112.317,108.214)\end{array}$ \\
\hline Rainfall (millimeters) & 467.225 & $\begin{array}{c}-176.213 \\
{[-280.569,-70.848]^{* * *}} \\
(-333.070,-17.075)^{++}\end{array}$ & $\begin{array}{c}37.382 \\
{[-70.783,146.644]} \\
(-75.049,150.929)\end{array}$ & $\begin{array}{c}110.114 \\
{[3.418,216.809]^{*}} \\
(-27.797,248.025)\end{array}$ \\
\hline Days with extreme temperatures & 173.961 & $\begin{array}{c}-3.750 \\
{[-23.945,16.019]} \\
(-26.037,17.963)\end{array}$ & $\begin{array}{c}-4.764 \\
{[-24.611,15.577]} \\
(-26.339,17.173)\end{array}$ & $\begin{array}{c}-8.611 \\
{[-28.361,11.475]} \\
(-30.684,14.207)\end{array}$ \\
\hline Household size & 4.102 & $\begin{array}{c}0.146 \\
{[-0.463,0.738]} \\
(-0.519,0.791)\end{array}$ & $\begin{array}{c}-0.101 \\
{[-0.670,0.453]} \\
(-0.689,0.471)\end{array}$ & $\begin{array}{c}-0.174 \\
{[-0.740,0.410]} \\
(-0.767,0.439)\end{array}$ \\
\hline
\end{tabular}

Notes: ${ }^{*} p<0.10,{ }^{* *} p<0.05,{ }^{* * *} p<0.01 ;{ }^{+} q<0.10,{ }^{++} q<0.05,{ }^{+++} q<0.01$, where $q$ is the false discovery rate. $90 \%$ confidence intervals in brackets, $90 \%$ false discovery rate-adjusted confidence intervals in parentheses. Standard errors are of the heteroskedasticity-robust "HC1" variety (MacKinnon and White, 1985). All characteristics displayed in the rows are measured at baseline except for gender, age, weather variables, and altitude of the dwelling. 
Table A.28: Classification analysis for child outcomes, continued

\begin{tabular}{|c|c|c|c|c|}
\hline & \multirow[b]{2}{*}{$\begin{array}{l}\text { Sample } \\
\text { average }\end{array}$} & \multicolumn{3}{|c|}{ (Most - Least) } \\
\hline & & Not stunted $(\mathrm{o} / \mathrm{1})$ & $\begin{array}{l}\text { Animal source foods } \\
(\mathrm{o} / \mathrm{1})\end{array}$ & $\begin{array}{c}\text { Dietary diversity } \\
\text { (count) }\end{array}$ \\
\hline Dependency ratio & 0.488 & $\begin{array}{c}-0.043 \\
{[-0.101,0.015]} \\
(-0.120,0.032)\end{array}$ & $\begin{array}{c}0.067 \\
{[0.008,0.127]^{*}} \\
(-0.013,0.149)\end{array}$ & $\begin{array}{c}0.002 \\
{[-0.058,0.064]} \\
(-0.064,0.070)\end{array}$ \\
\hline Average education (years) & 2.639 & $\begin{array}{c}0.569 \\
{[-0.540,1.687]} \\
(-0.746,1.884)\end{array}$ & $\begin{array}{c}-0.611 \\
{[-1.707,0.441]} \\
(-1.989,0.716)\end{array}$ & $\begin{array}{c}0.319 \\
{[-0.798,1.405]} \\
(-0.900,1.500)\end{array}$ \\
\hline Wealth $(\log )$ & 9.185 & $\begin{array}{c}-0.106 \\
{[-0.528,0.307]} \\
(-0.538,0.317)\end{array}$ & $\begin{array}{c}-0.795 \\
{[-1.199,-0.401]^{* * *}} \\
(-1.459,-0.145)^{+++}\end{array}$ & $\begin{array}{c}-0.357 \\
{[-0.775,0.078]} \\
(-0.851,0.157)\end{array}$ \\
\hline Dwelling has dirt floor $(\mathrm{o} / \mathrm{1})$ & 0.748 & $\begin{array}{c}0.000 \\
{[-0.136,0.147]} \\
(-0.147,0.157)\end{array}$ & $\begin{array}{c}0.139 \\
{[0.013,0.283]^{*}} \\
(-0.027,0.330)\end{array}$ & $\begin{array}{c}0.042 \\
{[-0.108,0.184]} \\
(-0.117,0.192)\end{array}$ \\
\hline Micronutrient supplement $(\mathrm{o} / \mathrm{1})$ & 0.511 & $\begin{array}{c}0.111 \\
{[-0.054,0.274]} \\
(-0.098,0.317)\end{array}$ & $\begin{array}{c}0.236 \\
{[0.075,0.397]^{* * *}} \\
(0.004,0.469)^{+}\end{array}$ & $\begin{array}{c}0.181 \\
{[0.018,0.344]^{*}} \\
(-0.039,0.401)\end{array}$ \\
\hline Conditional cash transfer recipient $(\mathrm{o} / \mathrm{1})$ & 0.409 & $\begin{array}{c}-0.097 \\
{[-0.259,0.065]} \\
(-0.292,0.099)\end{array}$ & $\begin{array}{c}0.014 \\
{[-0.148,0.179]} \\
(-0.148,0.179)\end{array}$ & $\begin{array}{c}-0.132 \\
{[-0.294,0.031]} \\
(-0.331,0.067)\end{array}$ \\
\hline Women's share of wealth & 0.306 & $\begin{array}{c}-0.035 \\
{[-0.141,0.068]} \\
(-0.143,0.070)\end{array}$ & $\begin{array}{c}0.001 \\
{[-0.101,0.103]} \\
(-0.108,0.111)\end{array}$ & $\begin{array}{c}0.003 \\
{[-0.103,0.105]} \\
(-0.105,0.107)\end{array}$ \\
\hline Had credit at baseline $(\mathrm{o} / \mathrm{1})$ & 0.116 & $\begin{array}{c}0.042 \\
{[-0.070,0.137]} \\
(-0.085,0.152)\end{array}$ & $\begin{array}{c}-0.153 \\
{[-0.251,-0.046]^{* * *}} \\
(-0.295,0.001)^{+}\end{array}$ & $\begin{array}{c}-0.111 \\
{[-0.208,-0.003]^{*}} \\
(-0.244,0.032)\end{array}$ \\
\hline Distance to market (minutes) & 64.264 & $\begin{array}{c}-16.333 \\
{[-32.314,0.563]} \\
(-38.293,7.977)\end{array}$ & $\begin{array}{c}-0.806 \\
{[-17.381,14.918]} \\
(-18.288,15.661)\end{array}$ & $\begin{array}{c}-6.667 \\
{[-23.522,10.058]} \\
(-25.398,12.108)\end{array}$ \\
\hline Dwelling has water filter $(\mathrm{o} / \mathrm{1})$ & 0.132 & $\begin{array}{c}0.042 \\
{[-0.070,0.143]} \\
(-0.084,0.155)\end{array}$ & $\begin{array}{c}0.014 \\
{[-0.098,0.119]} \\
(-0.120,0.137)\end{array}$ & $\begin{array}{c}0.028 \\
{[-0.082,0.131]} \\
(-0.085,0.135)\end{array}$ \\
\hline
\end{tabular}

Notes: ${ }^{*} p<0.10,{ }^{* *} p<0.05,{ }^{* * *} p<0.01 ;{ }^{+} q<0.10,{ }^{++} q<0.05,{ }^{+++} q<0.01$, where $q$ is the false discovery rate. $90 \%$ confidence intervals in brackets, $90 \%$ false discovery rate-adjusted confidence intervals in parentheses. Standard errors are of the heteroskedasticity-robust "HC1" variety (MacKinnon and White, 1985). 
Table A.29: Classification analysis for child outcomes, continued

\begin{tabular}{|c|c|c|c|c|}
\hline & \multirow[b]{2}{*}{$\begin{array}{l}\text { Sample } \\
\text { average }\end{array}$} & \multicolumn{3}{|c|}{ (Most - Least) } \\
\hline & & Not stunted $(\mathrm{o} / \mathrm{1})$ & $\begin{array}{l}\text { Animal source foods } \\
\qquad(\mathrm{o} / 1)\end{array}$ & $\begin{array}{c}\text { Dietary diversity } \\
\text { (count) }\end{array}$ \\
\hline Connected to water network $(\mathrm{o} / \mathrm{1})$ & 0.577 & $\begin{array}{c}-0.014 \\
{[-0.178,0.150]} \\
(-0.183,0.155)\end{array}$ & $\begin{array}{c}0.056 \\
{[-0.106,0.219]} \\
(-0.139,0.253)\end{array}$ & $\begin{array}{c}0.181 \\
{[0.019,0.341]^{*}} \\
(-0.044,0.404)\end{array}$ \\
\hline Connected to electricity network (o/1) & 0.461 & $\begin{array}{c}0.111 \\
{[-0.053,0.276]} \\
(-0.101,0.324)\end{array}$ & $\begin{array}{c}-0.264 \\
{[-0.423,-0.106]^{* * *}} \\
(-0.504,-0.025)^{++}\end{array}$ & $\begin{array}{c}-0.042 \\
{[-0.207,0.120]} \\
(-0.207,0.120)\end{array}$ \\
\hline Social capital index, household & 1.466 & $\begin{array}{c}0.278 \\
{[-0.333,0.907]} \\
(-0.418,0.990)\end{array}$ & $\begin{array}{c}0.139 \\
{[-0.462,0.764]} \\
(-0.518,0.825)\end{array}$ & $\begin{array}{c}0.208 \\
{[-0.415,0.835]} \\
(-0.458,0.880)\end{array}$ \\
\hline Group memberships (count) & 0.807 & $\begin{array}{c}0.097 \\
{[-0.286,0.478]} \\
(-0.309,0.500)\end{array}$ & $\begin{array}{c}0.097 \\
{[-0.286,0.481]} \\
(-0.309,0.509)\end{array}$ & $\begin{array}{c}0.125 \\
{[-0.276,0.514]} \\
(-0.294,0.530)\end{array}$ \\
\hline Calories (log) & 8.341 & $\begin{array}{c}0.381 \\
{[0.133,0.624]^{* * *}} \\
(0.029,0.739)^{+}\end{array}$ & $\begin{array}{c}-0.050 \\
{[-0.303,0.199]} \\
(-0.305,0.201)\end{array}$ & $\begin{array}{c}0.205 \\
{[-0.048,0.454]} \\
(-0.103,0.504)\end{array}$ \\
\hline Animal protein (log grams) & 1.572 & $\begin{array}{c}0.256 \\
{[-0.172,0.696]} \\
(-0.264,0.791)\end{array}$ & $\begin{array}{c}0.045 \\
{[-0.395,0.480]} \\
(-0.405,0.490)\end{array}$ & $\begin{array}{c}0.554 \\
{[0.143,0.966]^{* *}} \\
(-0.068,1.177)\end{array}$ \\
\hline Food consumption score & 19.708 & $\begin{array}{c}0.354 \\
{[-2.307,2.998]} \\
(-2.307,2.998)\end{array}$ & $\begin{array}{c}-0.708 \\
{[-3.335,1.825]} \\
(-3.773,2.224)\end{array}$ & $\begin{array}{c}3.729 \\
{[1.104,6.357]^{* *}} \\
(-0.578,8.080)\end{array}$ \\
\hline Egg unit value (quetzales/egg) & 1.186 & $\begin{array}{c}-0.006 \\
{[-0.043,0.030]} \\
(-0.043,0.031)\end{array}$ & $\begin{array}{c}-0.036 \\
{[-0.073,0.000]} \\
(-0.085,0.013)\end{array}$ & $\begin{array}{c}-0.024 \\
{[-0.061,0.012]} \\
(-0.066,0.018)\end{array}$ \\
\hline Eggs produced (log) & 1.401 & $\begin{array}{c}-0.384 \\
{[-1.130,0.348]} \\
(-1.275,0.495)\end{array}$ & $\begin{array}{c}-0.064 \\
{[-0.822,0.712]} \\
(-0.930,0.830)\end{array}$ & $\begin{array}{c}0.690 \\
{[-0.075,1.438]} \\
(-0.250,1.621)\end{array}$ \\
\hline Chickens owned (log) & 2.322 & $\begin{array}{c}-0.215 \\
{[-0.670,0.240]} \\
(-0.743,0.316)\end{array}$ & $\begin{array}{c}0.092 \\
{[-0.365,0.539]} \\
(-0.446,0.613)\end{array}$ & $\begin{array}{c}0.416 \\
{[-0.038,0.869]} \\
(-0.163,0.989)\end{array}$ \\
\hline
\end{tabular}

Notes: ${ }^{*} p<0.10,{ }^{* *} p<0.05,{ }^{* * *} p<0.01 ;{ }^{+} q<0.10,{ }^{++} q<0.05,{ }^{+++} q<0.01$, where $q$ is the false discovery rate. $90 \%$ confidence intervals in brackets, $90 \%$ false discovery rate-adjusted confidence intervals in parentheses. Standard errors are of the heteroskedasticity-robust "HC1" variety (MacKinnon and White, 1985). 


\section{A.15 Full machine learning results for household-level outcomes}

In this section we show full machine learning results for household-level outcomes. The full results include 90\% confidence intervals for the best linear prediction regression and group average intentto-treat effects, rather than only showing point estimates and indicators of statistical significance. We also show the results of classification analysis for all outcomes regardless of evidence for treatment effect heterogeneity. Note that some measures of treatment effect heterogeneity in tables A.30 and A.31 have $q$-values below 0.10 and $90 \%$ confidence intervals that include zero. This is possible because the confidence intervals and $q$-values are median values from the 199 sample splits. The median $q$-value for a given parameter estimate might not correspond to the median confidence interval. 
Table A.30: Best linear predictor of the average intent-to-treat effect and impact heterogeneity: household outcomes

\begin{tabular}{|c|c|c|c|}
\hline & Intent-to-treat & Heterogeneity & ML method \\
\hline Annual expenditure per adult male equivalent (log) & $\begin{array}{c}0.002 \\
{[-0.103,0.111]} \\
(-0.110,0.118)\end{array}$ & $\begin{array}{c}0.526 \\
{[-0.085,1.133]} \\
(-0.219,1.303)\end{array}$ & Elastic net \\
\hline Annual food expenditure per adult male equivalent (log) & $\begin{array}{c}0.023 \\
{[-0.086,0.142]} \\
(-0.091,0.146)\end{array}$ & $\begin{array}{c}0.367 \\
{[-0.317,1.046]} \\
(-0.354,1.118)\end{array}$ & Elastic net \\
\hline Daily calories per adult male equivalent (log) & $\begin{array}{c}0.017 \\
{[-0.085,0.126]} \\
(-0.098,0.138)\end{array}$ & $\begin{array}{c}0.733 \\
{[0.011,1.493]^{*}} \\
(-0.100,1.622)\end{array}$ & Elastic net \\
\hline Animal protein (log grams) & $\begin{array}{c}0.063 \\
{[-0.320,0.427]} \\
(-0.364,0.487)\end{array}$ & $\begin{array}{c}0.886 \\
{[0.245,1.563]^{* *}} \\
(-0.092,1.814)^{+}\end{array}$ & Elastic net \\
\hline Daily servings of eggs & $\begin{array}{c}-0.032 \\
{[-0.121,0.057]} \\
(-0.138,0.083)\end{array}$ & $\begin{array}{c}0.412 \\
{[-0.385,1.231]} \\
(-0.453,1.275)\end{array}$ & Random forest \\
\hline Eggs consumed per day per adult male equivalent & $\begin{array}{c}0.094 \\
{[-0.323,0.542]} \\
(-0.323,0.542)\end{array}$ & $\begin{array}{c}0.266 \\
{[-0.720,1.199]} \\
(-0.720,1.199)\end{array}$ & Elastic net \\
\hline Food consumption score & $\begin{array}{c}-0.699 \\
{[-2.478,0.979]} \\
(-2.966,1.528)\end{array}$ & $\begin{array}{c}0.830 \\
{[0.308,1.356]^{* * *}} \\
(-0.040,1.599)^{+}\end{array}$ & Elastic net \\
\hline Chickens owned (log) & $\begin{array}{c}-0.119 \\
{[-0.370,0.140]} \\
(-0.443,0.274)\end{array}$ & $\begin{array}{c}0.660 \\
{[-0.165,1.564]} \\
(-0.282,1.700)\end{array}$ & Elastic net \\
\hline Naked-neck chickens owned (log) & $\begin{array}{c}-0.018 \\
{[-0.235,0.206]} \\
(-0.242,0.214)\end{array}$ & $\begin{array}{c}0.985 \\
{[0.073,1.844]^{*}} \\
(-0.154,2.194)\end{array}$ & Elastic net \\
\hline Eggs produced in last six months (log) & $\begin{array}{c}0.188 \\
{[-0.352,0.705]} \\
(-0.475,0.812)\end{array}$ & $\begin{array}{c}0.657 \\
{[-0.642,2.112]} \\
(-0.688,2.172)\end{array}$ & Elastic net \\
\hline
\end{tabular}

Notes: ${ }^{*} p<0.10,{ }^{* *} p<0.05,{ }^{* * *} p<0.01 ;{ }^{+} q<0.10,{ }^{++} q<0.05,{ }^{+++} q<0.01$, where $q$ is the false discovery rate. $90 \%$ confidence intervals in brackets, $90 \%$ false discovery rate-adjusted confidence intervals in parentheses. 
Table A.31: Intent-to-treat effects for most and least affected households

\begin{tabular}{|c|c|c|c|}
\hline & Most & Least & (Most - Least) \\
\hline Annual expenditure per adult male equivalent (log) & $\begin{array}{c}0.136 \\
{[-0.099,0.370]} \\
(-0.135,0.417)\end{array}$ & $\begin{array}{c}-0.090 \\
{[-0.293,0.121]} \\
(-0.311,0.145)\end{array}$ & $\begin{array}{c}0.222 \\
{[-0.081,0.522]} \\
(-0.124,0.572)\end{array}$ \\
\hline Annual food expenditure per adult male equivalent (log) & $\begin{array}{c}0.081 \\
{[-0.090,0.259]} \\
(-0.113,0.274)\end{array}$ & $\begin{array}{c}-0.068 \\
{[-0.294,0.165]} \\
(-0.294,0.165)\end{array}$ & $\begin{array}{c}0.151 \\
{[-0.144,0.429]} \\
(-0.144,0.429)\end{array}$ \\
\hline Daily calories per adult male equivalent (log) & $\begin{array}{c}0.142 \\
{[-0.047,0.328]} \\
(-0.111,0.377)\end{array}$ & $\begin{array}{c}-0.119 \\
{[-0.323,0.094]} \\
(-0.365,0.125)\end{array}$ & $\begin{array}{c}0.281 \\
{[-0.007,0.551]} \\
(-0.042,0.581)\end{array}$ \\
\hline Animal protein (log grams) & $\begin{array}{c}0.628 \\
{[-0.022,1.267]} \\
(-0.453,1.673)\end{array}$ & $\begin{array}{c}-0.598 \\
{[-1.391,0.233]} \\
(-1.550,0.462)\end{array}$ & $\begin{array}{c}1.222 \\
{[0.181,2.235]^{* *}} \\
(-0.047,2.406)\end{array}$ \\
\hline Daily servings of eggs & $\begin{array}{c}0.064 \\
{[-0.097,0.230]} \\
(-0.104,0.237)\end{array}$ & $\begin{array}{c}-0.105 \\
{[-0.290,0.094]} \\
(-0.316,0.113)\end{array}$ & $\begin{array}{c}0.155 \\
{[-0.117,0.418]} \\
(-0.133,0.441)\end{array}$ \\
\hline Eggs consumed per day per adult male equivalent & $\begin{array}{c}0.279 \\
{[-0.456,1.037]} \\
(-0.482,1.070)\end{array}$ & $\begin{array}{c}-0.104 \\
{[-0.974,0.812]} \\
(-0.991,0.828)\end{array}$ & $\begin{array}{c}0.338 \\
{[-0.887,1.608]} \\
(-0.924,1.630)\end{array}$ \\
\hline Food consumption score & $\begin{array}{c}2.410 \\
{[-0.258,5.169]} \\
(-1.378,6.114)\end{array}$ & $\begin{array}{c}-4.235 \\
{[-7.950,-0.616]^{* *}} \\
(-9.966,1.568)\end{array}$ & $\begin{array}{c}6.752 \\
{[2.105,11.511]^{* *}} \\
(-0.119,13.062)^{+}\end{array}$ \\
\hline Chickens owned (log) & $\begin{array}{c}0.103 \\
{[-0.373,0.596]} \\
(-0.373,0.596)\end{array}$ & $\begin{array}{c}-0.416 \\
{[-0.873,0.049]} \\
(-1.122,0.195)\end{array}$ & $\begin{array}{c}0.541 \\
{[-0.145,1.197]} \\
(-0.200,1.260)\end{array}$ \\
\hline Naked-neck chickens owned (log) & $\begin{array}{c}0.228 \\
{[-0.151,0.615]} \\
(-0.224,0.719)\end{array}$ & $\begin{array}{c}-0.342 \\
{[-0.781,0.087]} \\
(-0.923,0.262)\end{array}$ & $\begin{array}{c}0.564 \\
{[-0.002,1.143]} \\
(-0.168,1.290)\end{array}$ \\
\hline Eggs produced in last six months (log) & $\begin{array}{c}0.408 \\
{[-0.502,1.345]} \\
(-0.599,1.454)\end{array}$ & $\begin{array}{c}-0.167 \\
{[-1.321,1.000]} \\
(-1.388,1.078)\end{array}$ & $\begin{array}{c}0.604 \\
{[-0.989,2.204]} \\
(-0.989,2.204)\end{array}$ \\
\hline
\end{tabular}

Notes: ${ }^{*} p<0.10,{ }^{* *} p<0.05,{ }^{* * *} p<0.01 ;{ }^{+} q<0.10,{ }^{++} q<0.05,{ }^{+++} q<0.01$, where $q$ is the false discovery rate. $90 \%$ confidence intervals in brackets, $90 \%$ false discovery rate-adjusted confidence intervals in parentheses. 
Table A.32: Classification analysis for household outcomes

\begin{tabular}{|c|c|c|c|c|}
\hline & \multirow[b]{2}{*}{$\begin{array}{l}\text { Sample } \\
\text { average }\end{array}$} & \multicolumn{3}{|c|}{ (Average in most affected) - (Average in least affected) } \\
\hline & & $\begin{array}{l}\text { Expenditure } \\
(\log )\end{array}$ & $\begin{array}{l}\text { Food expenditure } \\
(\log )\end{array}$ & $\begin{array}{l}\text { Calories } \\
(\log )\end{array}$ \\
\hline Meters above sea level & 746.487 & $\begin{array}{c}58.173 \\
{[-10.481,123.466]} \\
(-25.897,137.541)\end{array}$ & $\begin{array}{c}118.732 \\
{[52.294,182.706]^{* * * * * * *}} \\
(16.561,217.027)^{++}\end{array}$ & $\begin{array}{c}49.881 \\
{[-15.659,118.735]} \\
(-24.265,128.073)\end{array}$ \\
\hline Rainfall (millimeters) & 499.457 & $\begin{array}{c}-5.252 \\
{[-87.203,76.698]} \\
(-88.992,78.488)\end{array}$ & $\begin{array}{c}-42.047 \\
{[-124.432,39.172]} \\
(-130.374,44.992)\end{array}$ & $\begin{array}{c}-49.064 \\
{[-130.298,32.171]} \\
(-136.157,38.030)\end{array}$ \\
\hline Days with extreme temperatures & 171.750 & $\begin{array}{c}-16.754 \\
{[-30.790,-3.126]^{* * * *}} \\
(-36.210,2.186)\end{array}$ & $\begin{array}{c}-17.369 \\
{[-31.004,-3.553]^{* * * *}} \\
(-34.313,-0.612)^{+}\end{array}$ & $\begin{array}{c}14.646 \\
{[0.235,28.845]^{* *}} \\
(-2.338,31.543)\end{array}$ \\
\hline Household size & 4.022 & $\begin{array}{c}0.183 \\
{[-0.246,0.623]} \\
(-0.305,0.683)\end{array}$ & $\begin{array}{c}0.680 \\
{[0.248,1.115]^{* * * * * * *}} \\
(0.110,1.257)^{++}\end{array}$ & $\begin{array}{c}1.034 \\
{[0.601,1.473]^{* * * * * * *}} \\
(0.362,1.729)^{+++}\end{array}$ \\
\hline Dependency ratio & 0.393 & $\begin{array}{c}-0.062 \\
{[-0.115,-0.007]^{* *}} \\
(-0.132,0.011)\end{array}$ & $\begin{array}{c}-0.047 \\
{[-0.101,0.007]} \\
(-0.110,0.015)\end{array}$ & $\begin{array}{c}0.053 \\
{[-0.001,0.110]} \\
(-0.010,0.119)\end{array}$ \\
\hline Average education (years) & 2.535 & $\begin{array}{c}0.077 \\
{[-0.827,0.980]} \\
(-0.837,0.990)\end{array}$ & $\begin{array}{c}0.162 \\
{[-0.686,1.052]} \\
(-0.704,1.071)\end{array}$ & $\begin{array}{c}0.323 \\
{[-0.541,1.199]} \\
(-0.580,1.239)\end{array}$ \\
\hline Wealth $(\log )$ & 9.514 & $\begin{array}{c}0.831 \\
{[0.489,1.162]^{* * * * * *}} \\
(0.297,1.342)^{+++}\end{array}$ & $\begin{array}{c}0.363 \\
{[0.019,0.685]^{* *}} \\
(-0.047,0.745)\end{array}$ & $\begin{array}{c}0.446 \\
{[0.125,0.775]^{* * * *}} \\
(0.047,0.858)^{++}\end{array}$ \\
\hline Dwelling has dirt floor $(\mathrm{o} / \mathrm{1})$ & 0.633 & $\begin{array}{c}-0.123 \\
{[-0.244,-0.003]^{* *}} \\
(-0.278,0.032)\end{array}$ & $\begin{array}{c}-0.077 \\
{[-0.194,0.045]} \\
(-0.208,0.059)\end{array}$ & $\begin{array}{c}-0.146 \\
{[-0.259,-0.027]^{* * * * *}} \\
(-0.281,-0.004)^{+}\end{array}$ \\
\hline
\end{tabular}

Notes: ${ }^{*} p<0.10,{ }^{* *} p<0.05,{ }^{* * *} p<0.01{ }^{+} q<0.10,{ }^{++} q<0.05,{ }^{+++} q<0.01$, where $q$ is the false discovery rate. $90 \%$ confidence intervals in brackets, $90 \%$ false discovery rate-adjusted confidence intervals in parentheses. All characteristics displayed in the rows are measured at baseline except for weather variables and altitude of the dwelling. Weather variables are measured for the 2015 crop season, approximately one year after baseline interviews. 
Table A.33: Classification analysis for household outcomes, continued

\begin{tabular}{|c|c|c|c|c|}
\hline & \multirow[b]{2}{*}{$\begin{array}{l}\text { Sample } \\
\text { average }\end{array}$} & \multicolumn{3}{|c|}{ (Average in most affected) - (Average in least affected) } \\
\hline & & $\begin{array}{l}\text { Expenditure } \\
\qquad(\log )\end{array}$ & $\begin{array}{l}\text { Food expenditure } \\
(\log )\end{array}$ & $\begin{array}{l}\text { Calories } \\
(\log )\end{array}$ \\
\hline \multirow[t]{2}{*}{ Women's share of wealth } & 0.363 & -0.180 & -0.134 & -0.106 \\
\hline & & $\begin{array}{c}{[-0.262,-0.095]^{* * * * * *}} \\
(-0.299,-0.058)^{+++}\end{array}$ & $\begin{array}{c}{[-0.218,-0.050]^{* * * * * *}} \\
\quad(-0.249,-0.018)^{++}\end{array}$ & $\begin{array}{c}{[-0.184,-0.024]^{* * * *}} \\
(-0.201,-0.006)^{+}\end{array}$ \\
\hline \multirow[t]{3}{*}{ Had credit at baseline $(\mathrm{o} / 1)$} & 0.110 & 0.031 & 0.023 & 0.031 \\
\hline & & {$[-0.052,0.111]$} & {$[-0.052,0.100]$} & {$[-0.041,0.108]$} \\
\hline & & $(-0.060,0.119)$ & $(-0.053,0.101)$ & $(-0.044,0.112)$ \\
\hline \multirow[t]{3}{*}{ Distance to market (minutes) } & 58.436 & 5.646 & 19.462 & 1.246 \\
\hline & & {$[-7.007,17.953]$} & {$[6.889,32.134]^{* * * * * *}$} & {$[-11.231,14.778]$} \\
\hline & & $(-8.926,20.051)$ & $(3.289,35.517)^{++}$ & $(-11.635,15.231)$ \\
\hline \multirow[t]{3}{*}{ Connected to water network (o/1) } & 0.695 & 0.100 & 0.092 & 0.077 \\
\hline & & {$[-0.009,0.206]$} & {$[-0.020,0.209]$} & {$[-0.040,0.186]$} \\
\hline & & $(-0.037,0.234)$ & $(-0.036,0.223)$ & $(-0.050,0.196)$ \\
\hline \multirow[t]{3}{*}{ Connected to electricity network (o/1) } & 0.584 & 0.077 & 0.115 & 0.262 \\
\hline & & {$[-0.044,0.194]$} & {$[-0.001,0.231]^{* *}$} & {$[0.144,0.379]^{* * * * * *}$} \\
\hline & & $(-0.067,0.218)$ & $(-0.021,0.252)$ & $(0.100,0.423)^{+++}$ \\
\hline \multirow[t]{3}{*}{ Social capital index, household } & 1.564 & 0.108 & 0.292 & 0.154 \\
\hline & & {$[-0.370,0.597]$} & {$[-0.179,0.780]$} & {$[-0.322,0.643]$} \\
\hline & & $(-0.402,0.632)$ & $(-0.225,0.828)$ & $(-0.327,0.648)$ \\
\hline \multirow[t]{3}{*}{ Social capital, women (count) } & 0.925 & -0.062 & 0.115 & 0.085 \\
\hline & & {$[-0.383,0.259]$} & {$[-0.214,0.456]$} & {$[-0.253,0.406]$} \\
\hline & & $(-0.393,0.269)$ & $(-0.231,0.475)$ & $(-0.253,0.406)$ \\
\hline \multirow[t]{3}{*}{ Calories (log) } & 8.402 & -0.051 & -0.033 & -0.056 \\
\hline & & {$[-0.226,0.122]$} & {$[-0.215,0.138]$} & {$[-0.229,0.114]$} \\
\hline & & $(-0.236,0.133)$ & $(-0.224,0.145)$ & $(-0.233,0.117)$ \\
\hline
\end{tabular}

Notes: ${ }^{*} p<0.10,{ }^{* *} p<0.05,{ }^{* * *} p<0.01 ;{ }^{+} q<0.10,{ }^{++} q<0.05,{ }^{++} q<0.01$, where $q$ is the false discovery rate. $90 \%$ confidence intervals in brackets, $90 \%$ false discovery rate-adjusted confidence intervals in parentheses. 
Table A.34: Classification analysis for household outcomes, continued

\begin{tabular}{|c|c|c|c|c|}
\hline & \multirow[b]{2}{*}{$\begin{array}{l}\text { Sample } \\
\text { average }\end{array}$} & \multicolumn{3}{|c|}{ (Average in most affected) - (Average in least affected) } \\
\hline & & $\begin{array}{l}\text { Animal protein } \\
(\log \text { grams })\end{array}$ & $\begin{array}{l}\text { Daily servings } \\
\text { of eggs (count) }\end{array}$ & $\begin{array}{l}\text { Eggs consumed } \\
\text { per day (count) }\end{array}$ \\
\hline Meters above sea level & 746.487 & $\begin{array}{c}137.014 \\
{[65.384,208.926]^{* * * * * *}} \\
(28.093,245.715)^{+++}\end{array}$ & $\begin{array}{c}73.508 \\
{[5.485,139.182]^{* *}} \\
(-9.859,154.194)\end{array}$ & $\begin{array}{c}128.898 \\
{[60.842,198.048]^{* * * * * * *}} \\
(45.618,213.594)^{+++}\end{array}$ \\
\hline Rainfall (millimeters) & $499 \cdot 457$ & $\begin{array}{c}-60.658 \\
{[-142.232,20.468]} \\
(-161.075,38.921)\end{array}$ & $\begin{array}{c}3.759 \\
{[-79.369,86.467]} \\
(-84.238,91.256)\end{array}$ & $\begin{array}{c}-44.543 \\
{[-126.477,37.391]} \\
(-131.276,42.190)\end{array}$ \\
\hline Days with extreme temperatures & 171.750 & $\begin{array}{c}12.238 \\
{[-3.933,27.785]} \\
(-8.003,31.615)\end{array}$ & $\begin{array}{c}-10.431 \\
{[-24.307,3.367]} \\
(-26.344,5.333)\end{array}$ & $\begin{array}{c}-14.192 \\
{[-28.255,-0.434]^{* *}} \\
(-30.279,1.432)\end{array}$ \\
\hline Household size & 4.022 & $\begin{array}{c}0.134 \\
{[-0.299,0.557]} \\
(-0.319,0.576)\end{array}$ & $\begin{array}{c}-0.531 \\
{[-0.957,-0.086]^{* * * *}} \\
(-1.096,0.067)\end{array}$ & $\begin{array}{c}-0.793 \\
{[-1.223,-0.367]^{* * * * * *}} \\
(-1.311,-0.283)^{+++}\end{array}$ \\
\hline Dependency ratio & 0.393 & $\begin{array}{c}-0.024 \\
{[-0.077,0.032]} \\
(-0.082,0.037)\end{array}$ & $\begin{array}{c}-0.032 \\
{[-0.086,0.023]} \\
(-0.091,0.029)\end{array}$ & $\begin{array}{c}-0.040 \\
{[-0.095,0.013]} \\
(-0.101,0.019)\end{array}$ \\
\hline Average education (years) & 2.535 & $\begin{array}{c}-0.808 \\
{[-1.620,0.031]} \\
(-1.959,0.377)\end{array}$ & $\begin{array}{c}0.038 \\
{[-0.818,0.971]} \\
(-0.860,1.007)\end{array}$ & $\begin{array}{c}-0.254 \\
{[-1.123,0.631]} \\
(-1.133,0.640)\end{array}$ \\
\hline Wealth (log) & $9 \cdot 514$ & $\begin{array}{c}-0.163 \\
{[-0.490,0.179]} \\
(-0.531,0.219)\end{array}$ & $\begin{array}{c}-0.443 \\
{[-0.785,-0.094]^{* * * *}} \\
(-0.938,0.066)\end{array}$ & $\begin{array}{c}-0.835 \\
{[-1.171,-0.509]^{* * * * * *}} \\
(-1.292,-0.395)^{+++}\end{array}$ \\
\hline Dwelling has dirt floor $(\mathrm{o} / 1)$ & 0.633 & $\begin{array}{c}-0.092 \\
{[-0.206,0.022]} \\
(-0.238,0.055)\end{array}$ & $\begin{array}{c}0.000 \\
{[-0.119,0.122]} \\
(-0.119,0.122)\end{array}$ & $\begin{array}{c}0.131 \\
{[0.013,0.248]^{* *}} \\
(-0.005,0.266)\end{array}$ \\
\hline
\end{tabular}

Notes: ${ }^{*} p<0.10,{ }^{* *} p<0.05,{ }^{* * *} p<0.01 ;{ }^{+} q<0.10,{ }^{++} q<0.05,{ }^{+++} q<0.01$, where $q$ is the false discovery rate. $90 \%$ confidence intervals in brackets, $90 \%$ false discovery rate-adjusted confidence intervals in parentheses. Standard errors are of the heteroskedasticity-robust "HC1" variety (MacKinnon and White, 1985). All characteristics displayed in the rows are measured at baseline except for weather variables and altitude of the dwelling. Weather variables are measured for the 2015 crop season, approximately one year after baseline interviews. 
Table A.35: Classification analysis for household outcomes, continued

\begin{tabular}{|c|c|c|c|c|}
\hline & \multirow[b]{2}{*}{$\begin{array}{l}\text { Sample } \\
\text { average }\end{array}$} & \multicolumn{3}{|c|}{ (Average in most affected) - (Average in least affected } \\
\hline & & $\begin{array}{c}\text { Animal protein } \\
(\log \text { grams })\end{array}$ & $\begin{array}{l}\text { Daily servings } \\
\text { of eggs (count) }\end{array}$ & $\begin{array}{l}\text { Eggs consumed } \\
\text { per day (count) }\end{array}$ \\
\hline Women's share of wealth & 0.363 & $\begin{array}{c}-0.026 \\
{[-0.109,0.056]} \\
(-0.109,0.056)\end{array}$ & $\begin{array}{c}-0.004 \\
{[-0.088,0.080]} \\
(-0.089,0.081)\end{array}$ & $\begin{array}{c}-0.019 \\
{[-0.103,0.066]} \\
(-0.103,0.066)\end{array}$ \\
\hline Had credit at baseline $(\mathrm{o} / \mathrm{1})$ & 0.110 & $\begin{array}{c}-0.069 \\
{[-0.150,0.005]} \\
(-0.177,0.033)\end{array}$ & $\begin{array}{c}-0.069 \\
{[-0.148,0.014]} \\
(-0.162,0.027)\end{array}$ & $\begin{array}{c}-0.223 \\
{[-0.298,-0.142]^{* * * * * *}} \\
(-0.339,-0.100)^{+++}\end{array}$ \\
\hline Distance to market (minutes) & 58.436 & $\begin{array}{c}4.223 \\
{[-9.353,17.963]} \\
(-9.629,18.270)\end{array}$ & $\begin{array}{c}13.946 \\
{[1.908,25.973]^{* * * * *}} \\
(-1.369,28.977)\end{array}$ & $\begin{array}{c}33.746 \\
{[20.957,46.720]^{* * * * * * *}} \\
(15.212,52.465)^{+++}\end{array}$ \\
\hline Connected to water network (o/1) & 0.695 & $\begin{array}{c}0.062 \\
{[-0.057,0.180]} \\
(-0.073,0.196)\end{array}$ & $\begin{array}{c}-0.069 \\
{[-0.177,0.041]} \\
(-0.190,0.054)\end{array}$ & $\begin{array}{c}-0.092 \\
{[-0.205,0.023]} \\
(-0.218,0.036)\end{array}$ \\
\hline Connected to electricity network (o/1) & 0.584 & $\begin{array}{c}-0.031 \\
{[-0.152,0.092]} \\
(-0.159,0.099)\end{array}$ & $\begin{array}{c}-0.138 \\
{[-0.254,-0.020]^{* * * *}} \\
(-0.288,0.014)\end{array}$ & $\begin{array}{c}-0.292 \\
{[-0.408,-0.176]^{* * * * * *}} \\
(-0.446,-0.138)^{+++}\end{array}$ \\
\hline Social capital index, household & 1.564 & $\begin{array}{c}0.000 \\
{[-0.479,0.490]} \\
(-0.484,0.495)\end{array}$ & $\begin{array}{c}-0.592 \\
{[-1.078,-0.121]^{* * * * *}} \\
(-1.275,0.080)\end{array}$ & $\begin{array}{c}-0.969 \\
{[-1.470,-0.472]^{* * * * * *}} \\
(-1.599,-0.349)^{+++}\end{array}$ \\
\hline Social capital, women (count) & 0.925 & $\begin{array}{c}-0.038 \\
{[-0.352,0.266]} \\
(-0.374,0.293)\end{array}$ & $\begin{array}{c}-0.462 \\
{[-0.807,-0.117]^{* * * * *}} \\
(-0.983,0.058)\end{array}$ & $\begin{array}{c}-0.715 \\
{[-1.027,-0.366]^{* * * * * *}} \\
(-1.117,-0.264)^{+++}\end{array}$ \\
\hline Calories (log) & 8.402 & $\begin{array}{c}-0.041 \\
{[-0.219,0.146]} \\
(-0.233,0.159)\end{array}$ & $\begin{array}{c}0.009 \\
{[-0.171,0.188]} \\
(-0.177,0.194)\end{array}$ & $\begin{array}{c}-0.015 \\
{[-0.194,0.167]} \\
(-0.199,0.173)\end{array}$ \\
\hline
\end{tabular}

Notes: ${ }^{*} p<0.10,{ }^{* *} p<0.05,{ }^{* * *} p<0.01 ;{ }^{+} q<0.10,{ }^{++} q<0.05,{ }^{+++} q<0.01$, where $q$ is the false discovery rate. $90 \%$ confidence intervals in brackets, $90 \%$ false discovery rate-adjusted confidence intervals in parentheses. Standard errors are of the heteroskedasticity-robust "HC1" variety (MacKinnon and White, 1985). 
Table A.36: Classification analysis for household outcomes, continued

\begin{tabular}{|c|c|c|c|c|}
\hline & \multirow[b]{2}{*}{$\begin{array}{l}\text { Sample } \\
\text { average }\end{array}$} & \multicolumn{3}{|c|}{ (Average in most affected) - (Average in least affected) } \\
\hline & & $\begin{array}{l}\text { Animal protein } \\
(\log \text { grams })\end{array}$ & $\begin{array}{l}\text { Daily servings } \\
\text { of eggs (count) }\end{array}$ & $\begin{array}{l}\text { Eggs consumed } \\
\text { per day (count) }\end{array}$ \\
\hline Animal protein (log grams) & 1.883 & $\begin{array}{c}-0.038 \\
{[-0.369,0.294]} \\
(-0.381,0.305)\end{array}$ & $\begin{array}{c}-0.087 \\
{[-0.425,0.245]} \\
(-0.433,0.252)\end{array}$ & $\begin{array}{c}-0.510 \\
{[-0.838,-0.182]^{* * * * * *}} \\
(-0.898,-0.124)^{++}\end{array}$ \\
\hline Food consumption score & 21.075 & $\begin{array}{c}-1.285 \\
{[-3.281,0.736]} \\
(-3.621,1.092)\end{array}$ & $\begin{array}{c}-1.069 \\
{[-3.177,1.063]} \\
(-3.359,1.250)\end{array}$ & $\begin{array}{c}-1.454 \\
{[-3.419,0.604]} \\
(-3.564,0.749)\end{array}$ \\
\hline Egg unit value (quetzales/egg) & 1.174 & $\begin{array}{c}0.018 \\
{[-0.015,0.049]} \\
(-0.020,0.053)\end{array}$ & $\begin{array}{c}0.028 \\
{[-0.005,0.061]} \\
(-0.010,0.067)\end{array}$ & $\begin{array}{c}0.022 \\
{[-0.010,0.053]} \\
(-0.014,0.055)\end{array}$ \\
\hline Eggs produced (units in last six months) & 1.475 & $\begin{array}{c}0.518 \\
{[-0.039,1.099]} \\
(-0.218,1.295)\end{array}$ & $\begin{array}{c}0.512 \\
{[-0.069,1.099]} \\
(-0.184,1.217)\end{array}$ & $\begin{array}{c}0.056 \\
{[-0.529,0.641]} \\
(-0.542,0.654)\end{array}$ \\
\hline Chickens owned (log) & 2.382 & $\begin{array}{c}0.231 \\
{[-0.113,0.565]} \\
(-0.179,0.629)\end{array}$ & $\begin{array}{c}0.127 \\
{[-0.229,0.482]} \\
(-0.255,0.508)\end{array}$ & $\begin{array}{c}0.048 \\
{[-0.302,0.387]} \\
(-0.318,0.402)\end{array}$ \\
\hline
\end{tabular}

Notes: ${ }^{*} p<0.10,{ }^{* *} p<0.05,{ }^{* * *} p<0.01 ;{ }^{+} q<0.10,{ }^{++} q<0.05,{ }^{+++} q<0.01$, where $q$ is the false discovery rate. $90 \%$ confidence intervals in brackets, $90 \%$ false discovery rate-adjusted confidence intervals in parentheses. Standard errors are of the heteroskedasticity-robust "HC1" variety (MacKinnon and White, 1985). 
Table A.37: Classification analysis for household outcomes, continued

\begin{tabular}{|c|c|c|c|c|c|}
\hline & \multirow[b]{2}{*}{$\begin{array}{l}\text { Sample } \\
\text { average }\end{array}$} & \multicolumn{4}{|c|}{ (Average in most affected) - (Average in least affected) } \\
\hline & & $\begin{array}{l}\text { Food consumption } \\
\text { score }\end{array}$ & $\begin{array}{l}\text { Chickens } \\
(\log )\end{array}$ & $\begin{array}{c}\text { Naked-neck } \\
(\log )\end{array}$ & $\begin{array}{c}\text { Eggs produced } \\
\text { (count) }\end{array}$ \\
\hline Meters above sea level & 746.487 & $\begin{array}{c}51.688 \\
{[-19.442,122.151]} \\
(-28.342,130.791)\end{array}$ & $\begin{array}{c}-121.940 \\
{[-186.975,-53.762]^{* * * * * *}} \\
(-209.323,-32.572)^{+++}\end{array}$ & $\begin{array}{c}-14.135 \\
{[-84.837,56.941]} \\
(-87.000,59.329)\end{array}$ & $\begin{array}{c}37.959 \\
{[-31.382,107.450]} \\
(-45.034,121.405)\end{array}$ \\
\hline Rainfall (millimeters) & $499 \cdot 457$ & $\begin{array}{c}-23.058 \\
{[-103.327,57.210]} \\
(-105.079,58.962)\end{array}$ & $\begin{array}{c}268.673 \\
{[193.188,344.532]^{* * * * * *}} \\
(151.050,387.424)^{+++}\end{array}$ & $\begin{array}{c}107.033 \\
{[24.487,189.580]^{* * * *}} \\
(-6.640,220.706)\end{array}$ & $\begin{array}{c}-40.094 \\
{[-121.320,40.872]} \\
(-133.907,53.390)\end{array}$ \\
\hline Days with extreme temperatures & 171.750 & $\begin{array}{c}-4.962 \\
{[-19.870,10.153]} \\
(-20.027,10.314)\end{array}$ & $\begin{array}{c}48.677 \\
{[34.033,62.368]^{* * * * * *}} \\
(27.997,68.852)^{+++}\end{array}$ & $\begin{array}{c}5.792 \\
{[-9.075,19.127]} \\
(-10.147,20.132)\end{array}$ & $\begin{array}{c}-0.854 \\
{[-15.284,14.156]} \\
(-16.532,15.530)\end{array}$ \\
\hline Household size & 4.022 & $\begin{array}{c}0.161 \\
{[-0.267,0.604]} \\
(-0.282,0.618)\end{array}$ & $\begin{array}{c}-1.310 \\
{[-1.724,-0.894]^{* * * * * *}} \\
(-1.898,-0.737)^{+++}\end{array}$ & $\begin{array}{c}-0.699 \\
{[-1.125,-0.274]^{* * * * * *}} \\
(-1.315,-0.084)^{++}\end{array}$ & $\begin{array}{c}-0.088 \\
{[-0.535,0.339]} \\
(-0.540,0.344)\end{array}$ \\
\hline Dependency ratio & 0.393 & $\begin{array}{c}-0.029 \\
{[-0.082,0.024]} \\
(-0.085,0.027)\end{array}$ & $\begin{array}{c}-0.051 \\
{[-0.105,0.003]} \\
(-0.113,0.012)\end{array}$ & $\begin{array}{c}-0.033 \\
{[-0.086,0.021]} \\
(-0.097,0.031)\end{array}$ & $\begin{array}{c}-0.035 \\
{[-0.091,0.020]} \\
(-0.103,0.032)\end{array}$ \\
\hline Average education (years) & 2.535 & $\begin{array}{c}-1.208 \\
{[-2.016,-0.388]^{* * * * * *}} \\
(-2.273,-0.138)^{+}\end{array}$ & $\begin{array}{c}1.292 \\
{[0.466,2.145]^{* * * * * *}} \\
(0.257,2.365)^{++}\end{array}$ & $\begin{array}{c}-0.262 \\
{[-1.187,0.654]} \\
(-1.228,0.694)\end{array}$ & $\begin{array}{c}0.031 \\
{[-0.902,0.935]} \\
(-0.958,0.991)\end{array}$ \\
\hline Wealth $(\log )$ & $9 \cdot 514$ & $\begin{array}{c}-0.506 \\
{[-0.842,-0.174]^{* * * * * * *}} \\
(-0.991,-0.025)^{+}\end{array}$ & $\begin{array}{c}0.130 \\
{[-0.197,0.478]} \\
(-0.211,0.493)\end{array}$ & $\begin{array}{c}0.138 \\
{[-0.193,0.468]} \\
(-0.221,0.498)\end{array}$ & $\begin{array}{c}0.327 \\
{[-0.004,0.653]} \\
(-0.100,0.747)\end{array}$ \\
\hline Dwelling has dirt floor $(\mathrm{o} / \mathrm{1})$ & 0.633 & $\begin{array}{c}0.069 \\
{[-0.052,0.186]} \\
(-0.062,0.196)\end{array}$ & $\begin{array}{c}-0.138 \\
{[-0.257,-0.020]^{* * * *}} \\
(-0.284,0.007)^{+}\end{array}$ & $\begin{array}{c}-0.023 \\
{[-0.145,0.096]} \\
(-0.147,0.099)\end{array}$ & $\begin{array}{c}-0.015 \\
{[-0.135,0.098]} \\
(-0.147,0.109)\end{array}$ \\
\hline
\end{tabular}

Notes: ${ }^{*} p<0.10,{ }^{* *} p<0.05,{ }^{* * *} p<0.01 ;{ }^{+} q<0.10,{ }^{++} q<0.05,{ }^{++} q<0.01$, where $q$ is the false discovery rate. $90 \%$ confidence intervals in brackets, $90 \%$ false discovery rate-adjusted confidence intervals in parentheses. Standard errors are of the heteroskedasticity-robust " $\mathrm{HCl}^{\prime}$ " variety (MacKinnon and White, 1985). All characteristics displayed in the rows are measured at baseline except for weather variables and altitude of the dwelling. Weather variables are measured for the 2015 crop season, approximately one year after baseline interviews. 
Table A.38: Classification analysis for household outcomes, continued

\begin{tabular}{|c|c|c|c|c|c|}
\hline & \multirow[b]{2}{*}{$\begin{array}{l}\text { Sample } \\
\text { average }\end{array}$} & \multicolumn{4}{|c|}{ (Average in most affected) - (Average in least affected) } \\
\hline & & $\begin{array}{l}\text { Food consumption } \\
\text { score }\end{array}$ & $\begin{array}{l}\text { Chickens } \\
(\log )\end{array}$ & $\begin{array}{l}\text { Naked-neck } \\
\quad(\log )\end{array}$ & $\begin{array}{l}\text { Eggs produced } \\
\text { (count) }\end{array}$ \\
\hline Women's share of wealth & 0.363 & $\begin{array}{c}-0.034 \\
{[-0.118,0.050]} \\
(-0.121,0.054)\end{array}$ & $\begin{array}{c}0.036 \\
{[-0.047,0.120]} \\
(-0.053,0.126)\end{array}$ & $\begin{array}{c}0.057 \\
{[-0.027,0.141]} \\
(-0.048,0.162)\end{array}$ & $\begin{array}{c}0.027 \\
{[-0.058,0.110]} \\
(-0.060,0.112)\end{array}$ \\
\hline Had credit at baseline $(\mathrm{o} / \mathrm{1})$ & 0.110 & $\begin{array}{c}-0.085 \\
{[-0.161,-0.006]^{* *}} \\
(-0.176,0.010)\end{array}$ & $\begin{array}{c}0.046 \\
{[-0.025,0.126]} \\
(-0.033,0.133)\end{array}$ & $\begin{array}{c}0.008 \\
{[-0.067,0.087]} \\
(-0.072,0.092)\end{array}$ & $\begin{array}{c}0.069 \\
{[-0.010,0.148]^{* *}} \\
(-0.036,0.174)\end{array}$ \\
\hline Distance to market (minutes) & 58.436 & $\begin{array}{c}13.000 \\
{[0.979,26.117]^{* *}} \\
(-1.563,28.225)\end{array}$ & $\begin{array}{c}-13.854 \\
{[-26.117,-0.965]^{* *}} \\
(-28.346,1.781)\end{array}$ & $\begin{array}{c}2.231 \\
{[-11.128,15.221]} \\
(-11.271,15.355)\end{array}$ & $\begin{array}{c}-6.262 \\
{[-19.085,6.895]} \\
(-21.191,9.271)\end{array}$ \\
\hline Connected to water network (o/1) & 0.695 & $\begin{array}{c}0.123 \\
{[0.005,0.231]^{* *}} \\
(-0.013,0.247)\end{array}$ & $\begin{array}{c}0.031 \\
{[-0.085,0.143]} \\
(-0.085,0.143)\end{array}$ & $\begin{array}{c}-0.015 \\
{[-0.131,0.097]} \\
(-0.131,0.097)\end{array}$ & $\begin{array}{c}0.034 \\
{[-0.078,0.147]} \\
(-0.078,0.147)\end{array}$ \\
\hline Connected to electricity network (o/1) & 0.584 & $\begin{array}{c}-0.108 \\
{[-0.228,0.012]} \\
(-0.244,0.029)\end{array}$ & $\begin{array}{c}-0.092 \\
{[-0.213,0.026]} \\
(-0.229,0.042)\end{array}$ & $\begin{array}{c}-0.046 \\
{[-0.166,0.076]} \\
(-0.178,0.088)\end{array}$ & $\begin{array}{c}0.038 \\
{[-0.078,0.162]} \\
(-0.094,0.179)\end{array}$ \\
\hline Social capital index, household & 1.564 & $\begin{array}{c}-0.585 \\
{[-1.058,-0.112]^{* * * * *}} \\
(-1.164,0.001)\end{array}$ & $\begin{array}{c}-0.162 \\
{[-0.640,0.324]} \\
(-0.656,0.342)\end{array}$ & $\begin{array}{c}0.262 \\
{[-0.237,0.755]} \\
(-0.304,0.822)\end{array}$ & $\begin{array}{c}-0.097 \\
{[-0.582,0.388]} \\
(-0.604,0.410)\end{array}$ \\
\hline Social capital, women (count) & 0.925 & $\begin{array}{c}-0.477 \\
{[-0.807,-0.146]^{* * * * * * *}} \\
\quad(-0.943,-0.041)^{+}\end{array}$ & $\begin{array}{c}-0.062 \\
{[-0.374,0.260]} \\
(-0.378,0.263)\end{array}$ & $\begin{array}{c}0.254 \\
{[-0.107,0.602]} \\
(-0.225,0.698)\end{array}$ & $\begin{array}{c}-0.038 \\
{[-0.364,0.278]} \\
(-0.375,0.287)\end{array}$ \\
\hline Calories (log) & $8.4 \mathrm{O} 2$ & $\begin{array}{c}-0.100 \\
{[-0.277,0.080]} \\
(-0.291,0.092)\end{array}$ & $\begin{array}{c}0.090 \\
{[-0.080,0.277]} \\
(-0.093,0.293)\end{array}$ & $\begin{array}{c}0.107 \\
{[-0.072,0.288]} \\
(-0.103,0.320)\end{array}$ & $\begin{array}{c}0.132 \\
{[-0.049,0.314]} \\
(-0.095,0.358)\end{array}$ \\
\hline
\end{tabular}

Notes: ${ }^{*} p<0.10,{ }^{* *} p<0.05,{ }^{* * *} p<0.01{ }^{+} q<0.10,{ }^{++} q<0.05,{ }^{+++} q<0.01$, where $q$ is the false discovery rate. $90 \%$ confidence intervals in brackets, $90 \%$ false discovery rate-adjusted confidence intervals in parentheses. Standard errors are of the heteroskedasticity-robust "HC1" variety (MacKinnon and White, 1985). 
Table A.39: Classification analysis for household outcomes, continued

\begin{tabular}{|c|c|c|c|c|c|}
\hline & \multirow[b]{2}{*}{$\begin{array}{l}\text { Sample } \\
\text { average }\end{array}$} & \multicolumn{4}{|c|}{ (Average in most affected) - (Average in least affected) } \\
\hline & & $\begin{array}{c}\text { Food consumption } \\
\text { score }\end{array}$ & $\begin{array}{l}\text { Chickens } \\
(\log )\end{array}$ & $\begin{array}{l}\text { Naked-neck } \\
\quad(\log )\end{array}$ & $\begin{array}{l}\text { Eggs produced } \\
\text { (count) }\end{array}$ \\
\hline Animal protein (log grams) & 1.883 & $\begin{array}{c}-0.448 \\
{[-0.772,-0.120]^{* * * *}} \\
(-0.863,-0.027)^{+}\end{array}$ & $\begin{array}{c}0.520 \\
{[0.209,0.845]^{* * * * * * *}} \\
(0.114,0.939)^{++}\end{array}$ & $\begin{array}{c}0.177 \\
{[-0.140,0.498]} \\
(-0.188,0.548)\end{array}$ & $\begin{array}{c}0.387 \\
{[0.050,0.727]^{* * * * *}} \\
(-0.078,0.856)\end{array}$ \\
\hline Food consumption score & 21.075 & $\begin{array}{c}-1.519 \\
{[-3.590,0.530]} \\
(-3.805,0.727)\end{array}$ & $\begin{array}{c}0.846 \\
{[-1.189,2.853]} \\
(-1.306,2.972)\end{array}$ & $\begin{array}{c}-1.042 \\
{[-3.096,1.018]} \\
(-3.339,1.265)\end{array}$ & $\begin{array}{c}0.781 \\
{[-1.240,2.833]} \\
(-1.472,3.063)\end{array}$ \\
\hline Egg unit value (quetzales/egg) & 1.174 & $\begin{array}{c}0.001 \\
{[-0.031,0.035]} \\
(-0.031,0.035)\end{array}$ & $\begin{array}{c}0.010 \\
{[-0.021,0.044]} \\
(-0.022,0.044)\end{array}$ & $\begin{array}{c}0.022 \\
{[-0.010,0.055]} \\
(-0.019,0.065)\end{array}$ & $\begin{array}{c}0.005 \\
{[-0.027,0.036]} \\
(-0.029,0.039)\end{array}$ \\
\hline Eggs produced (units in last six months) & 1.475 & $\begin{array}{c}0.656 \\
{[0.062,1.254]^{* *}} \\
(-0.070,1.388)\end{array}$ & $\begin{array}{c}0.433 \\
{[-0.154,1.013]} \\
(-0.223,1.087)\end{array}$ & $\begin{array}{c}0.388 \\
{[-0.216,0.977]} \\
(-0.348,1.103)\end{array}$ & $\begin{array}{c}2.150 \\
{[1.610,2.678]^{* * * * * * *}} \\
(1.374,2.925)^{+++}\end{array}$ \\
\hline Chickens owned (log) & 2.382 & $\begin{array}{c}0.511 \\
{[0.175,0.845]^{* * * * * *}} \\
(-0.007,1.031)\end{array}$ & $\begin{array}{c}0.329 \\
{[-0.006,0.666]} \\
(-0.064,0.725)\end{array}$ & $\begin{array}{c}0.664 \\
{[0.324,1.015]^{\text {*******}}} \\
(0.134,1.199)^{+++}\end{array}$ & $\begin{array}{c}1.878 \\
{[1.587,2.168]^{* * * * * *}} \\
(1.431,2.325)^{+++}\end{array}$ \\
\hline
\end{tabular}

Notes: ${ }^{*} p<0.10,{ }^{* *} p<0.05,{ }^{* * *} p<0.01 ;{ }^{+} q<0.10,{ }^{++} q<0.05,{ }^{+++} q<0.01$, where $q$ is the false discovery rate. $90 \%$ confidence intervals in brackets, $90 \%$ false discovery rate-adjusted confidence intervals in parentheses. Standard errors are of the heteroskedasticity-robust "HC1" variety (MacKinnon and White, 1985). 


\section{A.16 Controlling for imbalanced baseline outcomes}

As shown in table $1, \log$ calories per adult male equivalent and the number of naked-neck chickens are significantly different in households assigned to treatment and control at baseline. In tables A.40 and A.41 we verify that our results are robust to including each of these outcomes as observed at baseline in the covariate set. 
Table A.40: Household-level intent-to-treat effects controlling for imbalanced baseline characteristics

\begin{tabular}{|c|c|c|}
\hline & Intent-to-treat effect & Control mean \\
\hline Annual expenditure per adult male equivalent (log) & $\begin{array}{c}-0.024 \\
{[-0.501,0.454]} \\
(-0.587,0.540)\end{array}$ & 9.088 \\
\hline Annual food expenditure per adult male equivalent (log) & $\begin{array}{c}-0.007 \\
{[-0.330,0.317]} \\
(-0.330,0.317)\end{array}$ & 8.365 \\
\hline Daily calories per adult male equivalent (log) & $\begin{array}{c}-0.006 \\
{[-0.252,0.240]} \\
(-0.266,0.254)\end{array}$ & 8.075 \\
\hline Daily grams of animal protein per adult male equivalent (log) & $\begin{array}{c}-0.031 \\
{[-1.083,1.021]} \\
(-1.223,1.161)\end{array}$ & 2.545 \\
\hline Daily servings of eggs & $\begin{array}{c}-0.030 \\
{[-0.277,0.217]} \\
(-0.336,0.276)\end{array}$ & 0.439 \\
\hline Eggs consumed per day per adult male equivalent & $\begin{array}{c}0.002 \\
{[-0.982,0.986]} \\
(-0.982,0.986)\end{array}$ & 1.766 \\
\hline Food consumption score & $\begin{array}{c}-1.310 \\
{[-8.254,5.634]} \\
(-11.146,8.527)\end{array}$ & 33.269 \\
\hline Chickens owned (log) & $\begin{array}{c}-0.094 \\
{[-0.570,0.382]} \\
(-0.633,0.445)\end{array}$ & 2.140 \\
\hline Naked-neck chickens owned (log) & $\begin{array}{c}-0.007 \\
{[-0.503,0.488]} \\
(-0.503,0.488)\end{array}$ & 0.964 \\
\hline Uses poultry registry $(\mathrm{o} / \mathrm{1})$ & $\begin{array}{c}0.028 \\
{[-0.008,0.064]} \\
(-0.022,0.079)\end{array}$ & 0.015 \\
\hline Eggs produced in last six months (log) & $\begin{array}{c}0.185 \\
{[-0.510,0.879]} \\
(-0.675,1.044)\end{array}$ & 2.600 \\
\hline Sold at least one egg in last six months $(\mathrm{o} / \mathrm{1})$ & $\begin{array}{c}0.006 \\
{[-0.048,0.060]} \\
(-0.051,0.063)\end{array}$ & 0.075 \\
\hline Observations & 791 & \\
\hline
\end{tabular}

Notes: ${ }^{*} p<0.10,{ }^{* *} p<0.05,{ }^{* *} p<0.01 ;{ }^{+} q<0.10,{ }^{++} q<0.05,{ }^{+++} q<0.01$, where $q$ is the false discovery rate. $95 \%$ confidence intervals in brackets, $95 \%$ false discovery rate-adjusted confidence intervals in parentheses. Standard errors and degrees of freedom estimated as in Young (2016). All regressions include an intercept, thirteen strata indicators, an indicator for assignment to treatment, lagged calories per adult male equivalent, and lagged number of naked-neck chickens. 
Table A.41: Intent-to-treat effects for children, ages 6 to 60 months, controlling for imbalanced household characteristics

\begin{tabular}{|c|c|c|c|c|c|}
\hline & \multicolumn{2}{|l|}{ Girls } & \multicolumn{2}{|l|}{ Boys } & \multirow[b]{2}{*}{ Difference } \\
\hline & Intent-to-treat effect & Control mean & Intent-to-treat effect & Control mean & \\
\hline Weight-for-age (Z-score) & $\begin{array}{c}0.378 \\
{[0.133,0.623]^{* * *}} \\
(0.089,0.666)^{++}\end{array}$ & -1.305 & $\begin{array}{c}0.025 \\
{[-0.424,0.473]} \\
(-0.424,0.473)\end{array}$ & -1.173 & $\begin{array}{c}0.353 \\
{[-0.065,0.770]^{*}} \\
(-0.179,0.885)\end{array}$ \\
\hline Not underweight $(\mathrm{o} / \mathbf{1})$ & $\begin{array}{c}0.103 \\
{[-0.014,0.220]^{*}} \\
(-0.020,0.226)^{+}\end{array}$ & 0.773 & $\begin{array}{c}0.019 \\
{[-0.100,0.137]} \\
(-0.120,0.158)\end{array}$ & 0.797 & $\begin{array}{c}0.084 \\
{[-0.108,0.276]} \\
(-0.117,0.285)\end{array}$ \\
\hline Not severely underweight (o/1) & $\begin{array}{c}0.052 \\
{[-0.019,0.123]} \\
(-0.019,0.123)\end{array}$ & 0.938 & $\begin{array}{c}0.029 \\
{[-0.027,0.084]} \\
(-0.052,0.110)\end{array}$ & 0.953 & $\begin{array}{c}0.023 \\
{[-0.081,0.127]} \\
(-0.081,0.127)\end{array}$ \\
\hline Height-for-age (Z-score) & $\begin{array}{c}0.581 \\
{[0.248,0.915]^{* * *}} \\
(0.153,1.010)^{+++}\end{array}$ & -2.209 & $\begin{array}{c}0.043 \\
{[-0.653,0.738]} \\
(-0.685,0.771)\end{array}$ & -2.010 & $\begin{array}{c}0.538 \\
{[-0.147,1.224]} \\
(-0.268,1.344)\end{array}$ \\
\hline Not stunted $(\mathrm{o} / \mathbf{1})$ & $\begin{array}{c}0.257 \\
{[0.120,0.395]^{* * *}} \\
(0.057,0.458)^{++}\end{array}$ & 0.412 & $\begin{array}{c}0.039 \\
{[-0.118,0.197]} \\
(-0.162,0.241)\end{array}$ & 0.414 & $\begin{array}{c}0.218 \\
{[-0.013,0.449]^{*}} \\
(-0.117,0.552)\end{array}$ \\
\hline Not severely stunted (o/1) & $\begin{array}{c}0.155 \\
{[0.037,0.273]^{* *}} \\
(0.024,0.286)^{++}\end{array}$ & 0.784 & $\begin{array}{c}0.008 \\
{[-0.119,0.135]} \\
(-0.132,0.148)\end{array}$ & 0.789 & $\begin{array}{c}0.147 \\
{[-0.056,0.350]} \\
(-0.077,0.371)\end{array}$ \\
\hline Consumed animal-source foods in past day (o/1) & $\begin{array}{c}-0.010 \\
{[-0.294,0.274]} \\
(-0.345,0.326)\end{array}$ & 0.598 & $\begin{array}{c}0.099 \\
{[-0.167,0.366]} \\
(-0.214,0.413)\end{array}$ & 0.547 & $\begin{array}{c}-0.109 \\
{[-0.325,0.107]} \\
(-0.363,0.145)\end{array}$ \\
\hline One-day dietary diversity score & $\begin{array}{c}0.032 \\
{[-0.978,1.041]} \\
(-0.978,1.041)\end{array}$ & 5.649 & $\begin{array}{c}-0.023 \\
{[-1.214,1.169]} \\
(-1.214,1.169)\end{array}$ & 5.484 & $\begin{array}{c}0.054 \\
{[-0.660,0.768]} \\
(-0.660,0.768)\end{array}$ \\
\hline Observations & 195 & & 241 & & 436 \\
\hline
\end{tabular}

Notes: ${ }^{*} p<0.10,{ }^{* *} p<0.05,{ }^{* * *} p<0.01 ;{ }^{+} q<0.10,{ }^{++} q<0.05,{ }^{+++} q<0.01$, where $q$ is the false discovery rate. $95 \%$ confidence intervals in brackets, $95 \%$ false discovery rate-adjusted confidence intervals in parentheses. Standard errors and degrees of freedom estimated as in Young (2016). Z-scores and indicators for stunting and underweight based on standards from World Health Organization (2011). Imbalanced household characteristics include calories per adult male equivalent and number of naked-neck chickens. 
Table A.42: Model-based versus randomization inference: intent-to-treat effects for girls, ages 6 to 60 months, controlling for imbalanced household characteristics

\begin{tabular}{lccccc}
\hline & $\begin{array}{c}\text { Intent-to-treat } \\
\text { effect }\end{array}$ & $\begin{array}{c}\text { Model-based } \\
p \text {-value }\end{array}$ & $\begin{array}{c}\text { Randomization } \\
p \text {-value }\end{array}$ & \multicolumn{2}{c}{ Model-based } \\
& -value & $q$-value \\
\hline Weight-for-age (Z-score) & 0.378 & 0.006 & 0.029 & 0.012 & 0.044 \\
Not underweight (o/1) & 0.103 & 0.080 & 0.064 & 0.095 & 0.077 \\
Not severely underweight (o/1) & 0.052 & 0.136 & 0.089 & 0.136 & 0.089 \\
Height-for-age (Z-score) & 0.581 & 0.003 & 0.018 & 0.009 & 0.036 \\
Not stunted (o/1) & 0.257 & 0.002 & 0.004 & 0.010 & 0.024 \\
Not severely stunted (o/1) & 0.155 & 0.015 & 0.011 & 0.023 & 0.033 \\
Consumed animal-source foods in past day (o/1) & -0.010 & 0.941 & 0.953 & 1.000 & 0.953 \\
One-day dietary diversity score & 0.032 & 0.946 & 0.948 & 0.946 & 1.000 \\
\hline
\end{tabular}

Notes: See section 4.1 for the estimating equation. Z-scores and indicators for stunting and underweight based on standards from World Health Organization (2011). Model-based $p$-values and $q$-values calculated using standard errors and degrees of freedom estimated as in Young (2016). 
Table A.43: Model-based versus randomization inference: intent-to-treat effects for boys, ages 6 to 60 months, controlling for imbalanced household characteristics

\begin{tabular}{lccccc}
\hline & $\begin{array}{c}\text { Intent-to-treat } \\
\text { effect }\end{array}$ & $\begin{array}{c}\text { Model-based } \\
p \text {-value }\end{array}$ & $\begin{array}{c}\text { Randomization } \\
\text {-value }\end{array}$ & $\begin{array}{c}\text { Model-based } \\
q \text {-value }\end{array}$ & $\begin{array}{c}\text { Randomization } \\
\text {-value }\end{array}$ \\
\hline Weight-for-age (Z-score) & 0.025 & 0.906 & 0.900 & 0.906 & 1.000 \\
Not underweight (o/1) & 0.019 & 0.734 & 0.755 & 1.000 & 1.000 \\
Not severely underweight (o/1) & 0.029 & 0.282 & 0.287 & 1.000 & 1.000 \\
Height-for-age (Z-score) & 0.043 & 0.895 & 0.948 & 1.000 & 0.948 \\
Not stunted (o/1) & 0.039 & 0.595 & 0.633 & 1.000 & 1.000 \\
Not severely stunted (o/1) & 0.008 & 0.893 & 0.932 & 1.000 & 1.000 \\
Consumed animal-source foods in past day (o/1) & 0.099 & 0.431 & 0.423 & 0.862 & 0.847 \\
One-day dietary diversity score & -0.023 & 0.968 & 0.978 & 0.968 & 0.978 \\
\hline
\end{tabular}

Notes: ${ }^{*} p<0.10,{ }^{* *} p<0.05,{ }^{* * *} p<0.01$. See section 4.1 for the estimating equation. Z-scores and indicators for stunting and underweight based on standards from World Health Organization (2011). Model-based $p$-values and $q$-values calculated using standard errors and degrees of freedom estimated as in Young (2016). 
Table A.44: Model-based versus randomization inference: differences in intent-to-treat effects by gender, ages 6 to 60 months, controlling for imbalanced household characteristics

\begin{tabular}{lccccc}
\hline & $\begin{array}{c}\text { Intent-to-treat } \\
\text { effect }\end{array}$ & $\begin{array}{c}\text { Model-based } \\
p \text {-value }\end{array}$ & $\begin{array}{c}\text { Randomization } \\
p \text {-value }\end{array}$ & $\begin{array}{c}\text { Model-based } \\
q \text {-value }\end{array}$ & $\begin{array}{c}\text { Randomization } \\
\text {-value }\end{array}$ \\
\hline Weight-for-age (Z-score) & 0.353 & 0.090 & 0.111 & 0.271 & 0.333 \\
Not underweight (o/1) & 0.084 & 0.358 & 0.457 & 0.430 & 0.549 \\
Not severely underweight (o/1) & 0.023 & 0.634 & 0.648 & 0.634 & 0.648 \\
Height-for-age (Z-score) & 0.538 & 0.113 & 0.136 & 0.225 & 0.272 \\
Not stunted (o/1) & 0.218 & 0.062 & 0.070 & 0.375 & 0.420 \\
Not severely stunted (o/1) & 0.147 & 0.140 & 0.178 & 0.211 & 0.267 \\
Consumed animal-source foods in past day (o/1) & -0.109 & 0.292 & 0.280 & 0.583 & 0.561 \\
One-day dietary diversity score & 0.054 & 0.871 & 0.849 & 0.871 & 0.849 \\
\hline
\end{tabular}

Notes: ${ }^{*} p<0.10,{ }^{* *} p<0.05,{ }^{* * *} p<0.01$. See section 4.1 for details on the estimating equation. Z-scores and indicators for stunting and underweight based on standards from World Health Organization (2011). Model-based $p$-values and $q$-values calculated using standard errors and degrees of freedom estimated as in Young (2016). 


\section{A.17 Heterogeneous intent-to-treat effects by naked-neck chicken owner- ship}

Naked-neck chicken ownership is not well balanced between the treatment and control groups at baseline. The baseline data make it clear that imbalance is occurring in the far right tail of the distribution of naked-neck chickens owned. In treatment and control communities, households at the $75^{\text {th }}$ percentile own one naked-neck chicken at baseline. At the $90^{\text {th }}, 95^{\text {th }}$, and $99^{\text {th }}$ percentiles of their respective baseline distributions, households in treatment communities own five, ten, and sixteen naked-neck chickens, while households in the control group own 4, 7.5, and 14 naked-neck chickens despite top coding the top and bottom $1 \%$ of values.

In the tables below we report average intent-to-treat effects on child outcomes for households with no more than one naked-neck chicken at baseline. The purpose of these robustness checks is to make sure that our results for child-level impacts are not driven by the subsample exhibiting differences in baseline naked-neck chicken ownership. The estimated effects were obtained by adding two variables to the right hand side of our main estimating equations: an indicator for being from a household that owned more than one naked-neck chicken at baseline, and the interaction between assignment to treatment and the new indicator. Changing the regression specification in this way ensures that the coefficient on the treatment group indicator is the estimated intent-to-treat for households with no more than one naked-neck chicken at baseline. 
Table A.45: Intent-to-treat effects for children, ages 6 to 60 months, households with one or fewer naked-neck chickens at baseline

\begin{tabular}{|c|c|c|c|c|c|}
\hline & \multicolumn{2}{|c|}{ Girls } & \multicolumn{2}{|l|}{ Boys } & \multirow[b]{2}{*}{ Difference } \\
\hline & Intent-to-treat effect & Control mean & Intent-to-treat effect & Control mean & \\
\hline Weight-for-age (Z-score) & $\begin{array}{c}0.378 \\
{[0.119,0.638]^{* * *}} \\
(0.006,0.750)^{++}\end{array}$ & -1.305 & $\begin{array}{c}-0.040 \\
{[-0.504,0.423]} \\
(-0.551,0.471)\end{array}$ & -1.173 & $\begin{array}{c}0.418 \\
{[-0.046,0.883]^{*}} \\
(-0.248,1.085)\end{array}$ \\
\hline Not underweight $(\mathrm{o} / \mathrm{1})$ & $\begin{array}{c}0.106 \\
{[-0.028,0.239]} \\
(-0.034,0.245)\end{array}$ & 0.773 & $\begin{array}{c}-0.018 \\
{[-0.160,0.125]} \\
(-0.185,0.149)\end{array}$ & 0.797 & $\begin{array}{c}0.123 \\
{[-0.099,0.346]} \\
(-0.109,0.356)\end{array}$ \\
\hline Not severely underweight $(\mathrm{o} / \mathrm{1})$ & $\begin{array}{c}0.043 \\
{[-0.018,0.104]} \\
(-0.018,0.104)\end{array}$ & 0.938 & $\begin{array}{c}0.024 \\
{[-0.034,0.082]} \\
(-0.060,0.108)\end{array}$ & 0.953 & $\begin{array}{c}0.019 \\
{[-0.082,0.119]} \\
(-0.082,0.119)\end{array}$ \\
\hline Height-for-age (Z-score) & $\begin{array}{c}0.546 \\
{[0.133,0.959]^{* *}} \\
(0.062,1.030)^{++}\end{array}$ & -2.209 & $\begin{array}{c}0.011 \\
{[-0.753,0.775]} \\
(-0.789,0.811)\end{array}$ & -2.010 & $\begin{array}{c}0.535 \\
{[-0.324,1.394]} \\
(-0.411,1.481)\end{array}$ \\
\hline Not stunted $(\mathrm{o} / \mathrm{1})$ & $\begin{array}{c}0.220 \\
{[0.056,0.383]^{* *}} \\
(0.012,0.427)^{++}\end{array}$ & 0.412 & $\begin{array}{c}0.040 \\
{[-0.128,0.208]} \\
(-0.174,0.255)\end{array}$ & 0.414 & $\begin{array}{c}0.179 \\
{[-0.096,0.455]} \\
(-0.143,0.502)\end{array}$ \\
\hline Not severely stunted $(\mathrm{o} / \mathrm{1})$ & $\begin{array}{c}0.155 \\
{[0.024,0.287]^{* *}} \\
(0.011,0.300)^{++}\end{array}$ & 0.784 & $\begin{array}{c}-0.000 \\
{[-0.155,0.155]} \\
(-0.155,0.155)\end{array}$ & 0.789 & $\begin{array}{c}0.155 \\
{[-0.070,0.381]} \\
(-0.131,0.442)\end{array}$ \\
\hline Consumed animal-source foods in past day $(\mathrm{o} / \mathrm{1})$ & $\begin{array}{c}-0.065 \\
{[-0.389,0.258]} \\
(-0.389,0.258)\end{array}$ & 0.598 & $\begin{array}{c}-0.014 \\
{[-0.310,0.282]} \\
(-0.310,0.282)\end{array}$ & 0.547 & $\begin{array}{c}-0.051 \\
{[-0.269,0.166]} \\
(-0.269,0.166)\end{array}$ \\
\hline One-day dietary diversity score & $\begin{array}{c}-0.230 \\
{[-1.348,0.888]} \\
(-1.540,1.081)\end{array}$ & 5.649 & $\begin{array}{c}-0.437 \\
{[-1.735,0.862]} \\
(-1.962,1.089)\end{array}$ & 5.484 & $\begin{array}{c}0.207 \\
{[-0.479,0.893]} \\
(-0.597,1.011)\end{array}$ \\
\hline Observations & 195 & & 241 & & 436 \\
\hline
\end{tabular}

Notes: ${ }^{*} p<0.10,{ }^{* *} p<0.05,{ }^{* * *} p<0.01 ;{ }^{+} q<0.10,{ }^{++} q<0.05,{ }^{+++} q<0.01$, where $q$ is the false discovery rate. $95 \%$ confidence intervals in brackets, $95 \%$ false discovery rate-adjusted confidence intervals in parentheses. Standard errors and degrees of freedom estimated as in Young (2016). Z-scores and indicators for stunting and underweight based on standards from World Health Organization (2011). Imbalanced household characteristics include naked-neck chickens owned and calories per adult male equivalent at baseline. 
Table A.46: Model-based versus randomization inference: intent-to-treat effects for girls, ages 6 to 60 months, households with one or fewer naked-neck chickens at baseline

\begin{tabular}{lccccc}
\hline & Intent-to-treat & Model-based & Randomization & \multicolumn{2}{c}{ Model-based } \\
& effect & $p$-value & $p$-value & $q$-value & $q$-value \\
\hline Weight-for-age (Z-score) & 0.378 & 0.008 & 0.018 & 0.045 & 0.054 \\
Not underweight (o/1) & 0.106 & 0.111 & 0.105 & 0.133 & 0.126 \\
Not severely underweight (o/1) & 0.043 & 0.157 & 0.190 & 0.157 & 0.190 \\
Height-for-age (Z-score) & 0.546 & 0.013 & 0.034 & 0.027 & 0.051 \\
Not stunted (o/1) & 0.220 & 0.012 & 0.022 & 0.037 & 0.044 \\
Not severely stunted (o/1) & 0.155 & 0.024 & 0.001 & 0.036 & 0.006 \\
Consumed animal-source foods in past day (o/1) & -0.065 & 0.669 & 0.745 & 0.669 & 0.745 \\
One-day dietary diversity score & -0.230 & 0.664 & 0.712 & 1.000 & 1.000 \\
\hline
\end{tabular}

Notes: See section 4.1 for the estimating equation. Z-scores and indicators for stunting and underweight based on standards from World Health Organization (2011). Model-based $p$-values and $q$-values calculated using standard errors and degrees of freedom estimated as in Young (2016). 
Table A.47: Model-based versus randomization inference: intent-to-treat effects for boys, ages 6 to 60 months, households with one or fewer naked-neck chickens at baseline

\begin{tabular}{lccccc}
\hline & $\begin{array}{c}\text { Intent-to-treat } \\
\text { effect }\end{array}$ & $\begin{array}{c}\text { Model-based } \\
p \text {-value }\end{array}$ & $\begin{array}{c}\text { Randomization } \\
p \text {-value }\end{array}$ & $\begin{array}{c}\text { Model-based } \\
q \text {-value }\end{array}$ & $\begin{array}{c}\text { Randomization } \\
q \text {-value }\end{array}$ \\
\hline Weight-for-age (Z-score) & -0.040 & 0.853 & 0.854 & 1.000 & 1.000 \\
Not underweight (o/1) & -0.018 & 0.792 & 0.811 & 1.000 & 1.000 \\
Not severely underweight (o/1) & 0.024 & 0.388 & 0.451 & 1.000 & 1.000 \\
Height-for-age (Z-score) & 0.011 & 0.975 & 0.985 & 1.000 & 1.000 \\
Not stunted (o/1) & 0.040 & 0.613 & 0.616 & 1.000 & 1.000 \\
Not severely stunted (o/1) & -0.000 & 0.999 & 0.999 & 0.999 & 0.999 \\
Consumed animal-source foods in past day (o/1) & -0.014 & 0.919 & 0.915 & 0.919 & 0.915 \\
One-day dietary diversity score & -0.437 & 0.478 & 0.556 & 0.955 & 1.000 \\
\hline
\end{tabular}

Notes: ${ }^{*} p<0.10,{ }^{* *} p<0.05,{ }^{* * *} p<0.01$. See section 4.1 for the estimating equation. Z-scores and indicators for stunting and underweight based on standards from World Health Organization (2011). Model-based $p$-values and $q$-values calculated using standard errors and degrees of freedom estimated as in Young (2016). 
Table A.48: Model-based versus randomization inference: differences in intent-to-treat effects by gender, ages 6 to 60 months, households with one or fewer naked-neck chickens at baseline

\begin{tabular}{lccccc}
\hline & $\begin{array}{c}\text { Intent-to-treat } \\
\text { effect }\end{array}$ & $\begin{array}{c}\text { Model-based } \\
p \text {-value }\end{array}$ & $\begin{array}{c}\text { Randomization } \\
p \text {-value }\end{array}$ & $\begin{array}{c}\text { Model-based } \\
q \text {-value }\end{array}$ & $\begin{array}{c}\text { Randomization } \\
\text {-value }\end{array}$ \\
\hline Weight-for-age (Z-score) & 0.418 & 0.074 & 0.078 & 0.444 & 0.468 \\
Not underweight (o/1) & 0.123 & 0.252 & 0.280 & 0.303 & 0.336 \\
Not severely underweight (o/1) & 0.019 & 0.695 & 0.724 & 0.695 & 0.724 \\
Height-for-age (Z-score) & 0.535 & 0.202 & 0.213 & 0.303 & 0.320 \\
Not stunted (o/1) & 0.179 & 0.183 & 0.189 & 0.366 & 0.378 \\
Not severely stunted (o/1) & 0.155 & 0.161 & 0.172 & 0.484 & 0.517 \\
Consumed animal-source foods in past day (o/1) & -0.051 & 0.619 & 0.647 & 0.619 & 0.647 \\
One-day dietary diversity score & 0.207 & 0.526 & 0.440 & 1.000 & 0.881 \\
\hline
\end{tabular}

Notes: ${ }^{*} p<0.10,{ }^{* *} p<0.05,{ }^{* * *} p<0.01$. See section 4.1 for details on the estimating equation. Z-scores and indicators for stunting and underweight based on standards from World Health Organization (2011). Model-based $p$-values and $q$-values calculated using standard errors and degrees of freedom estimated as in Young (2016). 


\section{A.18 Results when not dropping contaminated strata}

Below we present estimated intent-to-treat effects on household and child outcomes obtained without dropping two contaminated strata. None of our conclusions are affected. 
Table A.49: Household-level intent-to-treat effects, all strata

\begin{tabular}{|c|c|c|}
\hline & Intent-to-treat effect & Control mean \\
\hline Annual expenditure per adult male equivalent $(\log )$ & $\begin{array}{c}-0.012 \\
{[-0.409,0.384]} \\
(-0.479,0.454)\end{array}$ & 9.061 \\
\hline Annual food expenditure per adult male equivalent (log) & $\begin{array}{c}-0.003 \\
{[-0.277,0.272]} \\
(-0.277,0.272)\end{array}$ & 8.349 \\
\hline Daily calories per adult male equivalent (log) & $\begin{array}{c}-0.005 \\
{[-0.234,0.225]} \\
(-0.247,0.238)\end{array}$ & 8.059 \\
\hline Daily grams of animal protein per adult male equivalent (log) & $\begin{array}{c}-0.002 \\
{[-0.820,0.816]} \\
(-0.820,0.816)\end{array}$ & 2.494 \\
\hline Daily servings of eggs & $\begin{array}{c}-0.030 \\
{[-0.233,0.174]} \\
(-0.280,0.221)\end{array}$ & 0.422 \\
\hline Eggs consumed per day per adult male equivalent & $\begin{array}{c}-0.036 \\
{[-0.856,0.784]} \\
(-0.964,0.891)\end{array}$ & 1.730 \\
\hline Food consumption score & $\begin{array}{c}-1.379 \\
{[-7.259,4.502]} \\
(-9.653,6.896)\end{array}$ & 32.998 \\
\hline Chickens owned & $\begin{array}{c}-1.535 \\
{[-3.386,0.316]^{*}} \\
(-4.137,1.067)\end{array}$ & 8.637 \\
\hline Naked-neck chickens owned & $\begin{array}{c}-0.513 \\
{[-1.895,0.869]} \\
(-2.075,1.049)\end{array}$ & 2.648 \\
\hline Uses poultry registry $(\mathrm{o} / \mathrm{1})$ & $\begin{array}{c}0.027 \\
{[-0.006,0.060]} \\
(-0.014,0.068)\end{array}$ & 0.016 \\
\hline Eggs produced in last six months (log) & $\begin{array}{c}0.107 \\
{[-0.567,0.781]} \\
(-0.606,0.819)\end{array}$ & 2.702 \\
\hline Sold at least one egg in last six months (o/1) & $\begin{array}{c}-0.003 \\
{[-0.057,0.051]} \\
(-0.057,0.051)\end{array}$ & 0.082 \\
\hline Observations & 839 & \\
\hline
\end{tabular}

Notes: ${ }^{*} p<0.10,{ }^{* *} p<0.05,{ }^{* * *} p<0.01 ;{ }^{+} q<0.10,{ }^{++} q<0.05,{ }^{+++} q<0.01$, where $q$ is the false discovery rate. $95 \%$ confidence intervals in brackets, $95 \%$ false discovery rate-adjusted confidence intervals in parentheses. Standard errors and degrees of freedom estimated as in Young (2016). All regressions include an intercept, fifteen strata indicators, an indicator for assignment to treatment, and the lagged outcome. 
Table A.50: Intent-to-treat effects for children ages 6 to 60 months, all strata

\begin{tabular}{|c|c|c|c|c|c|}
\hline & \multicolumn{2}{|l|}{ Girls } & \multicolumn{2}{|l|}{ Boys } & \multirow[b]{2}{*}{ Difference } \\
\hline & Intent-to-treat effect & Control mean & Intent-to-treat effect & Control mean & \\
\hline Weight-for-age (Z-score) & $\begin{array}{c}0.301 \\
{[0.055,0.548]^{* *}} \\
(0.011,0.591)^{++}\end{array}$ & -1.286 & $\begin{array}{c}0.018 \\
{[-0.389,0.425]} \\
(-0.431,0.468)\end{array}$ & -1.154 & $\begin{array}{c}0.283 \\
{[-0.081,0.647]} \\
(-0.144,0.711)\end{array}$ \\
\hline Not underweight $(\mathrm{o} / \mathrm{1})$ & $\begin{array}{c}0.082 \\
{[-0.024,0.188]} \\
(-0.024,0.188)\end{array}$ & 0.791 & $\begin{array}{c}0.016 \\
{[-0.099,0.132]} \\
(-0.119,0.152)\end{array}$ & 0.800 & $\begin{array}{c}0.066 \\
{[-0.106,0.238]} \\
(-0.114,0.246)\end{array}$ \\
\hline Not severely underweight $(\mathrm{o} / \mathrm{1})$ & $\begin{array}{c}0.050 \\
{[-0.012,0.111]} \\
(-0.015,0.114)\end{array}$ & 0.945 & $\begin{array}{c}0.030 \\
{[-0.022,0.081]} \\
(-0.046,0.105)\end{array}$ & 0.952 & $\begin{array}{c}0.020 \\
{[-0.075,0.115]} \\
(-0.075,0.115)\end{array}$ \\
\hline Height-for-age (Z-score) & $\begin{array}{c}0.474 \\
{[0.129,0.819]^{* *}} \\
(0.032,0.916)^{++}\end{array}$ & -2.201 & $\begin{array}{c}0.001 \\
{[-0.671,0.674]} \\
(-0.671,0.674)\end{array}$ & -2.007 & $\begin{array}{c}0.473 \\
{[-0.127,1.073]} \\
(-0.294,1.239)\end{array}$ \\
\hline Not stunted $(\mathrm{o} / 1)$ & $\begin{array}{c}0.215 \\
{[0.086,0.344]^{* * *}} \\
(0.027,0.403)^{++}\end{array}$ & 0.409 & $\begin{array}{c}0.025 \\
{[-0.128,0.179]} \\
(-0.171,0.222)\end{array}$ & 0.428 & $\begin{array}{c}0.189 \\
{[-0.018,0.397]^{*}} \\
(-0.111,0.489)\end{array}$ \\
\hline Not severely stunted $(\mathrm{o} / \mathrm{1})$ & $\begin{array}{c}0.123 \\
{[0.006,0.241]^{* *}} \\
(-0.007,0.254)^{+}\end{array}$ & 0.809 & $\begin{array}{c}0.003 \\
{[-0.116,0.122]} \\
(-0.122,0.128)\end{array}$ & 0.786 & $\begin{array}{c}0.121 \\
{[-0.063,0.304]} \\
(-0.082,0.323)\end{array}$ \\
\hline Consumed animal-source foods in past day $(\mathrm{o} / \mathrm{1})$ & $\begin{array}{c}-0.081 \\
{[-0.377,0.216]} \\
(-0.431,0.269)\end{array}$ & 0.600 & $\begin{array}{c}0.037 \\
{[-0.225,0.299]} \\
(-0.272,0.346)\end{array}$ & 0.549 & $\begin{array}{c}-0.118 \\
{[-0.303,0.068]} \\
(-0.336,0.101)\end{array}$ \\
\hline One-day dietary diversity score & $\begin{array}{c}-0.149 \\
{[-1.170,0.873]} \\
(-1.170,0.873)\end{array}$ & 5.600 & $\begin{array}{c}-0.073 \\
{[-1.239,1.093]} \\
(-1.239,1.093)\end{array}$ & 5.444 & $\begin{array}{c}-0.075 \\
{[-0.740,0.589]} \\
(-0.740,0.589)\end{array}$ \\
\hline Observations & 213 & & 259 & & 472 \\
\hline
\end{tabular}

Notes: ${ }^{*} p<0.10,{ }^{* *} p<0.05,{ }^{* * *} p<0.01 ;{ }^{+} q<0.10,{ }^{++} q<0.05,{ }^{+++} q<0.01$, where $q$ is the false discovery rate. $95 \%$ confidence intervals in brackets, $95 \%$ false discovery rate-adjusted confidence intervals in parentheses. Standard errors and degrees of freedom estimated as in Young (2016). Z-scores and indicators for stunting and underweight based on standards from World Health Organization (2011). 
Table A.51: Model-based versus randomization inference: intent-to-treat effects for girls, ages 6 to 60 months, all strata

\begin{tabular}{|c|c|c|c|c|c|}
\hline & $\begin{array}{c}\text { Intent-to-treat } \\
\text { effect }\end{array}$ & $\begin{array}{c}\text { Model-based } \\
p \text {-value }\end{array}$ & $\begin{array}{c}\text { Randomization } \\
p \text {-value }\end{array}$ & $\begin{array}{l}\text { Model-based } \\
q \text {-value }\end{array}$ & $\begin{array}{c}\text { Randomization } \\
q \text {-value }\end{array}$ \\
\hline Weight-for-age (Z-score) & 0.301 & 0.021 & 0.053 & 0.042 & 0.080 \\
\hline Not underweight $(\mathrm{o} / \mathrm{1})$ & 0.082 & 0.116 & 0.107 & 0.116 & 0.107 \\
\hline Not severely underweight $(\mathrm{o} / \mathrm{1})$ & 0.050 & 0.104 & 0.087 & 0.125 & 0.105 \\
\hline Height-for-age (Z-score) & 0.474 & 0.012 & 0.045 & 0.035 & 0.135 \\
\hline Not stunted $(\mathrm{o} / \mathrm{1})$ & 0.215 & 0.004 & 0.006 & 0.022 & 0.036 \\
\hline Not severely stunted $(\mathrm{o} / \mathrm{1})$ & 0.123 & 0.042 & 0.047 & 0.063 & 0.094 \\
\hline Consumed animal-source foods in past day $(\mathrm{o} / \mathrm{1})$ & -0.081 & 0.561 & 0.576 & 1.000 & 1.000 \\
\hline One-day dietary diversity score & -0.149 & 0.754 & 0.763 & 0.754 & 0.763 \\
\hline
\end{tabular}

Notes: See section 4.1 for the estimating equation. Z-scores and indicators for stunting and underweight based on standards from World Health Organization (2011). Model-based $p$-values and $q$-values calculated using standard errors and degrees of freedom estimated as in Young (2016). 
Table A.52: Model-based versus randomization inference: intent-to-treat effects for boys, ages 6 to 60 months, all strata

\begin{tabular}{lccccc}
\hline & $\begin{array}{c}\text { Intent-to-treat } \\
\text { effect }\end{array}$ & $\begin{array}{c}\text { Model-based } \\
p \text {-value }\end{array}$ & $\begin{array}{c}\text { Randomization } \\
\text {-value }\end{array}$ & $\begin{array}{c}\text { Model-based } \\
q \text {-value }\end{array}$ & $\begin{array}{c}\text { Randomization } \\
\text {-value }\end{array}$ \\
\hline Weight-for-age (Z-score) & 0.018 & 0.923 & 0.920 & 1.000 & 1.000 \\
Not underweight $(\mathrm{o} / \mathrm{l})$ & 0.016 & 0.760 & 0.771 & 1.000 & 1.000 \\
Not severely underweight $(\mathrm{o} / \mathrm{1})$ & 0.030 & 0.233 & 0.263 & 1.000 & 1.000 \\
Height-for-age $(\mathrm{Z}$-score) & 0.001 & 0.997 & 0.997 & 0.997 & 0.997 \\
Not stunted (o/1) & 0.025 & 0.723 & 0.773 & 1.000 & 1.000 \\
Not severely stunted (o/1) & 0.003 & 0.958 & 0.971 & 1.000 & 1.000 \\
Consumed animal-source foods in past day $(\mathrm{o} / \mathrm{1})$ & 0.037 & 0.761 & 0.763 & 1.000 & 1.000 \\
One-day dietary diversity score & -0.073 & 0.892 & 0.889 & 0.892 & 0.889 \\
\hline
\end{tabular}

Notes: ${ }^{*} p<0.10,{ }^{* *} p<0.05,{ }^{* * *} p<0.01$. See section 4.1 for the estimating equation. Z-scores and indicators for stunting and underweight based on standards from World Health Organization (2011). Model-based $p$-values and $q$-values calculated using standard errors and degrees of freedom estimated as in Young (2016). 
Table A.53: Model-based versus randomization inference: differences in intent-to-treat effects by gender, ages 6 to 60 months, all strata

\begin{tabular}{lccccc}
\hline & $\begin{array}{c}\text { Intent-to-treat } \\
\text { effect }\end{array}$ & $\begin{array}{c}\text { Model-based } \\
p \text {-value }\end{array}$ & $\begin{array}{c}\text { Randomization } \\
p \text {-value }\end{array}$ & $\begin{array}{c}\text { Model-based } \\
q \text {-value }\end{array}$ & $\begin{array}{c}\text { Randomization } \\
q \text {-value }\end{array}$ \\
\hline Weight-for-age (Z-score) & 0.283 & 0.116 & 0.138 & 0.231 & 0.276 \\
Not underweight (o/1) & 0.066 & 0.420 & 0.478 & 0.505 & 0.574 \\
Not severely underweight (o/1) & 0.020 & 0.651 & 0.655 & 0.651 & 0.655 \\
Height-for-age (Z-score) & 0.473 & 0.111 & 0.107 & 0.334 & 0.321 \\
Not stunted (o/1) & 0.189 & 0.070 & 0.066 & 0.418 & 0.396 \\
Not severely stunted (o/1) & 0.121 & 0.177 & 0.207 & 0.266 & 0.311 \\
Consumed animal-source foods in past day $(\mathrm{o} / 1)$ & -0.118 & 0.191 & 0.192 & 0.383 & 0.384 \\
One-day dietary diversity score & -0.075 & 0.809 & 0.770 & 0.809 & 0.770 \\
\hline
\end{tabular}

Notes: ${ }^{*} p<0.10,{ }^{* *} p<0.05,{ }^{* * *} p<0.01$. See section 4.1 for details on the estimating equation. Z-scores and indicators for stunting and underweight based on standards from World Health Organization (2011). Model-based $p$-values and $q$-values calculated using standard errors and degrees of freedom estimated as in Young (2016). 


\section{A.19 Local average treatment effect estimates}

In this section we compare estimated intent-to-treat effects and local average treatment effects for all outcomes of interest, where the latter is the average treatment effect on households who would enroll in the program if assigned to the treatment group and not otherwise.

The local average treatment effect estimates were obtained using two-stage least squares models where taking the treatment is instrumented by random assignment to cohort 1 . We define being "treated" has receiving chickens at least six months before follow-up to allow adequate time for impacts on child health. The local average treatment effect is identified if there are no spillover effects of the program, being assigned to treatment group only affects the outcome through program participation (i.e., the exclusion restriction holds), and being assigned to the treatment group rather than the control group either induces a household to enroll in the program or has no effect (i.e., the "monotonicity” assumption (Imbens and Angrist, 1994)). In the present case, the assumption of no spillovers seems problematic, as there may have been spillovers from program participants to non-participants within communities. Average distance to the nearest neighbor is 74 meters for households in our data set, making sales, trade, or gifting chickens and eggs within communities quite plausible. Although we are unable to detect any program impacts on having sold eggs in our analysis, 54 of the 791 households in our final data set report selling eggs and doing so primarily within their communities, while another six households sold outside their communities. We did not ask specifically about egg transactions other than sales. Regardless, ruling out intra-community spillovers seems like a strong assumption in the present case. We include local average treatment effect estimates solely for comparison's sake.

Covariates are the same in intent-to-treat regressions and our two-stage least squares models. We perform inference on the local average treatment effects using the wild cluster bootstrap (Roodman et al., 2019). We report $p$-values because of difficulties with the grid search required to obtain $95 \%$ confidence intervals with the wild cluster bootstrap. As we would expect, the local average treatment effect estimates are larger in absolute value and less precise than the intent-to-treat effects. Among 
girls, local average treatment effects and intent-to-treat effects are statistically significant for the same outcomes. But significance of the former is not robust to adjustment for multiple comparisons.

Table A.54: Intent-to-treat and local average treatment effects for household-level outcomes

\begin{tabular}{|c|c|c|}
\hline & $\begin{array}{c}\text { Intent-to-treat } \\
\text { effect }\end{array}$ & $\begin{array}{l}\text { Local average } \\
\text { treatment effect }\end{array}$ \\
\hline Annual expenditure per adult male equivalent (log) & $\begin{array}{l}-0.008 \\
(0.967)\end{array}$ & $\begin{array}{l}-0.025 \\
(0.957)\end{array}$ \\
\hline Annual food expenditure per adult male equivalent (log) & $\begin{array}{l}0.004 \\
(0.977)\end{array}$ & $\begin{array}{c}0.012 \\
(0.967)\end{array}$ \\
\hline Daily calories per adult male equivalent (log) & $\begin{array}{l}-0.001 \\
(0.992)\end{array}$ & $\begin{array}{l}-0.004 \\
(0.983)\end{array}$ \\
\hline Daily grams of animal protein per adult male equivalent (log & $\begin{array}{c}0.007 \\
(0.987)\end{array}$ & $\begin{array}{c}0.020 \\
(0.973)\end{array}$ \\
\hline Daily servings of eggs & $\begin{array}{l}-0.024 \\
(0.811)\end{array}$ & $\begin{array}{l}-0.071 \\
(0.843)\end{array}$ \\
\hline Eggs consumed per day per adult male equivalent & $\begin{array}{c}0.013 \\
(0.975)\end{array}$ & $\begin{array}{c}0.038 \\
(0.963)\end{array}$ \\
\hline Food consumption score & $\begin{array}{l}-1.046 \\
(0.720)\end{array}$ & $\begin{array}{l}-3.100 \\
(0.713)\end{array}$ \\
\hline Chickens owned (log) & $\begin{array}{l}-0.130 \\
(0.492)\end{array}$ & $\begin{array}{c}-0.381 \\
(0.470)\end{array}$ \\
\hline Naked-neck chickens owned (log) & $\begin{array}{l}-0.017 \\
(0.941)\end{array}$ & $\begin{array}{l}-0.049 \\
(0.945)\end{array}$ \\
\hline Uses poultry registry $(\mathrm{o} / 1)$ & $\begin{array}{l}0.026 \\
(0.119)\end{array}$ & $\begin{array}{c}0.077 \\
(0.102)\end{array}$ \\
\hline Eggs produced in last six months (log) & $\begin{array}{c}0.203 \\
(0.537)\end{array}$ & $\begin{array}{c}0.594 \\
(0.559)\end{array}$ \\
\hline Sold at least one egg in last six months $(\mathrm{o} / 1)$ & $\begin{array}{l}0.004 \\
(0.865)\end{array}$ & $\begin{array}{c}0.012 \\
(0.897)\end{array}$ \\
\hline Observations & 790 & 790 \\
\hline
\end{tabular}

Notes: $p$-values in parentheses. For the intent-to-treat effects $p$-values calculated using standard errors and degrees of freedom estimated as in Young (2016). For the local average treatment effects $p$-values were obtained using the wild cluster bootstrap with 999 replications (Roodman et al., 2019). 
Table A.55: Intent-to-treat and local average treatment effects for child-level outcomes

\begin{tabular}{|c|c|c|c|c|}
\hline & \multicolumn{2}{|c|}{ Girls } & \multicolumn{2}{|c|}{ Boys } \\
\hline & $\begin{array}{c}\text { Intent-to-treat } \\
\text { effect }\end{array}$ & $\begin{array}{l}\text { Local average } \\
\text { treatment effect }\end{array}$ & $\begin{array}{c}\text { Intent-to-treat } \\
\text { effect }\end{array}$ & $\begin{array}{l}\text { Local average } \\
\text { treatment effect }\end{array}$ \\
\hline Weight-for-age (Z-score) & $\begin{array}{c}0.349 \\
(0.008)\end{array}$ & $\begin{array}{c}0.916 \\
(0.048)\end{array}$ & $\begin{array}{l}0.027 \\
(0.891)\end{array}$ & $\begin{array}{c}0.051 \\
(0.909)\end{array}$ \\
\hline Not underweight $(\mathrm{o} / 1)$ & $\begin{array}{l}0.090 \\
(0.102)\end{array}$ & $\begin{array}{l}0.235 \\
(0.126)\end{array}$ & $\begin{array}{l}0.023 \\
(0.687)\end{array}$ & $\begin{array}{l}0.043 \\
(0.675)\end{array}$ \\
\hline Not severely underweight $(\mathrm{o} / \mathrm{1})$ & $\begin{array}{l}0.054 \\
(0.105)\end{array}$ & $\begin{array}{c}0.139 \\
(0.124)\end{array}$ & $\begin{array}{c}0.032 \\
(0.220)\end{array}$ & $\begin{array}{l}0.062 \\
(0.252)\end{array}$ \\
\hline Height-for-age (Z-score) & $\begin{array}{c}0.539 \\
(0.005)\end{array}$ & $\begin{array}{c}1.389 \\
(0.054)\end{array}$ & $\begin{array}{c}0.065 \\
(0.839)\end{array}$ & $\begin{array}{c}0.124 \\
(0.909)\end{array}$ \\
\hline Not stunted $(\mathrm{o} / 1)$ & $\begin{array}{c}0.235 \\
(0.003)\end{array}$ & $\begin{array}{l}0.603 \\
(0.032)\end{array}$ & $\begin{array}{c}0.038 \\
(0.609)\end{array}$ & $\begin{array}{l}0.071 \\
(0.671)\end{array}$ \\
\hline Not severely stunted (o/1) & $\begin{array}{c}0.143 \\
(0.023)\end{array}$ & $\begin{array}{l}0.370 \\
(0.026)\end{array}$ & $\begin{array}{c}0.012 \\
(0.840)\end{array}$ & $\begin{array}{l}0.022 \\
(0.889)\end{array}$ \\
\hline Consumed animal-source foods in past day $(\mathrm{o} / \mathrm{1})$ & $\begin{array}{l}-0.039 \\
(0.775)\end{array}$ & $\begin{array}{l}-0.103 \\
(0.807)\end{array}$ & $\begin{array}{c}0.061 \\
(0.627)\end{array}$ & $\begin{array}{c}0.121 \\
(0.657)\end{array}$ \\
\hline One-day dietary diversity score & $\begin{array}{l}-0.014 \\
(0.976)\end{array}$ & $\begin{array}{l}-0.037 \\
(0.977)\end{array}$ & $\begin{array}{l}-0.041 \\
(0.942)\end{array}$ & $\begin{array}{l}-0.083 \\
(0.963)\end{array}$ \\
\hline Observations & 196 & 196 & 244 & 244 \\
\hline
\end{tabular}

Notes: $p$-values in parentheses. For the intent-to-treat effects $p$-values calculated using standard errors and degrees of freedom estimated as in Young (2016). For the local average treatment effects $p$-values were obtained using the wild cluster bootstrap with 999 replications (Roodman et al., 2019). 


\section{A.20 Impacts on children, including infants under six months of age}

In the main text, we describe our justification for focusing on children between the ages of six and 60 months. But it is possible that younger children benefited from the program through improved nutrition among mothers. We therefore check the robustness of our results to including children youngers than six months of age in tables A.56 through A.59. None of our conclusions are affected. 
Table A.56: Intent-to-treat effects for children, ages o to 60 months

\begin{tabular}{|c|c|c|c|c|c|}
\hline & \multicolumn{2}{|l|}{ Girls } & \multicolumn{2}{|l|}{ Boys } & \multirow[b]{2}{*}{ Difference } \\
\hline & Intent-to-treat effect & Control mean & Intent-to-treat effect & Control mean & \\
\hline Weight-for-age (Z-score) & $\begin{array}{c}0.314 \\
{[0.063,0.564]^{* *}} \\
(0.018,0.609)^{++}\end{array}$ & -1.170 & $\begin{array}{c}0.015 \\
{[-0.414,0.443]} \\
(-0.414,0.443)\end{array}$ & -1.078 & $\begin{array}{c}0.299 \\
{[-0.032,0.630]^{*}} \\
(-0.183,0.781)\end{array}$ \\
\hline Not underweight $(\mathrm{o} / \mathbf{1})$ & $\begin{array}{c}0.070 \\
{[-0.029,0.170]} \\
(-0.029,0.170)\end{array}$ & 0.794 & $\begin{array}{c}0.024 \\
{[-0.090,0.139]} \\
(-0.111,0.160)\end{array}$ & 0.812 & $\begin{array}{c}0.046 \\
{[-0.122,0.214]} \\
(-0.130,0.222)\end{array}$ \\
\hline Not severely underweight $(\mathrm{o} / \mathrm{1})$ & $\begin{array}{c}0.051 \\
{[-0.010,0.112]^{*}} \\
(-0.013,0.115)\end{array}$ & 0.944 & $\begin{array}{c}0.030 \\
{[-0.020,0.079]} \\
(-0.043,0.102)\end{array}$ & 0.957 & $\begin{array}{c}0.022 \\
{[-0.072,0.116]} \\
(-0.072,0.116)\end{array}$ \\
\hline Height-for-age (Z-score) & $\begin{array}{c}0.502 \\
{[0.134,0.869]^{* *}} \\
(0.029,0.974)^{++}\end{array}$ & -2.061 & $\begin{array}{c}0.074 \\
{[-0.566,0.714]} \\
(-0.596,0.744)\end{array}$ & -1.898 & $\begin{array}{c}0.428 \\
{[-0.231,1.087]} \\
(-0.417,1.273)\end{array}$ \\
\hline Not stunted $(\mathrm{o} / \mathbf{1})$ & $\begin{array}{c}0.202 \\
{[0.059,0.345]^{* *}} \\
(-0.008,0.412)^{+}\end{array}$ & 0.458 & $\begin{array}{c}0.062 \\
{[-0.080,0.204]} \\
(-0.121,0.244)\end{array}$ & 0.435 & $\begin{array}{c}0.140 \\
{[-0.089,0.370]} \\
(-0.113,0.394)\end{array}$ \\
\hline Not severely stunted $(\mathrm{o} / \mathrm{1})$ & $\begin{array}{c}0.131 \\
{[0.023,0.239]^{* *}} \\
(0.011,0.250)^{++}\end{array}$ & 0.804 & $\begin{array}{c}0.017 \\
{[-0.098,0.133]} \\
(-0.111,0.145)\end{array}$ & 0.804 & $\begin{array}{c}0.114 \\
{[-0.067,0.295]} \\
(-0.100,0.327)\end{array}$ \\
\hline Consumed animal-source foods in past day $(\mathrm{o} / \mathbf{1})$ & $\begin{array}{c}-0.024 \\
{[-0.299,0.252]} \\
(-0.299,0.252)\end{array}$ & 0.551 & $\begin{array}{c}0.043 \\
{[-0.217,0.302]} \\
(-0.217,0.302)\end{array}$ & 0.519 & $\begin{array}{c}-0.067 \\
{[-0.247,0.114]} \\
(-0.247,0.114)\end{array}$ \\
\hline One-day dietary diversity score & $\begin{array}{c}0.118 \\
{[-0.941,1.178]} \\
(-1.134,1.370)\end{array}$ & 5.271 & $\begin{array}{c}-0.224 \\
{[-1.458,1.011]} \\
(-1.684,1.237)\end{array}$ & 5.222 & $\begin{array}{c}0.342 \\
{[-0.352,1.035]} \\
(-0.476,1.159)\end{array}$ \\
\hline Observations & 208 & & 259 & & 467 \\
\hline
\end{tabular}

Notes: ${ }^{*} p<0.10,{ }^{* *} p<0.05,{ }^{* * *} p<0.01 ;{ }^{+} q<0.10,{ }^{++} q<0.05,{ }^{+++} q<0.01$, where $q$ is the false discovery rate. $95 \%$ confidence intervals in brackets, $95 \%$ false discovery rate-adjusted confidence intervals in parentheses. Standard errors and degrees of freedom estimated as in Young (2016). Z-scores and indicators for stunting and underweight based on standards from World Health Organization (2011). 
Table A.57: Model-based versus randomization inference: intent-to-treat effects for girls, ages o to 60 months

\begin{tabular}{lccccc}
\hline & $\begin{array}{c}\text { Intent-to-treat } \\
\text { effect }\end{array}$ & $\begin{array}{c}\text { Model-based } \\
p \text {-value }\end{array}$ & $\begin{array}{c}\text { Randomization } \\
p \text {-value }\end{array}$ & $\begin{array}{c}\text { Model-based } \\
q \text {-value }\end{array}$ & $\begin{array}{c}\text { Randomization } \\
\text {-value }\end{array}$ \\
\hline Weight-for-age (Z-score) & 0.314 & 0.019 & 0.037 & 0.038 & 0.056 \\
Not underweight (o/1) & 0.070 & 0.145 & 0.150 & 0.145 & 0.150 \\
Not severely underweight (o/1) & 0.051 & 0.091 & 0.063 & 0.109 & 0.076 \\
Height-for-age (Z-score) & 0.502 & 0.012 & 0.032 & 0.037 & 0.064 \\
Not stunted (o/1) & 0.202 & 0.010 & 0.015 & 0.061 & 0.090 \\
Not severely stunted (o/1) & 0.131 & 0.022 & 0.015 & 0.033 & 0.045 \\
Consumed animal-source foods in past day (o/1) & -0.024 & 0.851 & 0.869 & 0.851 & 0.869 \\
One-day dietary diversity score & 0.118 & 0.809 & 0.807 & 1.000 & 1.000 \\
\hline
\end{tabular}

Notes: See section 4.1 for the estimating equation. Z-scores and indicators for stunting and underweight based on standards from World Health Organization (2011). Model-based $p$-values and $q$-values calculated using standard errors and degrees of freedom estimated as in Young (2016). 
Table A.58: Model-based versus randomization inference: intent-to-treat effects for boys, ages o to 60 months

\begin{tabular}{lccccc}
\hline & $\begin{array}{c}\text { Intent-to-treat } \\
\text { effect }\end{array}$ & $\begin{array}{c}\text { Model-based } \\
p \text {-value }\end{array}$ & $\begin{array}{c}\text { Randomization } \\
p \text {-value }\end{array}$ & $\begin{array}{c}\text { Model-based } \\
q \text {-value }\end{array}$ & $\begin{array}{c}\text { Randomization } \\
q \text {-value }\end{array}$ \\
\hline Weight-for-age (Z-score) & 0.015 & 0.940 & 0.924 & 0.940 & 0.924 \\
Not underweight (o/1) & 0.024 & 0.644 & 0.667 & 1.000 & 1.000 \\
Not severely underweight (o/1) & 0.030 & 0.213 & 0.265 & 1.000 & 1.000 \\
Height-for-age (Z-score) & 0.074 & 0.802 & 0.898 & 0.963 & 1.000 \\
Not stunted (o/1) & 0.062 & 0.356 & 0.412 & 1.000 & 1.000 \\
Not severely stunted (o/1) & 0.017 & 0.749 & 0.811 & 1.000 & 1.000 \\
Consumed animal-source foods in past day $(\mathrm{o} / \mathrm{l})$ & 0.043 & 0.720 & 0.717 & 0.720 & 0.717 \\
One-day dietary diversity score & -0.224 & 0.694 & 0.697 & 1.000 & 1.000 \\
\hline
\end{tabular}

Notes: ${ }^{*} p<0.10,{ }^{* *} p<0.05,{ }^{* * *} p<0.01$. See section 4.1 for the estimating equation. Z-scores and indicators for stunting and underweight based on standards from World Health Organization (2011). Model-based $p$-values and $q$-values calculated using standard errors and degrees of freedom estimated as in Young (2016). 
Table A.59: Model-based versus randomization inference: differences in intent-to-treat effects by gender, ages o to 60 months

\begin{tabular}{|c|c|c|c|c|c|}
\hline & $\begin{array}{c}\text { Intent-to-treat } \\
\text { effect }\end{array}$ & $\begin{array}{c}\text { Model-based } \\
p \text {-value }\end{array}$ & $\begin{array}{c}\text { Randomization } \\
p \text {-value }\end{array}$ & $\begin{array}{c}\text { Model-based } \\
q \text {-value }\end{array}$ & $\begin{array}{c}\text { Randomization } \\
q \text {-value }\end{array}$ \\
\hline Weight-for-age (Z-score) & 0.299 & 0.072 & 0.061 & 0.433 & 0.366 \\
\hline Not underweight $(\mathrm{o} / \mathrm{1})$ & 0.046 & 0.559 & 0.599 & 0.671 & 0.718 \\
\hline Not severely underweight $(\mathrm{o} / \mathrm{1})$ & 0.022 & 0.620 & 0.644 & 0.620 & 0.644 \\
\hline Height-for-age (Z-score) & 0.428 & 0.181 & 0.188 & 0.542 & 0.565 \\
\hline Not stunted $(\mathrm{o} / \mathrm{1})$ & 0.140 & 0.205 & 0.237 & 0.308 & 0.356 \\
\hline Not severely stunted $(\mathrm{o} / \mathrm{1})$ & 0.114 & 0.194 & 0.194 & 0.387 & 0.388 \\
\hline Consumed animal-source foods in past day $(\mathrm{o} / \mathrm{1})$ & -0.067 & 0.432 & 0.422 & 0.432 & 0.422 \\
\hline One-day dietary diversity score & 0.342 & 0.300 & 0.267 & 0.601 & 0.535 \\
\hline
\end{tabular}

Notes: ${ }^{*} p<0.10,{ }^{* *} p<0.05,{ }^{* * *} p<0.01$. See section 4.1 for details on the estimating equation. Z-scores and indicators for stunting and underweight based on standards from World Health Organization (2011). Model-based $p$-values and $q$-values calculated using standard errors and degrees of freedom estimated as in Young (2016). 


\section{A.21 Impacts on children excluding households with no children at base- line}

It is possible that fertility decision would be affected by the program. Impacts on fertility would not imply that our results are biased, but would alter the interpretation of the results. In tables A.6o through A.63 we re-estimate impacts on children only using the subsample of households with children at baseline. None of our conclusions are affected by this change in the sample. 
Table A.6o: Intent-to-treat effects for children, ages 6 to 60 months, households with children at baseline only

\begin{tabular}{|c|c|c|c|c|c|}
\hline & \multicolumn{2}{|l|}{ Girls } & \multicolumn{2}{|l|}{ Boys } & \multirow[b]{2}{*}{ Difference } \\
\hline & Intent-to-treat effect & Control mean & Intent-to-treat effect & Control mean & \\
\hline Weight-for-age (Z-score) & $\begin{array}{c}0.375 \\
{[0.111,0.640]^{* *}} \\
(0.033,0.718)^{++}\end{array}$ & -1.393 & $\begin{array}{c}0.059 \\
{[-0.336,0.453]} \\
(-0.378,0.496)\end{array}$ & -1.250 & $\begin{array}{c}0.316 \\
{[-0.121,0.753]} \\
(-0.167,0.800)\end{array}$ \\
\hline Not underweight $(\mathrm{o} / \mathrm{1})$ & $\begin{array}{c}0.107 \\
{[-0.012,0.226]^{*}} \\
(-0.012,0.226)^{+}\end{array}$ & 0.722 & $\begin{array}{c}0.037 \\
{[-0.117,0.191]} \\
(-0.146,0.219)\end{array}$ & 0.787 & $\begin{array}{c}0.071 \\
{[-0.166,0.307]} \\
(-0.166,0.307)\end{array}$ \\
\hline Not severely underweight $(\mathrm{o} / \mathrm{1})$ & $\begin{array}{c}0.082 \\
{[0.017,0.146]^{* *}} \\
(0.010,0.153)^{++}\end{array}$ & 0.924 & $\begin{array}{c}0.044 \\
{[-0.030,0.118]} \\
(-0.065,0.154)\end{array}$ & 0.944 & $\begin{array}{c}0.038 \\
{[-0.082,0.157]} \\
(-0.087,0.163)\end{array}$ \\
\hline Height-for-age (Z-score) & $\begin{array}{c}0.528 \\
{[0.114,0.943]^{* *}} \\
(0.036,1.021)^{++}\end{array}$ & -2.319 & $\begin{array}{c}0.021 \\
{[-0.468,0.510]} \\
(-0.492,0.534)\end{array}$ & -2.017 & $\begin{array}{c}0.507 \\
{[-0.025,1.040]^{*}} \\
(-0.121,1.136)\end{array}$ \\
\hline Not stunted $(\mathrm{o} / \mathrm{1})$ & $\begin{array}{c}0.250 \\
{[0.110,0.391]^{* * *}} \\
(0.041,0.460)^{++}\end{array}$ & 0.392 & $\begin{array}{c}0.041 \\
{[-0.095,0.176]} \\
(-0.134,0.215)\end{array}$ & 0.417 & $\begin{array}{c}0.210 \\
{[0.026,0.394]^{* *}} \\
(-0.061,0.480)\end{array}$ \\
\hline Not severely stunted $(\mathrm{o} / \mathrm{1})$ & $\begin{array}{c}0.193 \\
{[0.034,0.352]^{* *}} \\
(0.027,0.359)^{++}\end{array}$ & 0.747 & $\begin{array}{c}-0.004 \\
{[-0.105,0.097]} \\
(-0.105,0.097)\end{array}$ & 0.815 & $\begin{array}{c}0.197 \\
{[-0.005,0.399]^{*}} \\
(-0.063,0.457)\end{array}$ \\
\hline Consumed animal-source foods in past day $(\mathrm{o} / \mathrm{1})$ & $\begin{array}{c}-0.043 \\
{[-0.391,0.304]} \\
(-0.456,0.369)\end{array}$ & 0.570 & $\begin{array}{c}0.136 \\
{[-0.147,0.419]} \\
(-0.200,0.471)\end{array}$ & 0.509 & $\begin{array}{c}-0.179 \\
{[-0.389,0.031]^{*}} \\
(-0.427,0.069)\end{array}$ \\
\hline One-day dietary diversity score & $\begin{array}{c}0.114 \\
{[-1.019,1.247]} \\
(-1.019,1.247)\end{array}$ & 5.481 & $\begin{array}{c}0.199 \\
{[-1.006,1.404]} \\
(-1.006,1.404)\end{array}$ & 5.222 & $\begin{array}{c}-0.085 \\
{[-0.838,0.668]} \\
(-0.838,0.668)\end{array}$ \\
\hline Observations & 159 & & 200 & & 359 \\
\hline
\end{tabular}

Notes: ${ }^{*} p<0.10,{ }^{* *} p<0.05,{ }^{* * *} p<0.01 ;{ }^{+} q<0.10,{ }^{++} q<0.05,{ }^{+++} q<0.01$, where $q$ is the false discovery rate. $95 \%$ confidence intervals in brackets, $95 \%$ false discovery rate-adjusted confidence intervals in parentheses. Standard errors and degrees of freedom estimated as in Young (2016). Z-scores and indicators for stunting and underweight based on standards from World Health Organization (2011). 
Table A.61: Model-based versus randomization inference: intent-to-treat effects for girls, ages 6 to 60 months, households with children at baseline only

\begin{tabular}{lccccc}
\hline & $\begin{array}{c}\text { Intent-to-treat } \\
\text { effect }\end{array}$ & $\begin{array}{c}\text { Model-based } \\
p \text {-value }\end{array}$ & $\begin{array}{c}\text { Randomization } \\
p \text {-value }\end{array}$ & \multicolumn{2}{c}{ Model-based } \\
& Randomization & $q$-value \\
\hline Weight-for-age (Z-score) & 0.375 & 0.011 & 0.031 & 0.032 & 0.047 \\
Not underweight (o/1) & 0.107 & 0.072 & 0.091 & 0.072 & 0.091 \\
Not severely underweight (o/1) & 0.082 & 0.019 & 0.011 & 0.028 & 0.033 \\
Height-for-age (Z-score) & 0.528 & 0.018 & 0.058 & 0.036 & 0.070 \\
Not stunted (o/1) & 0.250 & 0.003 & 0.007 & 0.018 & 0.042 \\
Not severely stunted (o/1) & 0.193 & 0.022 & 0.015 & 0.027 & 0.030 \\
Consumed animal-source foods in past day (o/1) & -0.043 & 0.783 & 0.818 & 1.000 & 1.000 \\
One-day dietary diversity score & 0.114 & 0.825 & 0.831 & 0.825 & 0.831 \\
\hline
\end{tabular}

Notes: See section 4.1 for the estimating equation. Z-scores and indicators for stunting and underweight based on standards from World Health Organization (2011). Model-based $p$-values and $q$-values calculated using standard errors and degrees of freedom estimated as in Young (2016). 
Table A.62: Model-based versus randomization inference: intent-to-treat effects for boys, ages 6 to 60 months, households with children at baseline only

\begin{tabular}{lccccc}
\hline & $\begin{array}{c}\text { Intent-to-treat } \\
\text { effect }\end{array}$ & $\begin{array}{c}\text { Model-based } \\
p \text {-value }\end{array}$ & $\begin{array}{c}\text { Randomization } \\
p \text {-value }\end{array}$ & $\begin{array}{c}\text { Model-based } \\
q \text {-value }\end{array}$ & $\begin{array}{c}\text { Randomization } \\
q \text {-value }\end{array}$ \\
\hline Weight-for-age (Z-score) & 0.059 & 0.744 & 0.709 & 1.000 & 1.000 \\
Not underweight (o/1) & 0.037 & 0.606 & 0.603 & 1.000 & 1.000 \\
Not severely underweight (o/1) & 0.044 & 0.211 & 0.278 & 1.000 & 1.000 \\
Height-for-age (Z-score) & 0.021 & 0.925 & 0.933 & 1.000 & 0.933 \\
Not stunted (o/1) & 0.041 & 0.517 & 0.527 & 1.000 & 1.000 \\
Not severely stunted (o/1) & -0.004 & 0.931 & 0.922 & 0.931 & 1.000 \\
Consumed animal-source foods in past day (o/1) & 0.136 & 0.307 & 0.269 & 0.613 & 0.539 \\
One-day dietary diversity score & 0.199 & 0.719 & 0.773 & 0.719 & 0.773 \\
\hline
\end{tabular}

Notes: ${ }^{*} p<0.10,{ }^{* *} p<0.05,{ }^{* * *} p<0.01$. See section 4.1 for the estimating equation. Z-scores and indicators for stunting and underweight based on standards from World Health Organization (2011). Model-based $p$-values and $q$-values calculated using standard errors and degrees of freedom estimated as in Young (2016). 
Table A.63: Model-based versus randomization inference: differences in intent-to-treat effects by gender, ages 6 to 60 months, households with children at baseline only

\begin{tabular}{lccccc}
\hline & $\begin{array}{c}\text { Intent-to-treat } \\
\text { effect }\end{array}$ & $\begin{array}{c}\text { Model-based } \\
p \text {-value }\end{array}$ & $\begin{array}{c}\text { Randomization } \\
p \text {-value }\end{array}$ & $\begin{array}{c}\text { Model-based } \\
q \text {-value }\end{array}$ & $\begin{array}{c}\text { Randomization } \\
\text {-value }\end{array}$ \\
\hline Weight-for-age (Z-score) & 0.316 & 0.138 & 0.217 & 0.207 & 0.326 \\
Not underweight (o/1) & 0.071 & 0.521 & 0.556 & 0.521 & 0.556 \\
Not severely underweight (o/1) & 0.038 & 0.500 & 0.533 & 0.601 & 0.639 \\
Height-for-age (Z-score) & 0.507 & 0.060 & 0.087 & 0.119 & 0.174 \\
Not stunted (o/1) & 0.210 & 0.029 & 0.008 & 0.177 & 0.048 \\
Not severely stunted (o/1) & 0.197 & 0.055 & 0.062 & 0.166 & 0.186 \\
Consumed animal-source foods in past day (o/1) & -0.179 & 0.086 & 0.108 & 0.173 & 0.216 \\
One-day dietary diversity score & -0.085 & 0.807 & 0.805 & 0.807 & 0.805 \\
\hline
\end{tabular}

Notes: ${ }^{*} p<0.10,{ }^{* *} p<0.05,{ }^{* * *} p<0.01$. See section 4.1 for details on the estimating equation. Z-scores and indicators for stunting and underweight based on standards from World Health Organization (2011). Model-based $p$-values and $q$-values calculated using standard errors and degrees of freedom estimated as in Young (2016). 


\section{A.22 Impacts on children who were alive at baseline}

In table A.64 we estimate impacts on children who are observed at baseline and follow up. None of the effects on boys are statistically significant once we adjust for multiple comparisons. Still, the impacts on boys shown in table A.64 are different enough from what we obtain in the main text that we explore potential explanations in this subsection of the appendix. The explanations we consider are: balance between treatment and control becomes substantially worse after limiting the sample to households with children observed in both rounds, survivor bias in the sample of boys (i.e., the program allowed boys with poor anthropometric statistics to surive, dragging down impacts), and duration of exposure to the program (i.e., children observed in both rounds are relatively old and therefore exposed to the program longer). 
Table A.64: Intent-to-treat effects for children, ages 6 to 60 months, children observed at baseline

\begin{tabular}{|c|c|c|c|c|c|}
\hline & \multicolumn{2}{|l|}{ Girls } & \multicolumn{2}{|l|}{ Boys } & \multirow[b]{2}{*}{ Difference } \\
\hline & Intent-to-treat effect & Control mean & Intent-to-treat effect & Control mean & \\
\hline Weight-for-age (Z-score) & $\begin{array}{c}0.452 \\
{[0.018,0.886]^{* *}} \\
(-0.030,0.934)^{+}\end{array}$ & -1.594 & $\begin{array}{c}0.380 \\
{[-0.015,0.775]^{*}} \\
(-0.133,0.894)\end{array}$ & -1.510 & $\begin{array}{c}0.072 \\
{[-0.521,0.665]} \\
(-0.550,0.693)\end{array}$ \\
\hline Not underweight $(\mathrm{o} / \mathrm{1})$ & $\begin{array}{c}0.231 \\
{[-0.088,0.549]} \\
(-0.088,0.549)\end{array}$ & 0.676 & $\begin{array}{c}0.122 \\
{[-0.061,0.305]} \\
(-0.070,0.314)\end{array}$ & 0.778 & $\begin{array}{c}0.109 \\
{[-0.259,0.476]} \\
(-0.324,0.541)\end{array}$ \\
\hline Not severely underweight $(\mathrm{o} / \mathrm{1})$ & $\begin{array}{c}0.136 \\
{[0.016,0.256]^{* *}} \\
(-0.007,0.278)^{+}\end{array}$ & 0.882 & $\begin{array}{c}0.117 \\
{[-0.014,0.249]^{*}} \\
(-0.029,0.263)\end{array}$ & 0.911 & $\begin{array}{c}0.018 \\
{[-0.167,0.204]} \\
(-0.167,0.204)\end{array}$ \\
\hline Height-for-age (Z-score) & $\begin{array}{c}0.781 \\
{[0.112,1.449]^{* *}} \\
(-0.091,1.652)^{+}\end{array}$ & -2.741 & $\begin{array}{c}0.480 \\
{[0.072,0.887]^{* *}} \\
(-0.130,1.089)\end{array}$ & -2.473 & $\begin{array}{c}0.301 \\
{[-0.473,1.074]} \\
(-0.692,1.293)\end{array}$ \\
\hline Not stunted $(\mathrm{o} / \mathbf{1})$ & $\begin{array}{c}0.246 \\
{[-0.021,0.514]^{*}} \\
(-0.035,0.527)^{+}\end{array}$ & 0.294 & $\begin{array}{c}0.153 \\
{[-0.011,0.317]^{*}} \\
(-0.042,0.348)\end{array}$ & 0.333 & $\begin{array}{c}0.093 \\
{[-0.237,0.424]} \\
(-0.272,0.459)\end{array}$ \\
\hline Not severely stunted $(\mathrm{o} / \mathrm{1})$ & $\begin{array}{c}0.379 \\
{[0.127,0.631]^{* * *}} \\
(0.000,0.757)^{++}\end{array}$ & 0.618 & $\begin{array}{c}0.069 \\
{[-0.100,0.239]} \\
(-0.100,0.239)\end{array}$ & 0.733 & $\begin{array}{c}0.309 \\
{[0.030,0.589]^{* *}} \\
(-0.099,0.718)\end{array}$ \\
\hline Consumed animal-source foods in past day $(\mathrm{o} / \mathrm{1})$ & $\begin{array}{c}-0.039 \\
{[-0.282,0.204]} \\
(-0.328,0.250)\end{array}$ & 0.618 & $\begin{array}{c}0.216 \\
{[-0.121,0.553]} \\
(-0.185,0.617)\end{array}$ & 0.533 & $\begin{array}{c}-0.255 \\
{[-0.564,0.055]^{*}} \\
(-0.620,0.110)\end{array}$ \\
\hline One-day dietary diversity score & $\begin{array}{c}0.193 \\
{[-1.017,1.403]} \\
(-1.017,1.403)\end{array}$ & 5.735 & $\begin{array}{c}0.655 \\
{[-0.504,1.813]} \\
(-0.504,1.813)\end{array}$ & 5.489 & $\begin{array}{c}-0.461 \\
{[-1.561,0.639]} \\
(-1.561,0.639)\end{array}$ \\
\hline Observations & 67 & & 87 & & 154 \\
\hline
\end{tabular}

Notes: ${ }^{*} p<0.10,{ }^{* *} p<0.05,{ }^{* * *} p<0.01 ;{ }^{+} q<0.10,{ }^{++} q<0.05,{ }^{+++} q<0.01$, where $q$ is the false discovery rate. $95 \%$ confidence intervals in brackets, $95 \%$ false discovery rate-adjusted confidence intervals in parentheses. Standard errors and degrees of freedom estimated as in Young (2016). Z-scores and indicators for stunting and underweight based on standards from World Health Organization (2011). 
In table A.65 we show sample balance when restricting the data to households with children observed at baseline. There is no evidence that restricting the sample to households with children observed in both survey rounds leads to spurious results because of a lack of balance. We therefore reject lack of balance as an explanation.

Next we consider survivor bias. Survivor bias could arise if boys observed at baseline who would not survive to the second survey round if assigned to the control group do survive when assigned to the treatment group, dragging down estimated impacts on anthropometric indicators among boys. This explanation seems very unlikely, since only two children under the age of 60 months who were observed at basleine did not survive until follow-up. But impacts on survivorship could manifest themselves in children born after baseline data collection. To explore this, we drop children observed at baseline and estimate the impacts of assignment to the treatment group on number of boys per household. The estimated intent-to-treat effect on the number of boys under 60 months of age at follow-up (excluding children observed at baseline) is -0.070 boys ( $p$-value $=0.222$ ). The sign of the effect is the opposite of what we would expect with survivor bias, and it is imprecisely estimated. In other words, we see no evidence of survivor bias among boys. For sake of comparison, the same effect estimated for girls under the age of 60 months is $0.049(p$-value $=0.379)$.

Ultimately, we are left with a bit of a puzzle. Impacts on girls are largely unaffected by changing the sample composition, which is reassuring. Impacts on boys appear larger for children who were alive at baseline, but it is hard to know how much to emphasize these results given that significant impacts are bound to show up if one slices the sample repeatedly. One possibility that differences in impacts by whether a boy is observed at baseline are a result of heterogeneous treatment effects by age. However, checking whether controlling for treatment effect heterogeneity by age can explain differences in impacts on boys observed and not observed at baseline is not an appealing approach. The problem is that there is very little overlap in age across boys observed at baseline and not observed at baseline. Estimating the treatment effect on boys not observed at baseline holding age fixed at the same average age observed among boys that are observed at baseline would require a great deal of extrapolation. Our conclusion is that program effects on girls are highly robust, whereas effects on 
Table A.65: Baseline summary statistics and balance: household-level variables, households with children observed in both survey rounds

\begin{tabular}{|c|c|c|c|}
\hline & Treatment & Control & Difference \\
\hline \multirow[t]{2}{*}{ Household size (adult male equivalents) } & 3.835 & 4.041 & -0.233 \\
\hline & $\{1.888\}$ & $\{1.840\}$ & {$[0.364]$} \\
\hline \multirow[t]{2}{*}{ Dependency ratio } & 0.503 & 0.506 & 0.005 \\
\hline & $\{0.164\}$ & $\{0.159\}$ & {$[0.036]$} \\
\hline \multirow[t]{2}{*}{ Wealth $(\log )$} & 9.098 & 9.145 & -0.135 \\
\hline & $\{1.308\}$ & $\{1.241\}$ & {$[0.271]$} \\
\hline \multirow{2}{*}{ Annual food expenditure per adult male equivalent (log) } & 8.233 & 8.495 & -0.276 \\
\hline & $\{1.367\}$ & $\{1.295\}$ & {$[0.374]$} \\
\hline \multirow[t]{2}{*}{ Daily calories per adult male equivalent (log) } & 8.839 & 8.968 & -0.185 \\
\hline & $\{0.789\}$ & $\{0.763\}$ & [0.164] \\
\hline \multirow[t]{2}{*}{ Daily grams of animal protein per adult male equivalent $(\log )$} & 3.652 & 3.630 & 0.001 \\
\hline & $\{2.054\}$ & $\{2.107\}$ & {$[0.673]$} \\
\hline \multirow[t]{2}{*}{ Daily servings of eggs } & 0.386 & 0.380 & -0.008 \\
\hline & $\{0.520\}$ & $\{0.637\}$ & {$[0.148]$} \\
\hline \multirow[t]{2}{*}{ Eggs consumed per day per adult male equivalent } & 11.549 & 13.508 & -2.449 \\
\hline & $\{22.628\}$ & $\{24.448\}$ & {$[4.648]$} \\
\hline \multirow[t]{2}{*}{ Food consumption score } & 18.979 & 20.481 & -1.941 \\
\hline & $\{7.009\}$ & $\{7.857\}$ & {$[1.658]$} \\
\hline \multirow[t]{2}{*}{ Chickens owned } & 10.959 & 9.000 & 2.143 \\
\hline & $\{12.634\}$ & $\{10.389\}$ & [1.955] \\
\hline \multirow[t]{2}{*}{ Naked-neck chickens owned } & 1.548 & 0.883 & 0.792 \\
\hline & $\{2.749\}$ & $\{2.127\}$ & {$[0.366]^{*}$} \\
\hline \multirow[t]{2}{*}{ Uses poultry registry $(\mathrm{o} / 1)$} & 0.123 & 0.117 & 0.023 \\
\hline & $\{0.331\}$ & $\{0.323\}$ & {$[0.041]$} \\
\hline \multirow{2}{*}{ Eggs produced in last six months (log) } & 1.277 & 1.173 & 0.141 \\
\hline & $\{2.206\}$ & $\{2.189\}$ & {$[0.266]$} \\
\hline \multirow[t]{2}{*}{ Sold at least one egg in last six months $(\mathrm{o} / \mathrm{1})$} & 0.014 & 0.013 & 0.008 \\
\hline & $\{0.117\}$ & $\{0.114\}$ & {$[0.024]$} \\
\hline Observations & 73 & 77 & 150 \\
\hline
\end{tabular}

Notes: ${ }^{*} p<0.10,{ }^{* *} p<0.05,{ }^{* *} p<0.01$. Standard deviations in curly braces, standard errors in brackets. All regressions for differences in means include the treatment indicator, an intercept, and indicators for thirteen strata. Standard errors and degrees of freedom were estimated as in Young (2016). Continuous outcomes were winsorized at their first and 99th percentiles. 
Table A.66: Baseline summary statistics and balance: children ages six to 60 months, households with children observed in both survey rounds

\begin{tabular}{|c|c|c|c|}
\hline & Treatment & Control & Difference \\
\hline \multicolumn{4}{|l|}{$\underline{\text { Girls }}$} \\
\hline \multirow[t]{2}{*}{ Age in months } & 32.604 & 31.655 & 1.298 \\
\hline & $\{17.057\}$ & $\{16.194\}$ & {$[2.458]$} \\
\hline \multirow[t]{2}{*}{ Height-for-age (Z-score) } & -1.474 & -1.724 & 0.233 \\
\hline & $\{1.977\}$ & $\{1.739\}$ & {$[0.248]$} \\
\hline \multirow[t]{2}{*}{ Not stunted $(\mathrm{o} / \mathrm{1})$} & 0.516 & 0.462 & 0.054 \\
\hline & $\{0.502\}$ & $\{0.501\}$ & [0.091] \\
\hline \multirow[t]{2}{*}{ Not severely stunted (o/1) } & 0.802 & 0.790 & 0.007 \\
\hline & $\{0.401\}$ & $\{0.409\}$ & [0.06o] \\
\hline \multirow[t]{2}{*}{ Weight-for-age (Z-score) } & -0.940 & -0.944 & -0.035 \\
\hline & $\{1.305\}$ & $\{1.391\}$ & [0.149] \\
\hline \multirow[t]{2}{*}{ Not underweight (o/1) } & 0.813 & 0.773 & 0.021 \\
\hline & $\{0.392\}$ & $\{0.421\}$ & {$[0.054]$} \\
\hline \multirow[t]{2}{*}{ Not severely underweight $(\mathrm{o} / 1)$} & 0.956 & 0.941 & 0.024 \\
\hline & $\{0.206\}$ & $\{0.236\}$ & {$[0.036]$} \\
\hline Observations & 91 & 119 & 210 \\
\hline \multicolumn{4}{|l|}{ Boys } \\
\hline \multirow[t]{2}{*}{ Age in months } & 32.210 & 30.694 & 1.082 \\
\hline & $\{15.016\}$ & $\{16.049\}$ & {$[1.806]$} \\
\hline \multirow[t]{2}{*}{ Height-for-age (Z-score) } & -1.766 & -1.762 & -0.055 \\
\hline & $\{1.794\}$ & $\{1.891\}$ & [0.439] \\
\hline \multirow[t]{2}{*}{ Not stunted $(\mathrm{o} / \mathrm{1})$} & 0.572 & 0.478 & 0.103 \\
\hline & $\{0.497\}$ & $\{0.501\}$ & {$[0.094]$} \\
\hline \multirow[t]{2}{*}{ Not severely stunted (o/1) } & 0.826 & 0.776 & 0.045 \\
\hline & $\{0.380\}$ & $\{0.418\}$ & [0.079] \\
\hline \multirow[t]{2}{*}{ Weight-for-age (Z-score) } & -0.911 & -0.995 & 0.059 \\
\hline & $\{1.513\}$ & $\{1.395\}$ & {$[0.306]$} \\
\hline \multirow[t]{2}{*}{ Not underweight (o/1) } & 0.790 & 0.791 & -0.016 \\
\hline & $\{0.409\}$ & $\{0.408\}$ & {$[0.045]$} \\
\hline \multirow[t]{2}{*}{ Not severely underweight $(\mathrm{o} / 1)$} & 0.949 & 0.948 & 0.006 \\
\hline & $\{0.220\}$ & $\{0.223\}$ & {$[0.036]$} \\
\hline Observations & 138 & 134 & 272 \\
\hline
\end{tabular}

Notes: ${ }^{*} p<0.10,{ }^{* *} p<0.05,{ }^{* * *} p<0.01$. Standard deviations in curly braces, standard errors in brackets. All regressions for differences in means include the treatment indicator, an intercept, and indicators for thirteen strata. Z-scores as well as indicators for stunting and underweight calculated according to World Health Organization standards (World Health Organization, 2011). Standard errors and degrees of freedom estimated as in Young (2016). 
boys are sensitive to sample composition. 